KAPTURING KAKUMA:

THE COMMODIFICATION OF REFUGEES

AND PARTICIPATORY COMMUNICATION ALTERNATIVES

By

Jacqueline Strecker

Bachelor of Arts, Information, Communication and Technoculture

University of Western Ontario, 2007

\author{
A thesis \\ presented to Ryerson University \& York University \\ in partial fulfillment of the \\ requirements for the degree of \\ Master of Arts \\ in the \\ Graduate Program in Communication and Culture
}

Toronto, Ontario, Canada 2010

(C) Jacqueline Strecker 2010 
I hereby declare that I am the sole author of this thesis or dissertation.

I authorize Ryerson University to lend this thesis or dissertation to other institutions or individuals for the purpose of scholarly research.

I further authorize Ryerson University to reproduce this thesis or dissertation by photocopying or by other means, in total or in part, at the request of other institutions or individuals for the purpose of scholarly research. 


\title{
Kapturing Kakuma: The Commodification of Refugees and Participatory Communication Alternatives
}

\author{
Jacqueline Strecker \\ Master of Arts, Program in Communication and Culture \\ Ryerson University and York University
}

2010

\begin{abstract}
Over the past 50 years, the image of statelessness has shifted from heroic European refugees to depictions of nameless, impoverished refugees from the 'Third World'. Although this shift apparently stems from noble intentions, the image of the 'vulnerable refugee' has stripped refugees of agency and expressive rights. The photographs published by The United Nations High Commissioner for Refugees (UNHCR) has employed this vulnerability frame in order to lobby for western aid by presenting an easily digestible discourse, congruent with Western ideology. The UNHCR has thus commodified refugees in order to ensure funding from western donors. This paper challenges this commodification by presenting a comparative analysis of the UNHCR's historical photographs, and images produced through a participatory photography project conducted in the Kenyan Kakuma Refugee Camp. This project shifts the conventional illustrative refugee discourse by identifying and rejecting the political and economic frameworks that have institutionalized the voiceless and commodified refugee.
\end{abstract}




\section{Contents}

List of Figures and Tables................................................ v

List of Illustrations ......................................................... vi

Acknowledgements..................................................... vii

List of Abbreviations...................................................... viii

Introduction............................................................

Chapter One:

The History of Refugee Protection and the Role of the UNHCR....... 15

Chapter Two:

Defining a Refugee: The Ideological Function of Refugees.............. 41

Chapter Three:

Commodifying Speechless Bodies....................................... $\quad 71$

Chapter Four:

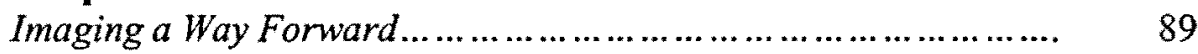

Conclusion......................................................... 115

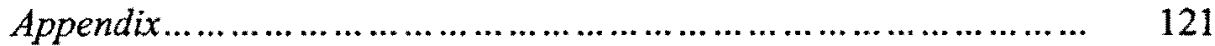

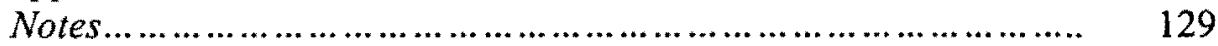

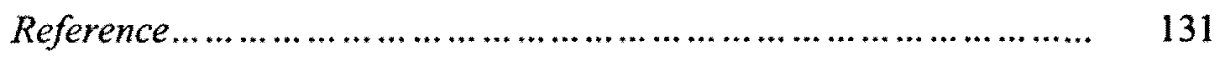


Figures \& Tables:

Figure 2.1: Proportion of Themes Represented in UNHCR Photographic Series from 1950-1958 (Series A) and 1960-1991 (Series B)............................ 56

Figure 2.2: $\quad$ Number of Individuals Featured In UNHCR Photographic Series from 1950-1958 (Series A) and 1960-1991 (Series B) by Percentage................ 58

Figure 2.3: Representations of Agency in UNHCR Photographs from 1950-1958

(Series A) and 1960-1991 (Series B) by Percentage.

Figure 2.4: Representations of Sex in UNHCR Photographs from 1950-1958 (Series

A) and 1960-1991 (Series B)

Figure 2.5A: Series A: Percentage of Themes and Sexes Represented in UNHCR

Photographs from 1950-1958

Figure 2.5B: Series B: Percentage of Themes and Sexes Represented in UNHCR

Photographs from 1960s-1991

Figure 2.6A:

Portion of Agency Represented in Series A Themes.

Figure 2.6B:

Portion of Agency Represented in Series B Themes

124

Figure 2.6C: Portion of Agency Represented in Kapturing Kakuma Themes

Figure 4.1: Kapturing Kakuma Series: Images by Theme and Sex.

Table 1: $\quad$ Series A: Percentage of Sex \& Age Represented in UNHCR

Photographic Themes from 1950-1958.

Table 2: $\quad$ Series B: Percentage of Sex \& Age Represented in UNHCR

Photographic Themes from 1960-1991

Table 3: Kapturing Kakuma: Percentage of Sex \& Age Represented in

Table 4:

Total Percent of Themes Represented in Each Series 


\section{Illusrations:}

IMG (A)1: $\quad$ UNHCR/1956 .................................................... 56

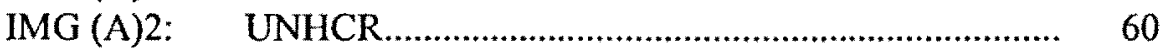

IMG (A)3: $\quad$ UNHCR

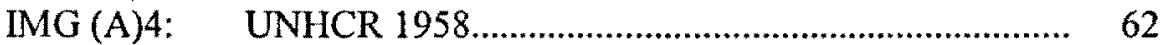

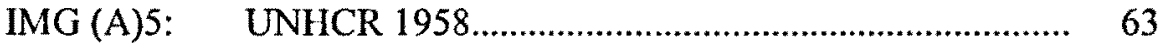

IMG (B)1: $\quad$ UNHCR/29063/1999/R. Chalasani............................. 57

IMG (B)2: $\quad$ UNHCR/19100/1989/L. Astrom.................................. 57

IMG (B)3: $\quad$ UNHCR/14139/1984/H. Gloaguen.............................. 59

IMG (B)4: $\quad$ UNHCR/22051/1992/K. Gooi.................................... 61

IMG (B)5: $\quad$ UNHCR/22073/1992/H.J. Davis.................................. 64

IMG (B)6: $\quad$ UNHCR/15065/1985/M. Vanappelghem...................... 65

IMG (B)7: $\quad$ UNHCR/WHO/2096/1971/D.Henrioud......................... 66

IMG (C)1: $\quad$ Kapturing Kakuma/P4/2009 ....................................... 104

IMG (C)2: Kapturing Kakuma/P2/2009..................................... 105

IMG (C)3: $\quad$ Kapturing Kakuma/P3/2009...................................... 106

IMG (C)4: Kapturing Kakuma/P2/2009...................................... 107

IMG (X)1： Kapturing Kakuma/2009............................................. 101

IMG (X)2: $\quad$ Kapturing Kakuma/2009............................................ 102

IMG (X)3: $\quad$ Kapturing Kakuma/2009.............................................. 103 


\section{Acknowledgements}

It is a pleasure to thank the individuals and organizations who have made this thesis possible. First and foremost, I would like to offer my sincerest gratitude to my remarkable supervisor, Dr. Patricia Mazepa, who has acted as both a mentor and role model, continually supporting this research and guiding me through my graduate studies. Without Dr. Mazepa"s assistance, this thesis would not have been feasible. I would also like to thank the other members of my committee, Dr. Amin Alhassan and Dr. Colin Mooers. Both of these wonderful individuals were instrumental in this research and went out of their way to provided me endless guidance. I would also like to extend my appreciation to the entire Ryerson University and York University's faculty of Communication and Culture, as well as York University"s Centre for Refugee Studies; both of these institutions afforded a remarkable graduate experience.

To the financial supporters of this research, I am also greatly indebted. I would especially like to thank the Social Sciences and Humanities Research Council for honouring me with the Joseph-Armand Bombardier Canada Graduate Scholarship. 1 would also like to show my deepest gratitude to Sony Canada, who realized the value of this project and graciously donated five Cybershot Digital Cameras. Without Sony Canada's participation, this research would not have been possible. I must also thank Dr. Jennifer Brayton, who was the primary financial sponsor of my field research in the Kakuma Refugee Camp, as well as Dr. Tas Venetsanopoulos, Vice President of Research and Innovation, who also kindly contributed to travel costs to Kakuma. I am also indebted to Robert Haaf, who initiated and nurtured my interest in photography, and who lovingly donated and hosted the project's website.

Numerous organizations and institutions were also instrumental to the success of this research, and must not be forgotten. Primarily, I would like to thank the World University Service of Canada (WUSC), who served as not only the catalyst for my interest and involvement in refugee protection, but also played an instrumental role in facilitating my time at the Kakuma Refugee Camp. WUSC must also be thanked for its unwavering efforts and dedication to ensuring that refugee students are provided the opportunity to study in a safe and stable environment. In addition, Windle Trust Kenya also played a key role in enabling this research in Kakuma, providing both the accommodations and institutional support for the Kapturing Kakuma project.

There were a number of individuals who played a significant role in the success of this thesis: Asni Mekonnen, for organizing and supporting the Refugee Study Seminar, which brought me to Kakuma; Madut Majok, for assisting in the organizing of the Seminar, and for facilitating my pre-departure orientation; Dr. James Milner, for provided a strong introduction to the politics and logistics of refugee protection, as well as offering continual guidance and support to this research; Dr. Glen Peterson, for guiding me as my field research supervisor while in Kakuma; and David Begg \& the Office of International Affairs, for their consistent support and guidance of international initiatives.

In addition, I am also truly indebted to Jo Ann Mackie, who was simply amazing and offered tremendous assistance and guidance throughout my entire graduate experience; Dr. Sandra Smeltzer, for her unwavering support in all aspects of my life and for being the impetus behind my involvement within development pursuits; Michael Fisher, for his patience and assistance during the drafting of my thesis; Beverlee Buzon, for her incredible assistance, editing chapters, providing emotional support, and even organizing the final submission; and of course - Laura Tribe, who generously edited, advised and supported this research and me throughout my entire university career!

I would also like to specially thank all of my family and friends for their endless support and love. In particular, I owe my deepest gratitude to my parents John and Brenda Strecker, who have been an incredible source of motivation and support throughout all of my endeavours; as well as my remarkable sister Nicole Strecker and her amazing husband Will Vreugdenhil, for their hospitality, constant inspiration, and their never-ending support. Lastly, I would like to thank all of the participants of this study, and all of the WUSC sponsored students, who opened up their hearts and shared their homes with me. This thesis would not have been possible without your participation or your inspiration, Asante Sana! 


\section{Abbreviations}

1951 Convention 1967 Protocol

AU

CIREFCA

CPA

ExCom

ICARA I

ICARA II

IOM

IRO

ISS

IRC

NGO

OAU

PRS

SHAEF

SRP

UN

UNDP

UNDRC

UNHCR

UNRRA

USCRI

WUSC
1951 Convention Relating to the Status of Refugee

1967 Protocol Relating to the Status of Refugees

African Union

International Conference on Central American Refugees (1989)

Comprehensive Plan of Action

Executive Committee of the Programme of the United Nations High

Commissioner for Refugees

First International Conference on Assistance to Refugees in Africa

Second International Conference on Assistance to Refugees in Africa

International Organization for Migration

International Refugee Organization

International Student Service

International Rescue Committee

Non-Governmental Organization

Organization of African Unity

Protracted Refugee Situation

Supreme Headquarters Allied Expeditionary Force

Student Refugee Program

The United Nations

United Nations Development Programme

United Nations Disaster Relief Coordinator

United Nations High Commissioner for Refugees

United Nations Relief and Rehabilitation Administration

U.S. Committee for Refugees and Immigrants

World University Service of Canada 


\section{Introduction}

In the twenty-first century, pictures far exceed words as representations of power. Visuals transform into mental images that affect public opinion far greater than words (Baroody, 1998). "Over the course of the last two centuries, Western culture has come to be dominated by visual rather than oral or textual media... Our values, opinions, and beliefs have increasingly come to be shaped in powerful ways by the many forms of visual culture that we encounter in our day-to-day lives" (Sturken, 2001, 1). The proliferation of visual media content has thus acted as a highly influential lens through which the world has been represented, and constructions of international crises affords a particular spectacle of lives plagued by conflict. Regrettably, the dominance of such traditional media representations has led many to mistake these images of crises as 'politically charged and distorting metaphors' for reality (Bleiker, $2001,510)$

It is for this reason that, Roland Bleiker in his 2001 article, "The Aesthetic Turn in International Political Theory", highlights the importance of celebrating an aesthetic approach to the study of world politics. He states that "some of the most significant theoretical and practical insight into world politics emerges not from endeavours that ignore representations, but from those that explore how representative practices themselves have come to constitute and shape political practices" (Bleiker, 2001, 510). Bleiker's aesthetical turn is expounded from the Kantian understanding of the aesthetic, which proposes that knowledge of an object is not bound by its a priori existence, but rather is constructed through the nature of how one perceives the object (Bleiker, 2001). Aesthetical analysis is therefore important because it 
engages the differences between representations and that which they represent, situating this gap within the political.

It is through this aesthetical understanding that this thesis deconstructs the Office of the United Nations High Commissioner for Refugees' (UNHCR) photographs of refugees, locating not only the hegemonic value bound within these aesthetical representations, but also identifying the political and economic structures which underlie the projections of these particular images. The UNHCR was selected for analysis because it is the leading multilateral Agency mandated to focus on refugee issues (Clark-Kazak, 2009). The Agency also occupies the principle position as the global producer and disseminator of refugee information (Chimni, 1998). Although this role was informally part of UNHCR operations since its inception; in 1996 the UNHCR solidified its role as the primary knowledge producer of refugee discourse with the formation of the Centre for Documentation and Research (CDR). This newly acquired post presents the UNHCR in a unique position, as it is now the foremost Agency responsible for protecting refugees and also representing them. It is this particular arrangement that this thesis has selected as the subject of analysis.

In the past, the majority of scholars who have approached the representation of refugees have engaged in either a semiotic or cultural analysis, calling upon postcolonial discourse. They focus in particular on the key works of Bhabha (1994), Fanon (1968), Foucault (1979), Hall (1997) and Said (1978) to postulate the means through which established practices of representation have constructed the refugee as "Other". While these examinations hold significant merit, uncovering the hegemonic structures bound within the refugee image, there appears to be a gap within the literature that fails to acknowledge the political and economic 
structures which have utilized the refugee's ideological position as a marketable trait, effectively transforming the refugee into an exchangeable commodity.

As a scholar of communication, which is fundamentally interdisciplinary, it was through a combination of situation and opportunity that I found my way to the field of forced migration studiesi. My interest in the representation of refugees began through my involvement with the non-governmental organization World University Service of Canada (WUSC). The impetus for WUSC developed in the 1920s through needs created by World War I. It was at this time that the International Student Service (ISS) was created to support student refugees fleeing oppression in Europe. In 1950, ISS changed not only its name to World University Service (WUS), but also its focus, which began to center around providing relief and rehabilitation operations to the Middle East and Asia. In 1957, the organization was incorporated as a non-profit based in Toronto. In 1978, WUSC launched the Student Refugee Program (SRP), assisting refugees to resettle in Canada as permanent residents in order to pursue their education in an environment free of violence and fear. Since WUSC was recognized as a Sponsorship Agreement holder with the Government of Canada and the Government of Québec, it entitled Canadian university and college committees, in collaboration with WUSC, to privately sponsor refugees from a variety of countries since 1978. The list of nations included in this agreement were Afghanistan, Burma, Burundi, Comoros Islands, DRC, Ethiopia, Eretria, Ghana, Guatemala, Iran, Kenya, Lesotho, Liberia, Mozambique, Namibia, Nigeria, Pakistan, Rwanda, Sierra Leone, Somalia, South Africa, Sri Lanka, Sudan, Togo, Uganda, Zaire, and Zimbabwe (WUSC, 2008).

It was through volunteering with this organization, as well as the personal relations developed as a result of my involvement with sponsored refugees, that I began to take more notice of the iconic refugee imagery being disseminated by mainstream media, and also 
humanitarian organizations. Similar to the stereotypical depictions of the so-called Third Worldii, which presents what de Waal describes as 'disaster pornography' (de Waal, 1995), images of refugees seemed to depict a repeated sense of helplessness and suffering.

Renowned scholar Susan Sontag explored the long pedigree of what she calls suffering iconography, which emerged in the seventeenth century when artists began to convey the contemporary 'realignments of power' (Sontag, 2003). Sontag noted from these investigates that "being a spectator of calamities taking place in another country is a quintessential modern experience", of which there seems to be a particular appetite for viewing bodies in pain (Sontag, 2003). She also highlighted that currently the prevalence of information about war causes internal conflicts for the consumer who must manage how they negotiate and digest this tragic 'news' (Sontag, 2003).

"Photographs", as Sontag explains, "do not inevitably lose their power to shock. But they are not much help if the task is to understand" (Sontag, 2003, 89). Biber echoes this notion by stating that photographs act as an 'ideological smokescreen' through which culture is naturalized and hegemony appears in visual form. For Biber, photographs have an inherent ability to 'speak' for themselves, and thus viewers become less likely to reject the connotations of the image because "the high level of modality of photographs are persuasive in separating the viewer "from their own capacities for judgment and ethical choice" (Biber, 2006, 141). Photographs are thus perceived as unbiased depictions of reality, as opposed to constructed representations. The hegemonic function of photography provides viewers with a contrived version of reality; one which corresponds to the political interests of its producer. 
The confrontation between the photographic representations of refugees and the material reality within which the refugee is situated became obtrusively evident in the summer of 2008 , when 1 had the opportunity to travel to the Kakuma Refugee Camp in northwest Kenya. During my time in the camp, the one astounding realization that dumbfounded my colleagues and I was the overwhelming resiliency exuded by the majority camp inhabitants. Unlike the helpless victim that dominates the majority of refugee images and publications, the refugees I encountered displayed significant levels of agency. They were erecting thriving businesses in the camp, acquiring tertiary educations through distance studies, producing public awareness films, and even facilitating their own recreational sports leagues. These were just some of the many endeavors that camp inhabitants were engaged with. It should be noted that by highlighting these activities, I do not mean to suggest that refugees in Kakuma were not riddled with suffering or hardship, or that they were entirely self-sufficient. On the contrary, these examples demonstrate that refugees, in spite of the significant limitations of refugee life, are actively engaged as agents of their own emancipation; so it raises a significant question of why this capability and agency is not reflected (or is otherwise abscent) in ÙNHCR photographic portrayals.

As Bleiker highlighted, representations are always an act of power, and those that are the most successful disguise their subjective origins and values (Bleiker, 2001). It is through this representational understanding that this research attempts to discern the values that have constructed the image of the refugee as a victim. The established frames through which refugees are represented are not, as Liisa Malkki notes, 'timeless', 'unchangeable', or 'absolute', but are practices which are "embedded in a complicated history of their own" (Malkki, 1996, 89). By expounding this 'history', this research will focus on a representative sample of the UNHCR's photographs in order to contextualize both the underlying motivations for the shifting refugee 
representations, as well as the hegemonic structures that govern it ${ }^{\mathrm{iii}}$. This thesis therefore begins by observing the general arena through which refugees are represented, and then focuses specifically on identifying how and why the UNHCR's photographs may have adopted an oppressive frame.

During the initial investigation of the illustrative discourse of refugees, it became increasingly evident that iconic representations of refugees have drastically shifted over the past fifty years. After World War II, and during the formation of the UNHCR, countries regarded the refugee as an ideological tool, which both validated and legitimized the West's ideological war against Communism. The European Cold War refugees were constructed as icons, which were 'voting with their feet' and rejecting Soviet values for the security and stability of the West and capitalism. The European refugee was depicted in association to the Western norm, characterized as non-threatening white males who were often accompanied by their nuclear families (Johnson, 2003). These refugees were revered as heroes who valiantly attempted to overturn Communist rule, and were thus viewed as valuable assets who were warmly accepted, and resettled as citizens of the West.

Refugees from the Third World however, were not treated with the same admiration. These refugees, whose representations emerged during the 1970s, did not hold the same ideological or geopolitical value as their European counterparts. The Third World refugee figure was constructed in contrast to the Cold War European refugee, in order to legitimate restrictive policy changes that no longer favoured resettlement of refugees as the most viable solution. These refugees were not depicted as the resilient individuals that I had interacted with in the Kakuma camp, but rather were constructed through what refugee scholar B.S. Chimni declares as, a 'Myth of Difference' (Chimni, 1998). This myth regarded refugees from the Third World as 
a threat to the international system, and strategically aimed to depoliticize these stateless beings.

Third World refugees were depicted as a homogeneous mass of helpless and impoverished migrants. By focusing on the enormity of the crises, as opposed to focusing on individuals, Third World refugees were ascribed a universal identity, which ultimately served to remove the refugees from their unique historical circumstance, reducing them to the role of victim. Third World illustrations therefore became dominated by a vulnerability discourse, which conveyed images of passive refugee victims in need of Western saving.

In the twenty-first century, this vulnerability discourse is still prevalent within refugee representations. Although the effects of this discourse went unnoticed for most of the 1970s and 1980 s, there has emerged a general consensus amongst refugee scholars that one of the main implications of vulnerability discourse is its ability to disregard the agency and voice of refugees.

For example Malkki highlights that,

One of the most far-reaching, important consequences of these established representational practices is the systematic, even if unintended, silencing of persons who find themselves in the classificatory space of 'refugees'. That is, refugees suffer from a peculiar kind of speechlessness in the face of the national and international organization whose object of care and control they are. Their accounts are disqualified almost a priori, while the languages of refugee relief, policy science, and 'development' claim the production of authoritative narratives about refugees (Malkki, 1996, 386).

The implications of silencing the refugee figure has also been taken up by many other prominent refugee scholars, including Agamben (1996), Chimni (1998), Hyndman (2000), Nyes (1998), Rajarm (2002), and Szorenyi (2006); all of whom have explored the diverse consequences of this repeated account or framing. In these assorted explorations, studies have expounded the impact of how the silencing of refugees has served to reinforce state-centric ideologies (Rajaram, 2002), as well as how this discourse has paved the way for development actors to direct the course of refugee protection, while alienating refugees from procuring an active role in this process 
(Malikki, 1996). The most apparent, yet ignored implication of this representational practice however, is the commodification of the refugee. Some scholars, such as Rajaram, have alluded to processes through which refugee images are commodified, stating that:

Repetitive and predictable in the gamut of emotions they convey, archetypal refugee images become then ripe to be utilized to further particular ends (such as fund raising schemes). Consigned to 'visuality' and struck in static signification of particular meanings, refugee images (indeed the very resonance of the refugee experience) become commodities (Rajarm, 2002, 253).

While this analysis does hold significant truth, this critique, and many others like it, fall short of recognizing the extent to which the refugees themselves have been reduced to the status of 'things' to be exchanged in the global market.

As I began to explore the gamut of refugee literature, I was repeatedly surprised at how, time and time again, the terms commodity, commodify, and commodification, were left out of the discussion. This is not to say that this matter was not presented within the discourse, but rather that the term commodity was strategically avoided, arguably for its harsh and dehumanizing connotations. The degree to which this trend perpetuated throughout the entire refugee regime became apparent during a lecture I attended at the University of Oxford's Refugee Studies Centre held on February $27^{\text {th }}, 2009$. It was there, during a lively question and answer period, that I became overtly aware of the conscious aversion made by scholars and practitioners to avoid associating the terms 'commodity' and 'refugee' with one another. Throughout the various discussions that followed the presentation, terms and phrases such as 'international marketplace' and 'making refugee issues 'sexy" flowed seamlessly from participants' mouths. However, despite the large amount of conversation about 'economics' and 'markets', the commodity-refugee association was never iterated by a single presenter or attendee. I found myself baffled by the disassociation, wondering whether I had missed some 
intrinsic element of the discussion. However, upon reflection and an intensive review of the literature, I realized that it was not within my logic that gap was situated, but rather within the scholarship dedicated to refugee representations. My research found that despite the many approaches taken by forced migration and refugee scholars, there remained a failure to engage in a political economic analysis of refugee representations.

A similar observation was made in communication studies by political economist Vincent Mosco (1996/2009), who indicated that all too often studies of communicative texts focus too strictly on content, rather than exploring the structures that promote its production. The following research therefore acknowledges this as an important facet of refugee studies, and foregrounds a political economic analysis to the study of illustrative refugee discourse. Through this form of analysis, this thesis is able to move beyond a strictly descriptive assessment of the ideological connotations underlying refugee representations, and also examine the political and economic structures supporting their construction. By initially drawing upon a political economic framework, this thesis is able to contextualize photography within an institutional analysis, thereby affording an in-depth assessment of the underlying political motivations and structural constraints responsible for the UNHCR's commodification of the refugee figure.

This research therefore begins by embarking on a political economic examination of the historical role that the UNHCR has played in constructing the iconic refugee through the dissemination of its photographic publications. Despite the numerous attempts made over the past nine months to contact the UNHCR to ascertain a detailed understanding of the process of image selection and publication, the Agency failed to respond. Although this information would have provided greater insight, this thesis is still adequately able to assess the role of the UNHCR, by examining: the political context in which the UNHCR is situated, the photographic 
representations the Agency chooses to employ, and the structural limitations embedded in the Office's mandate. By examining these various dimensions, this research does not have to assume, but rather can theoretically assess the role that political economy has played in the UNHCR's compliance with this vulnerable discourse.

The methodological approach for this research employs two forms of empirical analysis, one quantitative and one qualitative. It begins by foregrounding a political economic assessment of the UNHCR in order to identify the institution's structural limitations. These findings are then correlated to the historical transitions of refugee representations. In order to evaluate the political economic connections, a comparative textual study of the UNHCR's photographic depictions of European Cold War refugees from 1950-1958, and the UNHCR's depictions of Third World refugees from 1960-1991 is then employed. This study deduces the dominant frames the UNHCR has used to construct two divergent refugee icons. The correlation of the findings from these two examinations provides greater insights into the motivations supporting the UNHCR's alterations in their illustrative framing. By locating the political economic structure within the Agency's aesthetical discourse, this thesis is able to identify the implications of hegemonic influence within the broader refugee context.

This thesis therefore contends that the photographs published by the UNHCR have conformed to prescribed photographic traits, which reiterate vulnerability frames in compliance with dominant Western values. This has resulted in the unwitting commodification of refugees, through the desire and need to ensure funding from Western donors. Through the provision of iconic refugee images, the UNHCR is able to lobby for Western aid by presenting an easily digestible discourse that is congruent with Western ideology. 
While it is imperative that this research identifies the factors which underline the commodification of refugees, it is also important to acknowledge that this is only one part of the problematic. Drawing upon developmental communication, the latter portion of this thesis focuses on praxis. It begins by exploring developmental communication, postulating potential approaches for offsetting the process through which refugees are commodified. In particular this section utilizes techniques of self-representation, as a means to both engage and highlight the agency inherent in refugees. By employing the critical pedagogy espoused by Paulo Freire, which highlights the importance of dialogic action, this section engages in a participatory photography study situated in the Kakuma Refugee camp. Based on Freirian theory, participatory approaches enable 'vulnerable populations' to become conscious of the structures of their oppression by engaging them in dialogic introspection; thus making them able to confront these oppressive forces.

By comparing the illustrative frames depicted in the photographs captured by volunteer refugee participants in the Kapturing Kakuma ${ }^{i v}$ project with the data collected from the previously analyzed UNHCR samples, this study examines the ability for participatory communication to produce alternative narratives of refugee identity. This assessment is used to further contextualize the political and economic milieu of refugee representations by identifying the importance of self representations of refugee identity. It therefore enables the decommodification of refugees by displaying discursive narratives, and by highlighting the refugee-photographers' individual voice and capacity to raise salient issues in order to effect change. This participatory study therefore acknowledges the potential for participatory strategies to offset the process of refugee commodification, incorporating refugees as active human agents in the articulation of their illustrative identity. 
Overall, this examination of refugee commodification is structured in four parts. Chapter One examines the broader context of the refugee crisis and the political economic milieu that contextualizes the UNHCR. It then explores three limitations embedded within the Office's Statute, which have significantly impacted the funding and operations of the Agency. These limitations are examined in order to uncover the means through which they have contributed to the objectification of refugees. Chapter Two revisits the ideological depictions of European Cold War refugees, in comparison to those of refugees who originated from the Third World. This section explores both the illustrative frames through which the UNHCR's representations reinforced the "Myth of Difference", as well as the political interests that supported the differing ideological connotations. Chapter Three then examines the prevalence of vulnerability discourses in the current UNHCR campaigns, while also exploring the means through which these frames render the refugee silent and devoid of agency. This Chapter also connects the findings of Chapters One and Two, and expands on how the UNHCR's compliance with prescriptive photographic frames have unwittingly commodified refugees in order to lobby for financial aid from Western donors.

Chapter 4 concludes by looking ahead and exploring the potential for participatory photography to recast the ideological depictions of refugees through the visual-articulation and celebration of traditionally silenced narratives. This final chapter employs Freirian pedagogy, which emphasizes the importance of visualization as a way of engaging vulnerable populations in stimulating introspection. This section utilizes the participatory images captured during the Kapturing Kakuma project as an example of how conventional illustrative discourses associated with refugees can be shifted. The main focus of this section is to direct future scholarly initiatives towards the development of appropriate participatory ICT-inclusive pedagogy, to 
amplify the voice of marginalized populations, and help offset the process of commodification by advancing a platform to demonstrate their own lived agency. 


\section{Chapter One: The History of Refugee Protection and the Role of the UNHCR}

In order to understand the environment through which refugees have been commodified, an assessment of the broader context of the refugee crisis and the functions and limitations of the UNHCR must first be provided. Due to the framework of this thesis, the analysis is limited to a mere summary of the development of the UNHCR, as expounded within the 2008 publication "The United Nations High Commissioner for Refugees (UNHCR)," by collaborators Gil Loescher, Alexander Betts, and James Milner. Using this text as a point of departure, this analysis will explore the means through which the UNHCR's limitations have contributed to the commodification of refugees.

Identifying the global origins of the term 'refugee' reaches back to the seventeenth century, during which the notion of a sovereign state was born; ascribing populations to newly assigned territories. During this time, Monarchs attempted to ensure unity of newly established states by isolating individuals whose religious practices deviated from the norm. In 1648 , the Peace of Westphalia identified the basic rights of refugees, articulating the importance of offering asylum to individuals who had lost their state's protection because of religious differences (Loescher, Betts \& Milner, 2008, 6). Despite this understanding, asylum states were under no obligation to accept refugees, and thus grants of asylum were determined based on political and religious affinity for those fleeing. The first historically recognized outpouring of refugees occurred during the Edict of Fontainebleau, which outlawed Protestantism, causing hundreds of thousands of Huguenots Protestants to flee from France in of fear of religious prosecution (Milner, 2008).

Throughout the nineteenth century, instances of forced migration continued to increase, with asylum states responding to these situations in a predominantly ad hoc manner. Despite the 
informal international system however, these early responses instituted the framework for the refugee regime which formally emerged after the First World War. At the start of the twentieth century, the collapse of old Empires, the rise of the immigration law, nationalism, and the affirmation of national sovereignty, changed the nature of international politics (Loesche et al., $2008,7)$. In the early 1920 s, the first international coordination on refugee affairs was established. The League of Nations' High Commission for Refugees sought to assist over a million individuals fleeing the Russian Revolution and the subsequent civil wars (Loescher, 2001). The Office's function however, was limited to the role of relief coordinator, relying heavily on contributions of money, personnel and expertise from external welfare institutions (Cohen, 2008, 439). During this time, governments declined from universally defining the qualifications of a refugee, "fearing pressure from a super-governmental authority to recognize political dissidents of any state" (Loesche et al., 2008,8). The failure to articulate the parameters of refugee eligibility allowed for Western governments to demarcate only certain national groups as refugees, resulting in a significantly narrowed mandate for the High Commissioner. By the 1930s, the authority of the League of Nations had dissipated because of its inability to adequately resolve the Manchurian and Ethiopian conflicts, and the membership withdrawal of Germany, Japan, and Italy (Loesche et al., 2008).

During World War II, the scale of refugee crises increased to an unfathomable level, displacing over 50 million people (Loescher, 2008). The initial international responses mirrored those of the inter-war period, which tended to focus on the establishment of temporary provisions for emergency situations. In 1943, due to controversial repatriation methods of The Supreme Headquarters Allied Expeditionary Force (SHAEF), the United Nations Relief and Rehabilitation Administration (UNRRA) was established and assumed SHAEF's role proving 
aid to countries liberated from axis powers. From 1945 to 1947 , the UNRRA spent $\$ 10$ billion on the allocation of food supplies to displaced Europeans (Cohen, 2008, 437). However, despite the UNRRA's massive relief operations, the organization did not retain authority to assist with the resettlement of refugees and thus "in accordance with the terms of the February 1945 Yalta Agreements and in response to Soviet pressure, UNRRA played an active part in the controversial forcible repatriation of large numbers of people in Europe" (Loesche et al., 2008, 10). The United State's discontentment with the UNRRA's repatriation policy led to its disbandment in 1947. During this time, its tasks were bestowed upon the International Refugee Organization (IRO), which recognized the rights of refugees to not be repatriated against their will. The IRO, influenced highly by the United State's leadership and funding, focused primarily on the resettlement of refugees and two Western-endorsed intentions:

Western powers hoped that the IRO would achieve two goals: First, to resolve longstanding refugee situations with the potential to destabilize European economies still recovering from the ruins of war, and second, to "internationalize" the refugee problem by distributing refugees and refugee costs among a number of North and South America, Western European, Australasian and African countries (Loescher et al., 2008, 11).

In the IRO's first years of operation, the organization was able to resettle a significant amount of refugees in countries suffering from labour shortages. However, with the Cold War looming and several hundred thousand refugees still inhabiting camps across Europe, the need for a UN body to govern over refugee affairs became overwhelmingly apparent.

On December $14^{\text {th }}, 1950$, the United Nations High Commissioner for Refugees (UNHCR) was adopted by the United Nations General Assembly. Its mandate sought to 'protect and support refugees at the request of a government or the UN itself and assists in their voluntary repatriation, local integration or resettlement to a third country' (Milner, 2008).

Paragraph one of its Core Mandate states: 
The United Nations High Commissioner for Refugees, acting under the authority of the General Assembly, shall assume the function of providing international protection, under the auspices of the United Nations, to refugees who fall within the scope of the present Statute and of seeking permanent solutions for the problem of refugees by assisting Governments and, subject to the approval of the Governments concerned, private organizations to facilitate the voluntary repatriation of such refugees, or their assimilation within new national communities (UNHCR, 1951).

Similar to its predecessor, the UNHCR's mandate was viewed as a provisional recourse, initially instituted as a three-year directive, which included a variety of strategic limitations to the parameters of its Office.

The discussions surrounding the creation of the UNHCR coincided with the drafting of the 1951 UN Refugee Convention, which outlined the strictures defining a refugee and his or her individual rights. Article 1A(2) of the 1951 Convention Relating to the Status of Refugees articulated the specific parameters qualifying the determination of a refugee, stating that:

the term "refugee" shall apply to any person who: as a result of events occurring before 1 January 1951 and owing to well-founded fear of being persecuted for reasons of race, religion, nationality, membership of a particular social group or political opinion, is outside the country of his nationality and is unable or, owing to such fear, is unwilling to avail himself of the protection of that country; or who, not having a nationality and being outside the country of his former habitual residence as a result of such events, is unable or, owing to such fear, is unwilling to return to it (UNHCR, 1951).

The twenty-six countries which were involved in the negotiations did not grant refugees the right to asylum. However, they did establish what was called non-refoulement, which remains the foundation of international refugee protection. Article 33(1) of the 1951 Convention specifies that "no Contracting State shall expel or return ("refouler") a refugee in any manner whatsoever to the frontiers of territories where his life or freedom would be threatened on account of his race, religion, nationality, membership of a particular social group or political opinion" (UNHCR, 1951). Therefore although the Convention failed to uphold Article 14 of the 1948 Universal Declaration of Human Rights which states that "everyone has the right to seek and 
enjoy in other countries asylum from persecution," however they did afford refugees protection against being returned to a country where they risk persecution (Loesche et al., 2008).

The decisions to limit the definition and rights of refugees were coupled with strategic attempts to reduce the autonomous control of an international protection body. Despite the UNHCR's attempts to create an all-encompassing governing body, its initial functionality was severely limited by its Eurocentric birth. "The UNHCR was created by Western governments in such a way that it would neither pose a threat to their sovereignty nor impose new financial obligations on them" (Loescher, 2001, 35). The United States in particular, sought to capitalize on the instrumental function of Eastern European refugees, whose escape from the communist regime became an ideological tool delineating the superiority of the West and its capitalist system. US policymakers regarded refugee issues as fundamental to national security, and thus encouraged emigration from the Eastern bloc as one means of 'containing' the Communist threat (Loescher, 2001). The sensitivity of refugee policy was determined by the US as too critical to be controlled by the United Nations. The US therefore sought to limit the UN's functionality, by implementing restrictions to the independence and the scope of UNHCR operations (Loescher et al, 2008). Nations which maintained a more intimate relation with refugee populations, however, fought for an alternative UNHCR directive. France and the Benelux countries proposed that the UNHCR should be granted large-scale operational funding, while the United Kingdom argued that refugees should be the responsibility of the host state. Alternatively, India and Pakistan maintained that the UNHCR should be a permanent Agency (Loescher et al., 2008). The resulting UNHCR Statute predominantly reflected the interests of the more powerful international players, having little to no institutional or financial autonomy and very narrow parameters. "As specified by Chapter 1 of the Statute, UNHCR was established to act under the 
authority of the General Assembly to serve two specific functions: to protect refugees and to find permanent solutions to their plight, either through voluntary repatriation or through their assimilation within new national communities" (Loescher et al., 2008, 13).

Despite successfully restricting the scope of UNHCR operations, the US further guaranteed its control by coupling its policy lobbying with the establishment of an opposing well-funded US refugee office, called the US Escape Program. This Agency's mandate directly overlapped with the directive of the UNHCR but was designed to ensure American foreign policy interests (Loescher et al., 2008). It was only in 1955 that the US began to fund the UNHCR, and thusly significantly limited the Office's autonomy and legitimacy. "The denial of American-led financial and diplomatic support directly affected the organization's ability to define an independent role for itself. No international organization has such an unpromising beginning" (Loescher, 2001, 35).

Amongst the subtle limitations embedded to narrow the parameters and authority of the UNHCR's mandate, there are three primary restrictions which have influenced the progression of the UNHCR and have resulted in the commodification of the refugee. These limitations include temporal, political, and financial restrictions. The remainder of this chapter will expound the impact of these limitations, and how they have facilitated the construction of the framed refugee, which maintains a strategic ideological purpose constituting the current protracted refugee crisis.

\section{Temporal Restrictions}

Within the category of temporal restrictions, the UNHCR has to mediate two different limitations. The first applies a limitation to the duration of the UNHCR's operations as initially defined within paragraph five of the Statute, which states that "the General Assembly shall 
review, not later than at its eighth regular session, the arrangements for the Office of the High Commissioner with a view to determining whether the Office should be continued beyond 31 December 1953" (UNHCR, 1951). For over fifty years, the UNHCR has precariously operated on only limited extensions of its original three year directive. These extensions usually allocated an additional five year allotment to the mandate, forcing the UNHCR to constantly legitimate its necessity within international affairs. This continuous struggle to justify its existence was coupled with competition from other UN offices and international organizations whose humanitarian agendas overlapped with the UNHCR, forcing the Office to aggressively extend the scope of its operations. Although on December 22, 2003, the UNHCR secured a position as a permanent program within the UN, the legacy of instability had become embedded within the UNHCR's operations. The insecurity fostered from this initial stipulation became reflected in the short-term activities which dominated UNHCR's programming.

The second temporal limitation the UNHCR faces is housed within the historic parameters defining the qualification of asylum seekers that are protected under the High Commissioner's authority. Paragraph six, Article 1A (ii) defines a "refugee" as:

any person who, as a result of events occurring before 1 January 1951 and owing to wellfounded fear of being persecuted for reasons of race, religion, nationality or political opinion, is outside the country of his nationality and is unable or, owing to such fear or for reasons other than personal convenience, is unwilling to avail himself of the protection of that country (UNHCR, 1951).

This definition restricts the UNHCR temporally, inferring that the protection offered through the Office may only extend to those individuals who have fled their country because of events which transpired prior to the January $1^{\text {st }} 1951$. The limitation further produces a geopolitical constraint to the UNHCR's mandate, primarily confining the reach of the Office to within Europe. 
Within the first five years of UNHCR operations however, the Office responded to the Soviet invasion of Hungary, demonstrating its ability to surpass the temporal limitation restricting its operational mandate. The Soviets' invasion of Hungary in November 1956 forced nearly two-hundred thousand refugees to flee to Austria and Yugoslavia; marking the first significant refugee crisis of the Cold War. Austria, unable to adequately respond to the influx, appealed to UNHCR for international assistance. The UNHCR, led by High Commissioner Auguste Lindt (1956-1960) maintained that although the exodus took place in 1956, its initial cause could be traced back to the establishment of a Communist People's Republic in Hungary in 1947. As these events predated 1951, they adhered within the mandate's restrictions, bestowing Hungarian refugees with the status of "Convention Refugees" (Davies, 2008).

Despite the creative legal calisthenics applied to the Hungarian crisis, refugees in other geographic locations during this time failed to receive the same treatment. The temporal inadequacies of the UNHCR's mandate were temporarily resolved under the General Assembly Resolution 1963 (XVI) of 1961 which permitted the High Commissioner to extend assistance offered by the UNHCR to 'groups of refugees' through the 'good offices' function (Davies, 2008). The 'good offices' approach therefore allocated the UNHCR the authority to raise funds and implement assistance programs to groups who failed to adhere to the Convention's refugee determination qualifications (Loescher, 2001). This new formula provided the initial framework for the UNHCR's expansion into the developing world.

In May 1957, the UNHCR responded to its first Third World refugee crisis situation, after Tunisia requested assistance to aid the eight-five thousand refugees fleeing from Algeria (Loescher et al., 2008). The decision to actively respond to the Algerian refugee crisis arose from intense internal and external debates about the mandate of the UNHCR. France, the colonial 
power within Algeria, denied the UNHCR authority to respond to the crisis. They feared that the UNHCR's involvement would only increase the internalization of the situation, and claimed that the only solution was the eventual repatriation of Algerians claiming refuge in Tunisia and Morocco (Loescher, 2001). In the face of opposition from France, and from many Western governments which refused to oppose the will of their ally, many UNHCR officials insisted that the Office should uphold its original mandate and focus its efforts towards the thousands of refugees remaining within Europe. High Commissioner Auguste Lindt however, maintained that this crisis permitted the UNHCR to confirm its position as the leading international refugee Agency, assisting the plight of all refugees, not just those fleeing from communist Europe (Loescher et al., 2008). It was further proposed that the

UNHCR's decision to intervene in the Hungarian refugee emergency on the basis that all the Hungarians prima facie fell under UNHCR's mandate and that it was impossible in a mass exodus to screen each asylum seeker individually had established a precedent for action which was difficult for the UNHCR to ignore in the Algerian case (Loescher et al., 2008, 24).

By the conclusion of 1958, the UNHCR, in spite of Western-governmental resistance, had launched an emergency relief program in association with the League of Red Cross Societies. This response and the 'good offices' approach legitimized the UNHCR's expansion into geographic regions which resided outside of Europe, thereby overcoming the temporal restrictions inherent in its Statute (Loescher et al., 2008).

In 1964, High Commissioner Félix Schnyder, sought to eradicate the outstanding temporal constraints through the elimination of the 1951 Convention dateline. On April $21^{\text {st }}$ 1965, the UNHCR held a colloquium with thirteen legal representatives from Algeria, Colombia, France, Ghana, Hungary, India, Italy, Norway, Switzerland, the United Kingdom, the United States, Yugoslavia, and a delegate from the World Council of Churches (Davies, 2008). Upon 
the conclusion of the three-day roundtable, the legal experts proposed the creation of a Protocol which would be attached to the 1951 Convention. The representatives maintained that drafting a new Convention would 'be too lengthy and cumbersome' for the pressing issue, and thus the creation of a Protocol would afford the implementation of a legally binding instrument, avoiding the traditional amendment process (Davies, 2008). The rate at which the Protocol was created and implemented reflected the international urgency surrounding the desire for a new legal instrument (Davies, 2008). In November 1966, the Protocol's proposal was passed to the Executive Committee of the High Commissioner's Programme ${ }^{\mathrm{vi}}$. The General Assembly approved the Protocol on December $16^{\text {th }} 1966$, and it was put into force less than a year later on October $4^{\text {th }} 1967$ (Davies, 2008). In contrast to the 1951 Convention, which took ten years to obtain 27 ratifications, the 1967 Protocol matched this number within two years, increasing to fifty-two state members by 1972 (Davies, 2008). In total one hundred and forty-four countries signed the 1967 Protocol, including Cape Verde, United States, and Venezuela, who did not authorize the initial 1951 Convention (Kyoichi, 2008).

Despite the support and speed through which the 1967 Protocol came to light, an assortment of criticisms surfaced concerning the Protocol's failure to address High Commissioner Schnyder's initial agenda. Sara Davies highlighted that although the Protocol was successful in removing the dateline restrictions of the 1951 Convention, it failed to address the Euro-centrism embedded within the instrument; "the Protocol essentially universalized the Eurocentric definition of a refugee and attendant support mechanisms, rather than developing a system based on the type of refugee crises confronting Africa, Asia and elsewhere" (Davis, 2008, 721). Thus, despite the UNHCR's successful elimination of its temporal limitations, the Office failed to extend the scope of the amendment to ensure the UNHCR's capacity to equitably allocate 
protective provisions for all global refugees (Loescher et al, 2008). Therefore the temporal and historical limitations entrenched within the Statute still restrict the operations of the UNCHR today.

\section{Political Restrictions}

The temporal restrictions of the UNHCR were further exacerbated by the political limitations that also originated from the Statute. During the formational debates of the UNHCR, 'humanitarian' and 'political' became principal terms of argument for the General Assembly. Eastern European states maintained that the influence that Western Powers had over the International Refugee Organization's operations enabled them to ensure their own political and economic interests, by discouraging repatriation (Kyoichi, 1998). During these formative meeting, which took place in the early 1950 s, these claims were refuted by various delegates who stated that these arguments did not embrace a humanitarian approach, but rather "paid lipservice to humanitarianism while claiming that the refugee problem would have been settled a long time ago if some major Powers had not kept it alive for political reasons" (Kyoichi, 1998, 40). The culmination of these tense debates led to the drafting of a proposed amendment presented by the Yugoslav delegate on November $30^{\text {th }}, 1950$. The intensions of the proposal were emphasized more astutely in their concurrent amendment to the preamble of the draft Convention Relating to the Status of Refugees in which they stated:

The Contracting States shall do all within their power to prevent the refugee problem from becoming a cause of friction between States. To this end, they shall forbid all hostile activity on the part of political or other refugee organizations directly against the country of origin of the refugees concerned and intended to create tension in the relations between the that State and those in which the refugees are living; all activity aimed at inciting the nationals of other countries to seek refuge or at preventing voluntary repatriation; activity designed to exploit the difficult position of refugees, with a view to using it for political ends contrary to the principles and purposes of the United Nations 
Charter. They shall further forbid the creation of refugee military formations (as cited in Kyoichi, 1998, 41).

This proposal echoed the concerns raised by Eastern European states of Western imposition, and although its initial articulation only proposed the insertion of the undefined terms "humanitarian" and "social," the proposal was incorporated into the adopted UNHCR Statue. Paragraph 2 of the mandate dictates that "the work of the High Commissioner shall be of an entirely nonpolitical character; it shall be humanitarian and social and shall relate, as a rule, to groups and categories of refugees" (UNHRC, 1951). It is evident that the 'non-political' clause embedded into the mandate was therefore a direct result of the tensions within East-West relations, as opposed to being created with the refugees in mind.

This stipulation has been a part of larger debates regarding the 'political'/'non-political' nature of humanitarianism. Legal scholar Sugino Kyoichi maintains that "all activities in society with pure objectives for promoting human welfare may have 'political' effects." (Kyoichi, 1998). Kyoichi argues that:

Depending on the criteria, every mandate can be categorized as 'political' in a broad sense, and all actions aimed at and motivated by concern for human beings can be categorized 'humanitarian'. Thus labeling a particular organ or agency as 'humanitarian' or 'political' by invoking ambiguous criteria may be ill-suited for defining the character of its statutory competence and type of activity (Kyoichi, 1998, 48).

Although theoretical discussions regarding the political nature of humanitarianism are significant to defining the obligations of the UNHCR, the pragmatic implications of this loosely defined specification are more profoundly uncovered by observing the actions of the Office and its interpretations of the clause. From 1951 to the early 1970 s, there was wide consensus that the Office needed to confine its activities to countries of asylum in order to respect the 'nonpolitical' designation. This rationale discouraged the UNHCR from concerning itself with the 
causes of forced migration and refugee populations, stating that this was beyond the scope of the its mandate (Loescher et al., 2008).

The UNHCR's concentration on countries of asylum dramatically shifted in the early 1970s, with the increasing influxes of Third World refugee flows. This change was motivated by pressure from Western countries which sought to avert these new refugee flows by addressing the root cause. On October $29^{\text {th }} 1986$, then High Commissioner Jean-Pierre Hocké articulated his interpretations of the 'non-political' status at the Joyce Pearce Memorial Lecture, stating that:

Sometimes a facile distinction is made by referring to all action addressed to the situation in the country of asylum as 'humanitarian' and any action addressed to the causes of the situation in the country of origin as 'political'. I reject this distinction. To me, any action which is addressed to and motivated by the concern and well being of human beings is 'humanitarian' whether such actions relate to the country of asylum or the country of origin...UNHCR must be concerned with the question of root causes in order to be aware of the exact reasons for refugee flows and thus to be able to identify solutions in a more appropriate manner (as cited in Kyoichi, 1998, 55).

The alteration in the UNHCR's priorities was furthered during the late 1980s, with the rise of internal displacement. In 1993, the General Assembly acknowledged the need for assistance in this area, and formally authorized the UNCHR to commence activities which would ensure individuals with in-country protection (Kyoichi, 1998). These modifications enabled the UNHCR to emphasize the responsibility of states of origin, while also monitoring and promoting compliance with international human rights standards (Kyoichi, 1998).

Despite the seemingly positive adaptations to the 'non-political' designation, many scholars suggest that these changes in interpretation were linked to greater geopolitical interests, which sought to change from an exilic approach to a newer system of containment (Chimni, 1998). It was therefore in the interest of Western states that the focus was shifted from countries of asylum to countries of origin. Thus despite creating a more liberal understanding to the 'non- 
political' status, the motivations behind these modifications can be traced to the self-serving interests of Western states.

It is also important to note that although the UNHCR has been granted some leeway, the Office is still discouraged from "raising delicate political questions when dealing with host governments for fear of overstepping their mandate or damaging relations with governments, most of whom would consider such intrusions to be interference in their internal affairs" (Loescher et al., 2008, 18). The UNHCR is also forced to nurture its relationships with donor governments who control the lifeline of the Office. The UNHCR is therefore quick to employ its 'non-political' status as a way of rationalizing why it avoids address concerns with donor states which have the potential to disrupt their positive funding relationships. This latter argument is further explored through a careful analysis of the budgetary restrictions faced by the UNHCR.

\section{Financial Limitations}

Although the directive to maintain a non-political disposition and its initial temporal restrictions present a variety of restraints for the UNHCR, its most crippling limitation is the constrained nature of its budget, which is highlighted in Paragraph 20 of the Statute:

The Office of the High Commissioner shall be financed under the budget of the United Nations. Unless the General Assembly subsequently decides otherwise, no expenditure other than administrative expenditures relating to the functioning of the Office of the High Commissioner shall be borne on the budget of the United Nations and all other expenditures relating to the activities of the High Commissioner shall be financed by voluntary contributions (UNHCR, 1950).

The restrictions placed on the UNHCR's budget have had an extremely detrimental impact on the realization of its espoused mandate. During its first years of operations, the UNHCR functioned with a thirty-four member staff, a budget of US $\$ 300,000$ and focused primarily on the legal protection of European refugees (Loescher et al., 2008). In addition to this modest 
budget, the UNHCR had to overcome the significant state opposition, which nearly resulted in its closure.

In the early 1950 s, Gerrit van Heuven Goedhart, the first High Commissioner, expressed the need for adequate financial support to the General Assembly in several lectures. Goedhart insisted that "protection without material assistance - the image of the UNHCR set out in the Convention - was an incomplete mechanism for addressing the problem of refugees" (as cited in Davies, 2008, 709). He therefore called for the General Assembly to allocate the UNHCR the authority to procure funds through member state donations, in order to ensure the Office's capacity to meet the material requirements of refugee protection. The General Assembly permitted the UNHCR to conduct a campaign to raise $\$ 3$ million. However, despite the US donating $\$ 45$ million to the Intergovernmental Committee for European Migrants, Goedhart was only able to secure $\$ 1$ million for UNHCR operations (Davies, 2008).

It was through obtaining a $\$ 2.9$ million dollar grant from the Ford Foundation in 1952 , that Goedhart was able to lift the UNHCR from its financial crisis, encouraging donations from private enterprises and governments, and effectively expanding the scope of the UNHCR's operations. The Ford funds were used to ensure the integration of asylum seekers into Western countries, and also enabled the UNHCR to manage the response to the West Berlin refugee crisis in 1953, legitimating the need for the organization. Loescher noted that it was because of these initial successes that the UNHCR's program for permanent solutions and emergency assistance was established, paving its participation as a 'lead agent' in the 1956 emergency operation for Hungarian refugees (Loescher, 2001). "Largely on its own initiatives, UNHCR grew from a strictly non-operational Agency with no authority to appeal for funds to an institution with a 
long-range program emphasizing not only protection but, increasingly, material assistance" (Loescher, 2001, 36).

This significant and successful deployment of the UNHCR's Hungarian operation demonstrated not only the important diplomatic function of the organization, but its ability to surpass the financial limits of its Statute. Its accomplishments earned the confidence of the United States, who became its chief donor, and consequently the UNHCR was able to expand both its funding and operational capabilities (Loescher et al., 2008).

Over time the UNHCR's budgetary structure adopted a dual system, partitioning General Programs and Special Programs funding. The General Programs budget consisted of unconditional collective funding, which financed administrative operations and basic refugee protection, resettlement, and repatriation projects. The Special Programs budget was composed of conditional and earmarked funds which were used to support emergency refugee and humanitarian crises relief and intervention (Väyrynen, 2001). In 1986, the UNHCR's operational budget had increased to a total of $\$ 422$ million; $61 \%$ dedicated to General Programs, and $39 \%$ towards Special Programs. In 1991, following the conclusion of the Cold War, the UNHCR's budget dramatically increased to a total of $\$ 1004$ million, nearly doubling its budget of $\$ 583$ million from the year before (Väyrynen, 2001). These additional funds were required to assist with the increasing instances of forced displacement, which were "the result of both communal conflicts and human rights abuses, all fuelled by the increasing availability of arms in the aftermath of the Cold War (Loescher et al., 2008, 50) ${ }^{\text {vii }}$. The UNHCR's donors responded to these larger needs by increasing their annual contributions to the Agency. As the UNHCR's 1992 Annual Report stated, "donor support was exceptionally strong [in 1991] and most of the traditional major donors increased their total contributions by up to $60 \%$ in absolute terms. 
Private sector donor support was also marked by an extraordinary increase of $\$ 18$ million over 1990 contributions" (UNHCR, 1992).

Coupled with this remarkable growth in resources was the onset of profoundly divergent allocation patterns. From 1986-1990, donor contributions maintained a consistent $60 \mathrm{~s} / 30 \mathrm{~s}$ split, with $61-69 \%$ of the majority of funding pledged towards General Programs, and $31-39 \%$ dedicated towards Special Programs. 1991 marked the beginning of a new era through which earmarking contributions became the preferred method of contribution. In $1991,64 \%$ of donor donations were allocated for Special Programs; a pattern which continued to proliferate throughout the following decades. Raimo Väyrynen hypothesizes that "the erosion of the bipolar international structure and the escalation of local conflicts for most donor countries opened new opportunities of political action and made them more conscious of their own interests" (Väyrynen, 2001, 157). Thus the 1990s signified not only increased funding for UNHCR programming, but also new opportunities for governments to promote political agendas through strategically allocated humanitarian assistance.

Initially, the UNHCR was unconcerned by the alteration in contribution allotment. The trend towards earmarking donations remained at a reasonably syntax level, and provided increasing financial resources for the UNHCR. In 1993, the UNHCR's global directive attained its operational peak, with financial contributions reaching a staggering $\$ 1195$ Million (Väyrynen, 2001). The UNHCR stated in 1999 that "earmarking at the program level without further limitations on the use of funds have to date not been the most difficult for UNHCR to accommodate" (as cited in Väyrynen, 2001). Väyrynen notes however, that gradually the situation became detrimental; "donors began earmarking funds below the program or even country level...they could single out support to a particular beneficiary group, a specific activity, 
or certain implementing partners... also made funds usable only during a certain time period, stipulating that any unused money had to be returned to the donor" (Väyrynen, 2001, 159). By 1999 , the level of earmarked contributions reached the highest percentage in the agencies history, with $80 \%$ of the total funding earmarked to some degree (Väyrynen, 2001). The extent of earmarking is categorized by three designations: unrestricted funding, which enables the UNHCR to allocate funds where needed most; lightly earmarked contributions, which are allocated by the donor for use within specific geographical regions, and tightly earmarked funds, which are to be used only for specific countries or types of activities (UNHCR, 2007). In 1999, $44.5 \%$ of donor contributions were tightly earmarked (Loescher et al., 2008), and only two of the top fifteen donor governments gave more than $50 \%$ of their total contributions without any form of earmarking (Väyrynen, 2001).

The trend towards earmarking resulted in two major problems for the UNHCR. Small earmarked contributions were not cost-effective because they required significant monitoring and enforcement. However, the UNHCR was continuously obliged to accept the assistance in order to maintain positive donor-relations with the contributing government (Väyrynen, 2001). The larger problem associated with earmarked contributions is that they do not cover the overhead expenses which account for research, administration, and coordination. Väyrynen noted that "these agency-related 'collective goods' have been possible to provide only because some donors have been willing to provide funds for the General Programs. In doing so, they have made possible the 'free-riding' by those governments that have been attracted for their own reasons to Special Programs" (Väyrynen, 2001, 160). Despite the limitations presented by earmarked contributions, the UNHCR willingly accepted these donations in order to maximize its income and extend its donor base. 
In 2000 , the UNHCR attempted to gain greater control over its financial situation by introducing a new budget structure, which consolidated the UNHCR's programmes into one Unified Budget - the Annual Programme Budget. The UNHCR's 2000 report stated that the aim of this financial reform was to "provide governments and others interested in UNHCR's work with an overall, transparent and comprehensive picture of the totality of its operations in terms of protection and assistance, while at the same time provide increased flexibility for UNHCR in the management of its financial resources" (UNHCR, 2000). The Unified Budget is also comprised of a secondary category, titled 'Supplementary Programmes'. This source includes any funds not accounted for in the Annual Programme Budget, which must be acquired through additional appeals. If these programs are carried over into the following year, the UNHCR's financial rules dictate that these lingering Supplementary Programmes must then be incorporated into the Annual Programme Budget.

The UNHCR also instituted an Operational Reserve, which amalgamated the financial requirements initially encompassed by the Emergency Fund, the Voluntary Repatriation Fund, and the Programme Reserve. It was specified by the Advisory Committee on Administrative \& Budgetary Questions (ACABQ) that this reserve would contain a minimum of $10 \%$ of programmed activities costs to cover a range of expenses which were broken down into classifications of Emergency, Care and Maintenance, Voluntary Repatriation, Local Settlement and Resettlement. These include, but are not limited to: assistance for emergency situations not allocated provisions in the Executive Committee's approved programming; unexpected cost increases for influxes in refugee populations receiving assistance; and increased housing and amenities funds for International field staff and operations (UNHCR, 2000). 
Although the Unified Budget structure attempted to incorporate transparency, predictable funding, reduced earmarking, and better prioritization, the results of the financial reform fell short of its perceived advantages. In actuality, the UNHCR found numerous weaknesses embedded in the unified model. First, the Supplementary Programme consistently represented $20-30 \%$ of the UNHCR's Unified Budget. The 'automatic' mainstreaming of these programmes into the Annual Budget yielded 'unfundable' programmes which led to project capping (UNHCR, 2007). The UNHCR also found that funding remained remarkably difficult to predict annually, and that despite the model's attempts to thwart earmarking in the Annual Budget, the degree of tightly earmarked contributions continually increased from $44.5 \%$ in 2000 , to $52.5 \%$ in 2006 (Loescher, et al., 2008).

Significantly high levels of earmarking remains one of the most influential factors in the UNHCR's programming today. In 2008, contributions from the United States, the European Commission, and Japan accounted for $47 \%$ of the UNHCR's total governmental donations; a $4 \%$ increased from 2007 (UNHCR, 2008). Sweden (7\%) and the Netherlands (5\%) round out the top five contributors in 2008 and 2007 . Overall, $81 \%$ of all governmental contributions were earmarked to some degree (UNHCR Annual Report, 2008). In 2007, the top five governmental contributors tightly earmarked $48 \%$ of their funding, leaving only $9 \%$ without restrictions (UNHCR, 2007). In contrast to the significant restrictions placed upon the donations from the top four governments, the Netherlands was the largest provider of unrestricted contributions, followed by Norway (UNHCR, 2008). The motivations behind governmental donations to the UNHCR remain complex. As Loescher, Betts \& Milner articulated, formal norms such as the 1951 Convention, and notions of burden sharing and moral obligation have some influence on persuading governments to provide support. They also emphasize however, that "states have 
rarely contributed to UNHCR for purely altruistic reasons" (Loescher et al., 2008, 94). In

October 2000, UN Secretary-General Kofi Annan articulated his understanding and relative disgust for governmental funding allocations:

Too often, when donor governments decide which of your activities to fund, there is a flagrant political arrière-pensée. Your humanitarian work is used, or rather abused, as a substitute for political action to address the root causes of mass displacement. You have become a part of a 'containment strategy,' by which this world's more fortunate and powerful countries seek to keep the problems of the poorer at arm's length. How else can one explain the disparity between the relatively generous funding for relief efforts in countries close to the frontiers of the prosperous world, and the much more parsimonious effort made for those who suffer in remote parts of the world such as Asia or Africa (Annan, 2000).

Studies conducted by Alexander Betts in 2008 confirm several alternative motivations behind governmental funding. Betts found that a strong correlation exists between colonialism, foreign policy, and states from which asylum seekers originate, and the allocation of European contributions. He also found that in-kind and financial contributions from Northern donors, in conferences and processes (including First Intemational Conference on Assistance to Refugees in Africa (ICARA), the Comprehensive Plan of Action (CPA), International Conference on Central American Refugees (CIREFCA), and Convention Plus) were largely motivated by strategic security, migration and trade relation concerns (Betts, 2009).

The United States, which is consistently the largest donor to the UNHCR, contributed $32 \%$ of the UNHCR's 2008 contributions (UNHCR, 2008). In $2007,100 \%$ of their donations were earmarked, with $59.5 \%$ broadly allocated, and the remaining $40.5 \%$ tightly restricted (UNHCR, 2007). The significant contributions made by the US reflect not only the country's relative size and authority, but also the important role that refugees occupy within US foreign policy. The considerable donations from the US enable it to procure a large degree of influence over the UNHCR: "While the scale of US support has enabled UNHCR to carry out many of its 
programs, American dominance has enabled Washington to determine many policy and personnel decisions within UNHCR" (Loescher et al., 2008, 95).

Overall, the significant contributions from the US and the other top five donors afford a narrow group of countries hegemonic control over the modern refugee regime. In 2007 , the broadly and tightly earmarked contributions of these top five countries accounted for over $50 \%$ of the UNHCR's total funding (UNHCR, 2007). These states thereby maintain a disproportionate amount of influence on the UNHCR's agenda, placing the Office into a precarious political position from which it is forced to yield to the specifications of its mandate, while also complying with the interests of its key governmental contributors. Earmarking, and the significant degree to which countries employ it, has thus presented major limitations to the UNHCR's operations, and could be regarded as one of the most detrimental conditions restricting the fulfillment of the UNHCR mandate.

Although this relationship is clearly not in the best interests of the UNHCR, the stipulations outlined within Paragraph 20 of the Statute have forced the UNHCR to adapt to these less than ideal arrangements. Overall, there have been two principle implications that have resulted from the lack of permanent funding for the UNHCR. The first repercussion is the difficulty of facilitating multi-year programs. These initiatives require significant financial allocation, and as the UNHCR is unable to guarantee the level of donor contributions from one year to the next, it is increasingly difficult for the Office to invest in programs which require multi-year financial commitments (Loescher et al., 2008).

The second implication is the increased focus on the production of fundraising campaigns and initiatives to elicit donor support. Although the UNHCR professes that fundraising, public awareness and advocacy only account for $1 \%$ of their total budget, the tremendous time and 
effort the Office allocates to eliciting funding places strong demands on the UNCHR. As noted by Väyrynen, the UN's financial contribution only accounts for $2 \%$ of the entire UNHCR budget, and thus the remaining $98 \%$ must be raised by the Office (Väyrynen, 2001). It is for this reason that she concludes that "the High Commissioner's office is, in effect, a huge fundraising organization that must be constantly on the move to be able to finance its operations in the field" (Väyrynen, 2001, 150). The significance of fundraising has even encroached on the responsibilities of the High Commissioner. During a farewell speech in 2000 , then High Commissioner Sadako Ogata highlighted that the UNHCR was in an unfortunate and discouraging financial situation. Although she expressed gratitude to many governments for their consistent contributions, she alerted the Executive Committee to the reality that the UNHCR had become an underfunded organization. Ogata also relented that during her ten year tenure as High Commissioner, raising funds was her primary activity and responsibility (Ogata, 2000).

In order to elicit contributions from donors, the UNHCR first formulates the Annual Programme Budget, which must then be approved by the Executive Committee. Once the budget has been confirmed, a Global Appeal is published in December. This appeal outlines the priorities and strategic programs set out by the UNHCR for the coming year. The Office then arranges an annual pledging conference, and it is during this time that donors commit to fund activities (Loescher et al., 2008). It is through the production of the Global Appeal, and the selection and framing of the UNHCR's priorities and programs that the Office enters into a precarious arrangement, negotiating the needs of refugees against the political priorities of its predominant donors. "On the one hand, it has attempted to safeguard the integrity of its mandate by being seen to be politically impartial. On the other hand, its existence and ability to carry out 
its programs have been dependent upon its ability to respond to the interests of a relatively small number of donor states" (Loescher et al., 2008, 92). The Annual Appeala is also coupled with various other awareness campaigns through which the UNCHR effectively attempts to not only raise awareness about the plight of refugees, but to also utilize these opportunities to effectively lobby for support and donations.

It can be concluded that the financial restrictions embedded within the UNHCR's Statute represent a detrimental inhibitor, which has produced an uneven terrain from which the UNHCR has been forced to validate its presence, and also lobby for the means to conduct its operations. These sentiments are echoed by refugee scholar Gil Loescher, who maintains that "the absence of an autonomous resource base for UNHCR and the limited mandates and competencies of international humanitarian agencies will continue to limit the international community in its response to future refugee crises just as they have done for the past 50 years" (Loescher, 2001, 53).

It is therefore because of its budgetary limitations, coupled with its temporal and political restrictions that the capacity of the UNHCR has been dictated by broader political agendas. The Office is thus faced with a daunting challenge; it must balance its adherence to the interests of its donor states in order to acquire voluntary contributions, while also maintaining positive relationships with host governments and states with increasingly volatile internal situations. These concerns have inhibited the UNHCR from realizing its foremost priority, which is to seek durable solutions for refugee populations. However, despite the Office acknowledging its limitations, the UNHCR's dependency on the assistance of governments has made the Office highly defensive and weary of outside criticism:

UNHCR feels that it is in a competitive environment with other agencies for funds and media attention. Therefore, it feels the need to preserve the institution by protecting 
public confidence in the agency and, more importantly, by safeguarding the confidence of donor governments in UNHCR... In its effort to justify its existence to donors, the office emphasizes the good it does and is quick to thwart any accusation of failure (Loescher, 2001, 50).

Thus the UNHCR's preoccupation with its public image and its donor relationships has enabled both the Office and states to utilize refugees to obtain their own self-serving interests. 


\section{Chapter Two: Defining a Refugee: The Ideological Function of Refugees}

Since refugee populations first emerged in the 1600 s, the refugee figure has maintained a strategic political function. This function has been enabled and maintained through a variety of constructs, including the textual structure of legal definitions and policies, and through the illustrative discourse of multimedia campaigns. Over the years, the changing global arena has altered not only the treatment of refugees but it has also reconfigured the very essence of what a refugee is and the means through which individuals qualify for this designation. Underlying the shifting refugee connotations are strategic political motivations, which the UNHCR has unwittingly supported as a means of ensuring financial contributions from donor governments. By analyzing the shifting scope of refugee representations, the ways in which political motivations have utilized the refugee as an ideological tool become evident. The aim of this chapter is to locate the hegemonic motivations underlying the changing presentations of the refugee, examining both the definitional designations of refugees, and also the ways in which they are visual representations.

As noted in Chapter One, the decision to employ a legal definition to outline the specifications for refugee status was a highly disputed matter. The League of Nations' High Commission for Refugees consciously refrained from universally defining refugee qualifications in the 1920s (Loescher et al., 2008). However, with the onset of the Cold War, the refugee became a principle subject of oppositional capitalist and socialist ideologies; "welcoming and even encouraging flows of refugees from the East allowed Western governments both to weaken the Soviet enemy ideologically and achieve greater political legitimacy in the Cold War environment" (Haddad, 2008, 138). It was against this political milieu that the UNHCR was formed and the definition of the refugee was constructed to propagate the fundamental East and 
West differences. As such, the parameters expressed within the Conventional definition were inherently Eurocentric and framed around granting status to 'refugees fleeing Communism.'

Emma Haddad, research associate at the Refugee Studies Centre at Oxford University, highlighted that the concept of persecution as the defining factor for refugee status strategically favored Western liberal values over Soviet ideals in two prominent ways. First, Haddad notes that the concept of 'fear of persecution' remained adequately expansive, enabling the West to grant protection to ideological opponents of the Soviet regime. Second, the qualifications for persecution were based on a failure to uphold the civil or political rights, categorized by determinants of race, religion, nationality, membership of a particular social group, or political opinion; as opposed to persecution stemming from a failure to respect socio-economic rights (Haddad, 2008). Haddad articulated that by integrating these particular qualifications into the Conventional definition, the title of refugee became more appropriately designated to those from Communist states, rather than citizens from the West. J. W. Hathaway supported this argument when he stated in 1991, that "by mandating protection for those whose (Western inspired) civil and political rights are jeopardized, without at the same time protecting persons whose (socialist inspired) socio-economic rights are at risk, the Convention adopted an incomplete and politically partisan human rights rationale" (as cited in Haddad, 2008, 139). The strategic articulation of the 1951 Conventional definition can therefore be understood to be a mechanism constructed to deliberately reserve the status of refugee for persons fleeing Communism.

This ideological positioning was further promoted through the inclusion of the individualistic designation within the 1951 Convention, which remains a legacy of the IRO's refugee classification (Soguk, 1999). The Convention articulates that qualification for refugee status remained dependent on the possession of a 'well-founded fear of being persecuted', 
granting states further control and regimentation by controlling how this criterion of individuality is determined (Soguk, 1999). Despite mass influxes of refugees throughout the Cold War, the image of the individual persisted, affiliating Cold War refugees with the historically romanticized political exiles of the nineteenth century:

The West held a romantic image of the Cold War refugees, in stark contrast to the image afforded by large groups of refugees at the end of the nineteenth century and throughout the inter-war period. They were individual figures who had been expelled due to dictatorial governments, individuals to whom the West owed thanks and support for attempting to bring democratic values to non-liberal societies (Haddad, 2008, 143).

By constructing the refugee in alignment with the Western discourse of freedom, the West was able transform the refugee figure from being a burden to a hero. Cold War refugees thus entered into a new era of identity politics from which they were no longer demarcated as 'others' but were rather constructed with acknowledgement of their similarities to the Western world. Haddad claims that this period became one of respite for the refugee, through which the refugee became 'visceral proof' of the Communist threat:

'The Cold War,' says Campbell 'was a powerful and pervasive historical configuration of the discursive economy of identity/difference'. Within this discursive economy the refugee was strategically and purposefully positioned between 'identity' and 'difference' to draw attention to the distance between the two concepts. She acted, once again, to blur the boundaries between inside and outside. The refugee was now employed as an indicator of identity and difference in an inclusionary, not exclusionary fashion (as cited in Haddad, 2008, 156).

Cold War refugees were therefore welcomed into the West, depicted as 'other-insiders,' retaining no danger or threat to the Western societies they were settled into (Haddad, 2008). Instead it was their statelessness that legitimized the Communist risk and need for Western intervention, and thus validated the West in its ideological war (Johnson, 2003).

It is important to note that during the drafting of the 1951 Convention, Third World refugees were prevalent, however they were not regarded as persons of concern; thus the 
Conventional definition failed to account for these already existing populations because they possessed no significant political value (Chimni, 1998). Haddad highlighted that it was because of these alternate refugee populations that the Conventional definition was articulated to reconstruct the 'problem of refugees' as a problem of 'refugees fleeing Communism',

The change of emphasis in the early Cold War era to focus on 'refugees fleeing Communism' demonstrates the socially constructed nature of the refugee regime... A shift in the conceptions of identity between East and West caused a repositioning of western states' interests relative to refugees and hence a redefinition of the refugee category. It was this redefinition that became inscribed in international legislation via the 1951 Convention and the Statue of UNHCR. (Haddad, 2008, 158).

The refugee designation was therefore constructed with a specific Western agenda that enabled states to exploit the refugees' ascribed political value. By formally recognizing Europeans escaping Communist control as refugees, the West was able to utilize the UNHCR to institutionalize an ideological framework which employed the refugee figure as a political icon. Refugees were positioned as 'voting with their feet', and rejecting Soviet ideologies for the security of the West. The welcoming of individuals escaping Communism, as well as the legislative protection afforded to these groups, can be viewed as a hegemonic maneuver for asserting the superiority of Western values (Johnson, 2003).

It is through this reconstruction of the refugee's identity that the iconic image became represented as a "non-threatening, white male, often accompanied by his nuclear family, and who had "a past, a story and a voice"" (Johnson, 2003). By attributing a familiar identity to these refugees, citizens from the West empathically recognized the commonality they shared with these individuals, and thus supported the action that their states were taking to ensure protection for these refugees within their borders. The exilic approach to the refugee problem thus corresponded positively with the propagation of an external view of sovereignty, which 
prescribed individuals the responsibility for ensuring human rights (Haddad, 2008). These rights however, were limited to refugees who fit the narrowly defined identity discourse contained within the Convention. As such, the West paid little attention to the increasing numbers of refugees that remained outside of European borders, and thus outside of the Convention's protection.

By the beginning of the 1960 s, however, the increasing scope and severity of refugee issues exploded into a vast array of new geographic landscapes, transcending European borders. Although these erupting conflicts resided outside of the Conventional parameters, these struggles began to retain a strategic importance as the East and West competed to secure allies and advance their own hegemonic interests across the globe (Loescher et al., 2008). The United States was particularly concerned that the instability of the developing world offered an ideal terrain for the Soviet Union to exploit and disseminate its Communist ideologies. As a result, Western governments willingly supported the UNHCR's expansion into the Third World (Loescher, 2001, 39). Thus, the original 'non-concern' for Third World individuals was revised during the later periods of the Cold War, through a "strategic vision which dictated that refugees [from the Third World] possessed ideological and political value" (Chimni, 1998, 356). However, the UNHCR's mandate still restricted it from providing assistance to these new geographical locations and thus the 1967 Protocol was constructed to overcome these territorial limitations.

As highlighted in Chapter One, the 1967 Protocol was adopted under High Commissioner Félix Schnyder, and effectively eradicated the geographical limitations contained within the Conventional definition, but failed to amend the embedded Eurocentric qualifications. 
The 1967 Protocol, though important because it removed the time and geographical constraints contained in the Convention, prohibited alternative interpretations of who a refugee was and how this status could be determined... It was clear, by the 1960 s, that individuals from the developing world would dominate the refugee population, yet the instrument developed to serve this vulnerable group did not reflect their needs or interest (Davies, 2008, 727).

As a result of increasing dissatisfaction with reformation of the 1967 Protocol, many regional legal reforms were instituted by developing states that sought to redefine the legal qualifications of the term 'refugee' for themselves. In 1964, the Organization of African Unity (OAU) formed a Commission on Refugee Related Problems in Africa, and in association with the UNHCR, they extended the Convention's definition to suit the expanding African refugee context. The resulting 1969 OAU Refugee Convention broadened the criterion of persecution to a wider list of factors, stating that:

The term 'refugee' shall also apply to every person who, owing to external aggression, occupation, foreign domination or events seriously disturbing public order in either part or the whole of his country of origin or nationality, is compelled to leave his place of habitual residence in order to seek refuge in another place outside his country of origin or nationality (As cited in Gorman, 2000, 161).

Similar to the Eurocentric experience underlying the 1951 Convention, this definition reflected the historical African context, highlighting that the criterion of persecution was not the only determining factor for refugee status. Unlike the 1967 Protocol, which failed to rectify the Convention's insistence on determining individual refugee status, the OAU's definition confronted the insignificance and impracticality of this system. As Haddad states, "The OAU definition acknowledges that if an individual or a group of individuals fears the accidental but nonetheless dangerous consequences of armed conflict, this is sufficient grounds for the granting of refugee status" (Haddad, 2008, 154). This regional definition therefore responded to the more generalized violence that refugees faced. The $\mathrm{OAU}$ had initially planned to establish an entirely self-contained African Refugee Convention. However, based on concerns that this could 
undermine the universality of the refugee regime, the OAU decided that the African Refugee Convention would be a complementary instrument to the UNHCR's Convention, and the 1967 Protocol (Jackson, 1999).

Similarly, in 1984, the Latin American Cartagena Declaration, tailored the legal definition of a refugee to include "persons who had fled their country because their lives, safety or freedom have been threatened by generalized violence, foreign aggression, internal conflicts, massive violations of human rights or other circumstances which have seriously disturbed public order" (Loescher et al., 2008). These separate definitions more accurately reflected the contexts in Africa, Central America, and Asia, which cause exile. These expansions thus provided regional protection to populations who could not generate documented evidence of individual persecution, because they fled for reasons of generalized violence and human rights abuses.

Despite the overt changes made by these amendments, Anais Tuepker argues that these departures have provided no challenge to the underlying presumptions of the 1951 Convention. Instead Tuepker highlights how the 'radicality' of the OAU definition became regulated through 'manipulation of cultural specificity' acting as a deterring factor for involvement from the Western states (Tuepker, 2002). He notes that it was through the employment of these regional definitions that justification was provided for limiting the obligation of Western states to Third World refugee crises.

[African asylum seekers] are deemed 'better suited' to the OAU definition and protection in (culturally more appropriate) Africa, and by flawed logic thus denied protection elsewhere under the UN definition... The OAU definition refugee, once outside Africa, has thus arguably come to be seen as a 'second-class' refugee (Tuepker, 2002, 412).

By utilizing the very instruments Third World nations created to extend the scope of the refugee definition, the West was able to once again reconstruct the refugee title to suit the geopolitics of 
the time. In 1969, when the OAU Refugee Convention was formally adopted, Third World refugees did not possess the same ideological value as European Cold War refugees. The refugee figure was therefore partitioned into the 'normal' refugee, represented as a heroic European male endowed with political and economic agency, and the poverty stricken displaced persons of the Third World. This partitioning was legitimatized through claims that the nature and character of refugee flows in the Third World were radically different from refugee flows in Europe at the end of First World War (Chimni, 1998). This fragmenting of the refugee label was ultimately used as a means to validate differential treatment of asylum seekers from the Third World (Chimni, 1998).

Internationally renowned legal scholar, B.S. Chimni, argued that the justifications used to legitimatize differential treatment of refugees were sustained through a contrived "Myth of Difference." The 'Myth of Difference', as proposed by Chimni, applied an internalist interpretation of the root causes of refugee flows, laying blame on post-colonial societies and states, and negating the significant influence of external states and macro-economic reforms. This perspective thus served to assert the belief that Third World refugees were not fleeing their homes because of fear of persecution, but rather because of extravagant ethnic wars and violence.

Chimni highlights in his 1998 publication "The Geopolitics of Refugee Studies: A View from the South," that there were six principle features used to verify 'inherent' differences between Third World and Cold War refugees. First, Chimni points out how numbers were employed to qualify the radical scope of these new refugee situations. Unlike representations from the past, Third World refugees came to be represented through numbers, with constant references to the 'enormous magnitude' and 'unprecedented nature' of these new crises (Chimni, 
1998). Second, it was suggested that advancements in communication and transport technology had abolished the physical barriers which in the past reduced the number of direct asylum seekers who reached the West. It was argued therefore that because of these advancements this new environment constituted grounds for regime reforms. Third, Chimni notes that allegations were made which claimed that the majority of Third World asylum seekers were actually economic migrants, seeking relocation through unsubstantiated refugee claims (Chimni, 1998). This latter point correlated to the fourth principle, which made a correlation between Third World refugees and internal unrest. This argument suggested that unlike Cold War refugees, who were uprooted because of international events, Third World refugee flows often resulted from internal conflict and therefore responsibility was solely attributed to the post-colonial state. The fifth feature further utilized this rationality, highlighting that many Third World refugees failed to satisfy the individualist criteria of political persecution required by the 1951 Convention, and were instead relocating because of generalized violence and poverty (Chimni, 1998). The sixth and final feature that Chimni notes is the contention that the existence of the 1969 Convention was a clear acknowledgement of the differences between Cold War and Third World Refugees (Chimni, 1998). The international community argued that based on these proposed differences the original basis of international refugee law was unsuitable for providing assistance to these divergent refugee populations, and thus a new regime emerged which translated into a series of restrictive measures were adopted.

This new regime, classified by J.C. Hathaway as the 'non-entree regime' was portrayed as a necessary measure to reduce the abuses of those claiming refugee status in order to obtain a better life through resettlement in the West (Chimni, 1998). To counter this feared, voluntary repatriation, and in-country protection became the ideal durable solutions to these 'new' crises. 
This enabled an internalist perspective to propagate, which maintained that it was the responsibility of the states of physical origin to resolve refugee flows, and thus there remained no obligation for other countries to resettle refugees fleeing inhumane environments. "At best other states had the obligation of offering 'temporary protection'" (Chimni, 1998, 362). This perspective provided the needed justification for enabling states to restrict resettlement to this 'vast hoard' of refugees, while still asserting control over the crisis through the careful allocation of financial support to the UNHCR.

It was through the establishment of earmarked funds that donors mediated the UNHCR's agenda, that the materialization of Western objectives was ensured. As noted in Chapter One, the influence of powerful Western states was evident from the birth of the UNHCR, which like all international organizations was brought into existence to defend the interest of these states (Chimni, 1998). Thus in the era of the 'non-entree regime,' the UNHCR was forced to relocate and legitimate itself within the new political climate. The UNHCR responded to this new political shift in two significant ways: it conceded to the policies of 'non-entrée' agenda, and it adopted a new aesthetical approach for depicting the lives of refugees (Chimni 1998).

\section{Depicting Refugees}

Similar to the evolving legal definitions that designate the parameters of a refugee, the illustrative representations of refugees have also shifted significantly to reinstate and legitimate the changes in the international refugee regime. As noted in the introduction, in the twenty-first century, visual imagery has become a prominent factor in framing public perception. The proliferation of refugee representations has therefore created as a highly influential lens through which the lives of refugees have been constructed. As refugee scholar Liisa Malkki notes, 
"pictures of refugees are now a key vehicle in the elaboration of a transnational social imagination of refugeeness" (Malkki, 1996, 386). This understanding of 'refugeeness' has become a site for the reproduction of Western ways of knowing, which serves the hegemonic interests by reinstating the dominant discourse of the time (Rajaram, 2002).

By employing an aesthetic approach to the study of shifting refugee regimes, the inherent underscoring of politics becomes even more apparent. As Bleiker highlights, aesthetic approaches "embark on a direct political encounter, for they engage the gap that inevitably opens up between a form of representation and the object it seeks to represent" (Bleiker, 2002, 510). Therefore, the remainder of this chapter is dedicated to exploring how the ideological value of refugees was constructed through their visual representations. Utilizing the principles articulated in Chimni's 'Myth of Difference', this analysis will assess how the UNHCR's visual depictions reiterated a Western vision, presenting refugees in an easily digestible discourse congruent with Western ideology. This following assessment is by no means a semiotic analysis, nor is it an exhaustive examination of the larger body of the UNHCR's illustrative publications; rather this section considers how the shifting identity of refugees, as previously discussed, was illustrated in the UNHCR photographs at different temporal junctures.

The UNHCR holds an extensive collection of over 250,000 images, from varying decades. In January 2009, the UNHCR's main website page (www.unhcr.org), featured an online photo-series entitled 'UNHCR -Pictorial History'. This collection, along with another online series entitled 'Hungarian Crisis - 50th Anniversary', provided a glimpse of the historical progression of UNHCR's imagery from the early 1950s until the 1990s. The UNHCR's website was selected as the primary source for investigation because it has emerged as the Agency's principle mode of communication with the public, the media, and its potential donors. Over the 
years, the number of photo-series that are featured on the UNHCR's website gallery has

continued to increase. The opening statement to this gallery declares:

A picture tells a thousand words - and UNHCR has more than 250,000 of them dating back decades. The Agency's photo library in Geneva is guardian of the world's largest collection of refugee-related photos covering nearly all of the major displacements of the last 60 years. These images provide a comprehensive portrait of the lives of refugees, asylum seekers, internally displaced people and the stateless in all corners of the globe (www.unhcr.org, 2009).

This online gallery features a strategic selection from the UNHCR's extensive archive, and the gallery's webpage also encourages viewers to visit the organization's more expansive exhibit on the social networking site Flickr (www.flickr.com/photos/unhcr). The images showcased on the UNHCR's gallery and Flickr pages are arranged in thematic sets that chronicle different geographic locations, historical events, and aspects of the refugee experience. For the basis of this comparison, the two previously mentioned sets were chosen from the one hundred and fiftyeight series featured on these two websites. These two selected sets were favoured because they provided a sampling of images from different geographic locations, which also pertained to specific periods in history.

The first series reviewed, entitled, 'Hungarian Crisis - 50th Anniversary', depicts images from the Hungarian uprising in 1956. This series was the only collection featured on either site that archived the first representation of Cold War refugees. It was therefore selected as the sample of the dominant imagery from this time. Selected images from this series were also contained within the second series used, entitled 'UNHCR - A Pictorial History'. The majority of images from this series were included in the UNHCR's 1991 publication, 'Images of Exile', which was produced by the UNHCR to celebrate its fortieth anniversary. The 'UNHCR - A Pictorial History' series embodies a small representative sample of the visual discourse utilized 
by the UNHCR from the early 1950s through until 1991. The UNHCR's decision to select these scries of images in both the printed publication 'Images of Exile' and within their online collection 'UNHCR - A Pictorial History' demonstrates the Agency's confidence that these images serve as a representative collection of UNHCR's historical visual depictions.

In order to structure this image review, the thematic assessment first proposed by Christina Clark-Kazak in her publication 'Representing Refugees in the Life Cycle: A Social Age Analysis of United Nations High Commissioner for Refugees Annual Reports and Appeals 1999-2008' was employed. The Clark-Kazak study, conducted in 2009, challenges the validity of the commonly held assertion that children are over-represented in contemporary UNHCR imagery. Clark-Kazak's research implemented a quantitative and qualitative analysis of the UNHCR's Annual Appeals and Annual Reports published over a ten-year period, beginning in 1999. Although Clark-Kazak's main focus was to investigate the depiction of children within the textual and visual representations of a large collection of the UNHCR's publications, her findings and the espoused framework are useful when assessing the greater thematic trends inherent in the selected UNHCR collections.

By employing the framework instituted in Clark-Kazak's research, with slight modifications as indicated below, the following research uncovered the dominant illustrative themes which supported differing ideological conceptions of refugees at specific temporal junctures. The Clark-Kazak approach applied a longitudinal quantitative and qualitative analysis to the study of photographs. It recognized the denotative and connotative meanings contained within illustrative representations and accounted for both forms of data. To document the denotative meaning, a copy of the image along with a brief description of the photograph was recorded, along with a note of the researcher's immediate reaction to the image ${ }^{\text {viii }}$. This 
description included the number of human subjects and their sex, race, physical age group ${ }^{\mathrm{ix}}$ and any noticeable religious and cultural markings (Clark-Kazak, 2009). As prescribed in the ClarkKazak approach, physical markers were used to determine age classification, however if the physical characteristics were indiscernible the uncertainty was recorded, the imperceptible figures were not counted towards the quantitative analysis. The study thus accounted for the absolute presence of each age classification as either a principle or secondary subject ${ }^{\mathrm{x}}$, instead of the total number of subjects from each category ${ }^{\mathrm{xi}}$ (Clark-Kazak, 2009). The principle activity in which the primary subjects were engaged was then thematically coded in each of the photographs. The Clark-Kazak study employed ten activities for coding:

1. Assistance - subjects are giving and/or receiving aid of some kind

2. Documentation - subjects involved in administering or completing forms, paperwork, registration, etc

3. Education - all activities in which formalized instruction was depicted, including schooling, literacy classes or sensitization

4. Health - depictions of the provision of health care

5. Mobility - where principal subjects are walking, traveling or moving in some way

6. Passivity - describes images in which subjects are sitting, waiting or not doing anything in particular

7. Portrait - subjects are posing for the camera, or are not necessarily posed, but a close-up to medium depiction of the principal subject(s) which prevents contextualizing features

8. Play - subjects are engaged in leisure, sport or recreational activities

9. Production - activities that are undertaken for monetary gain or exchange (trading, farming, constructing buildings etc.)

10. Reproduction - activities that are undertaken for familial and societal survival and continuity (cooking, fetching water and preparing food) (Clark-Kazak, 2009, 8).

Although Clark-Kazak's study provided a useful framework for coding thematic trends, the nature of her study focused specifically on human participants, and therefore disregarded the coding of aerial images. For the sake of this research however, it is important to include images that contextualized the magnitude of different refugee crises. It is for this reason that an 'Aerial 
frame,' designating above ground photographs of refugee compounds or camps, was added to Clark-Kazak's preexisting ten coding activities.

In addition to the inclusion of this new frame, one other criterion has also been added to the evaluation of these photos. In addition to the aforementioned criteria, each photograph was also evaluated for the level of agency of the principal subject(s). Although the Clark-Kazak framework included a separate designated activity code for passivity, it became evident that various activity codes could depict refugees as either active or passive actors. To account for this variable, within this current evaluation of the UNHCR's photographs, agency was recorded on a three point scale. 'High' agency indicated principle subject(s) acting on their own volition. 'Medium' agency designated principle subject(s) who were being assisted in the photograph, and 'Low' agency indicated principle subject(s) who displayed little to no participation in the primary activity (except in cases where the primary activity was 'Passivity'). When images failed to depict human subjects, for example in 'Aerial' frames, the level of agency was not recorded and the image was not included in the total assessment. In photographs where there were numerous principle subjects displaying different levels of agency, the level which was most prevalent amongst principle subjects was recorded.

\section{Photograph Assessment}

A total of fifty-one images from the UNHCR were reviewed; twenty-four from the collection 'Hungarian Crisis - 50th Anniversary', which depicted European Cold War refugees from 1950-1958 (hereinafter referred to as Series A), and twenty-seven photographs from the collection 'UNHCR -Pictorial History' which depicted Third World refugees from 1960-1991 (hereinafter referred to as Series B) ${ }^{\mathrm{xii}}$. As illustrated in Figure 2.1, the dominant activity in both 


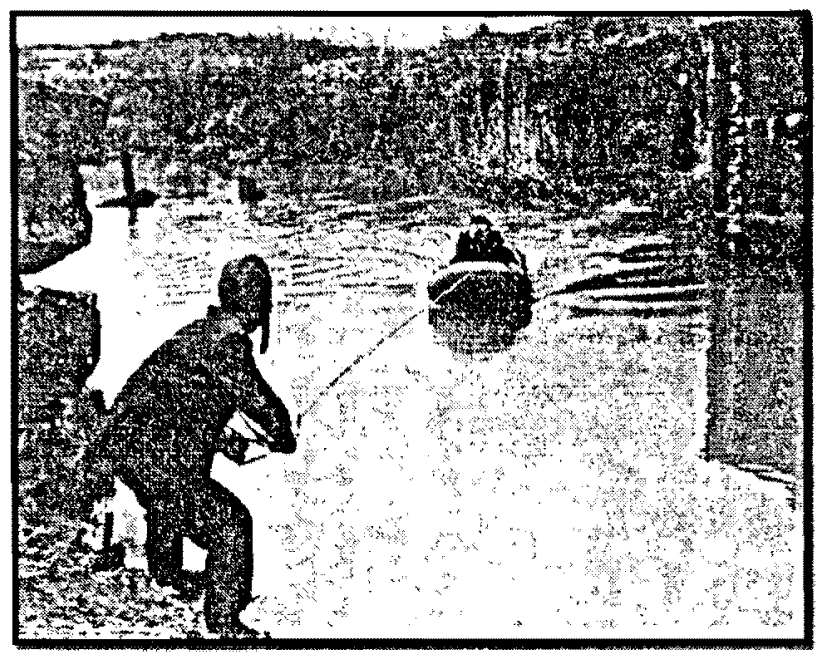

IMG (A)I:UNHCR/ 1956
Series A and B was the theme of 'Mobility', which was present in $25 \%$ of the images in Series A, and 19\% of those in Series B. Despite this similarity, the contextualization of this theme denotes explicit differences between the two series. For instance, $83 \%$ of the images displaying 'Mobility' in Series A demonstrated a high degree of agency, illustrating

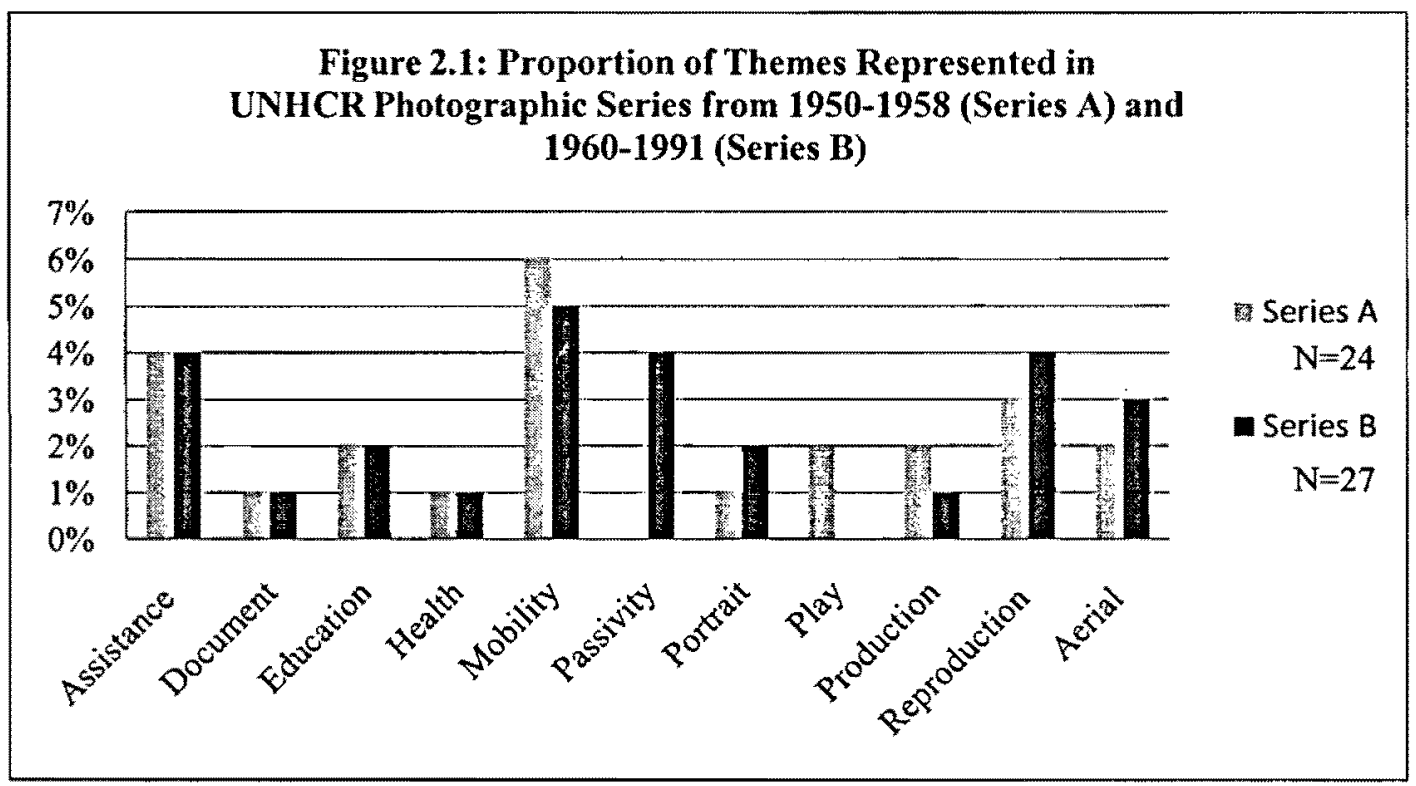

refugees moving on their own volition. As an example, IMG. (A)1 depicts two individuals tackling environmental obstacles restricting their mobility. The included description further qualifies the depicted event, stating, "Some Hungarians used boats or rafts to cross canals and lakes straddling the Hungarian-Austrian border" (UNHCR.org, 2009). This image, along with its accompanying description, presents the refugee figure as an independent and capable individual. 


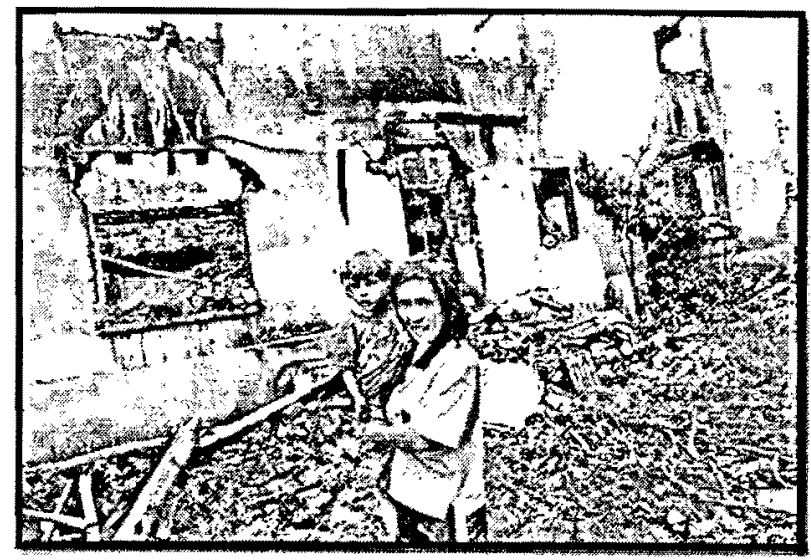

IMG (B)1: UNHCR / 29063 / 1999/R. Chalasani

The level of agency associated with

the 'Mobility' theme in the images in Series

B painted a different picture. Only $40 \%$ of

'Mobility' images illustrated a high degree of agency. The remaining $60 \%$ portrayed refugees being assisted with their movement, therefore demonstrating only a medium degree of agency. As well, the majority $(57 \%)$ of 'Mobility' images in Series A featured less than five individuals, whereas the bulk of Series B 'Mobility' frames depicted groups of people moving, with only one image in the entire series depicting less than five individuals. This image (IMG (B)1) depicted only two figures: a mother with her child, who had returned to Kosovo to 'utter destruction', as indicated by the description. This image denotes a different form of movement than the majority of the images in Series B, because the subjects are returning back to their homeland, instead of moving away from it. The majority of Series B

'Mobility' photographs presented a solid mass of refugees relocating from their country of origin. These masses often faded into the horizon or disappeared off the image's frame, alluding to a 'neverending' flow of people, as depicted in IMG (B)2.

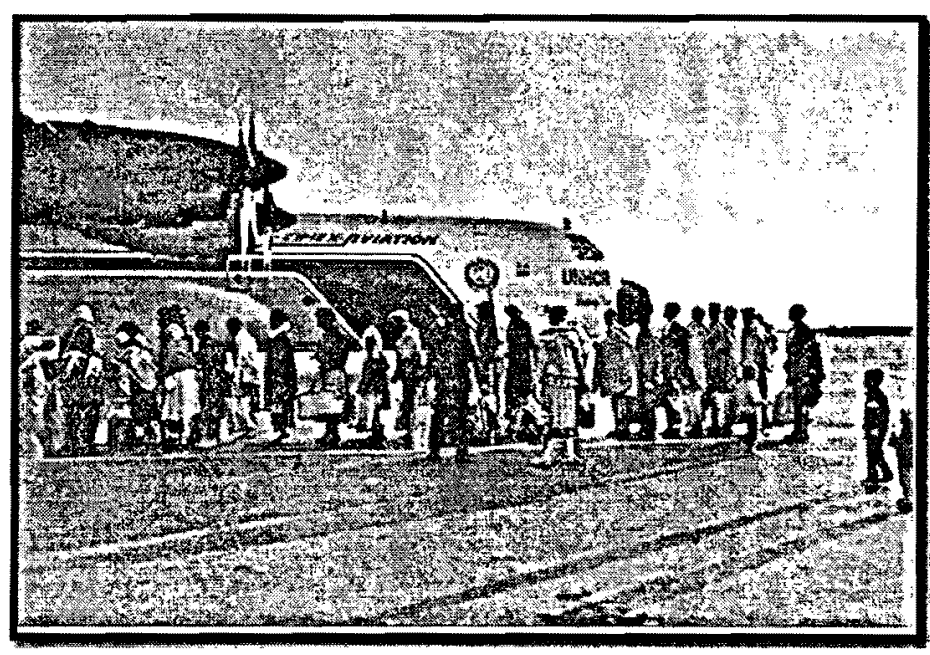

IMG (B)2: UNHCR / 19100/1989/L. Astrom 


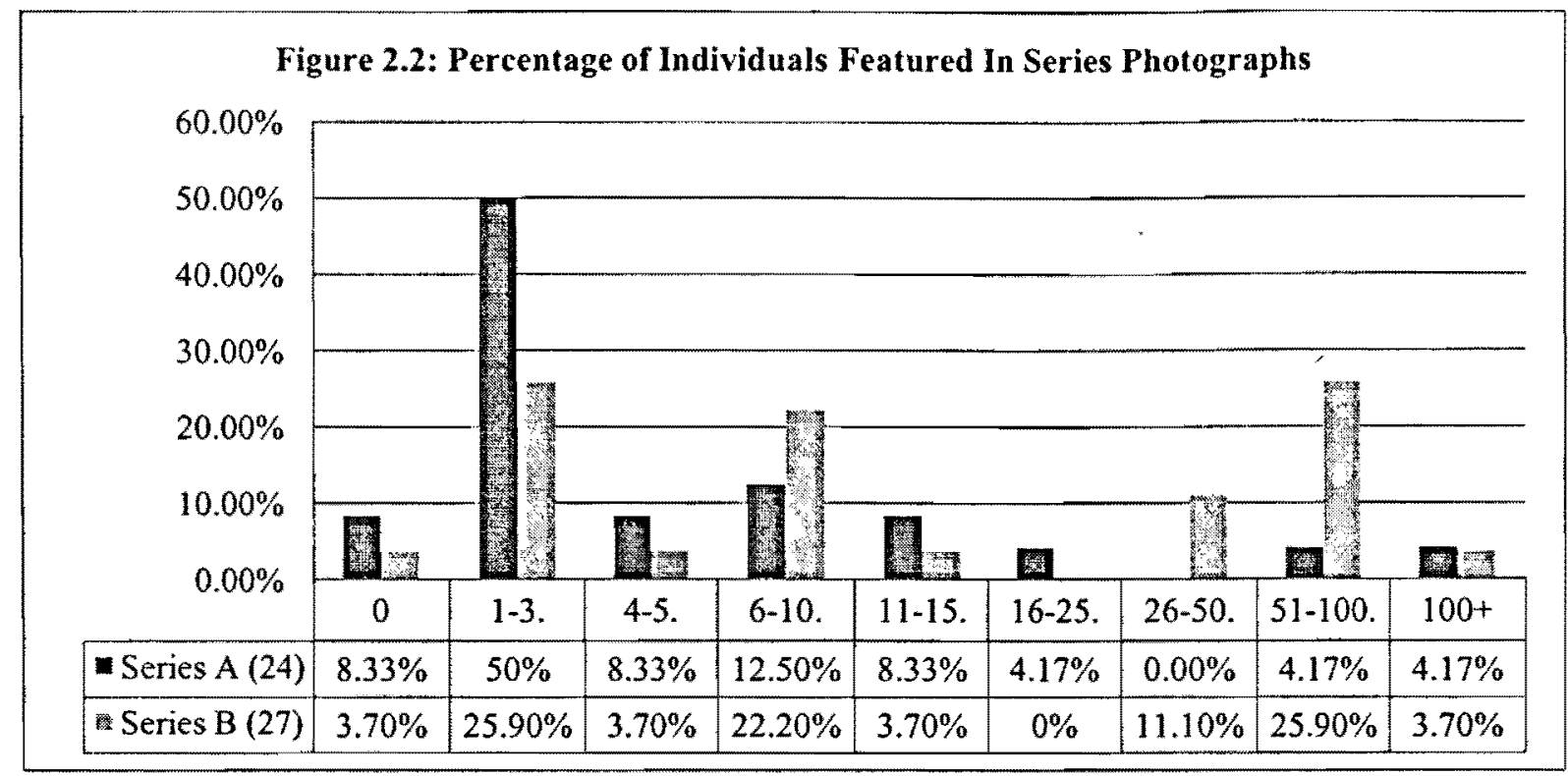

Showcasing Scale

The depiction of an endless mass correlates to the first feature described in the "Myth of Difference', which highlights the shift towards representing refugees in terms of numbers. As noted by Chimni, "there is constant reference in the literature to the enormous magnitude and the unprecedented nature of the contemporary crisis" (Chimni, 1998, 356). The suggested magnitude of Third World crises is therefore reinforced through these visual illustrations presenting infinite crowds of moving refugees.

As illustrated in Figure 2.2, in total over $71 \%$ of images from Series A contained less than ten individuals, with $50 \%$ depicting less than three people. In contrast, only $26 \%$ of images in Series B contained fewer than three individuals, and just $52 \%$ featured less than ten people in the image. Similarly, Series B had almost triple the amount of photographs containing twentyfive refugees or more. Photographs such as IMG (B)3, which showcase an unending mass, are reflective of many Third World refugee depictions. As highlighted by Malkki "mass displacements are often captured as a 'sea' or 'blur of humanity' or as a 'vast and throbbing 
mass"' (Malkki, 1996, 387). However, despite the consistency with which Third World refugees were depicted in a mass, Chimni refutes the myth that the enormity of Third World refugee flows are new or unprecedented. Rather, Chimni quotes from Widgren, to contest this misrepresentation:

Popular European belief seems to be based on the conviction that the present rate of intercontinental movements of immigrants is unprecedented in history. This is completely wrong. Taking a 200-year perspective for 1800 to 2000 , by far the peak of migration was reached during the years 1845-1923, when 50 million people, mainly Europeans, moved to the Western hemisphere at a time when world population counted only somewhat more than one billion (As cited in Chimni, 1998, 358).

Chimni uses this idea to propose that the global struggle for territory and resources has been a consistent factor throughout history. He notes that in the past three centuries, new spaces have been uncovered, while older spaces are subjugated. However, in the contemporary struggle for land, space is now contextualized as either 'filled' or 'empty' (Chimni, 1998). This new rationale presents justification for restrictive access to resettlement, representing most of the West as

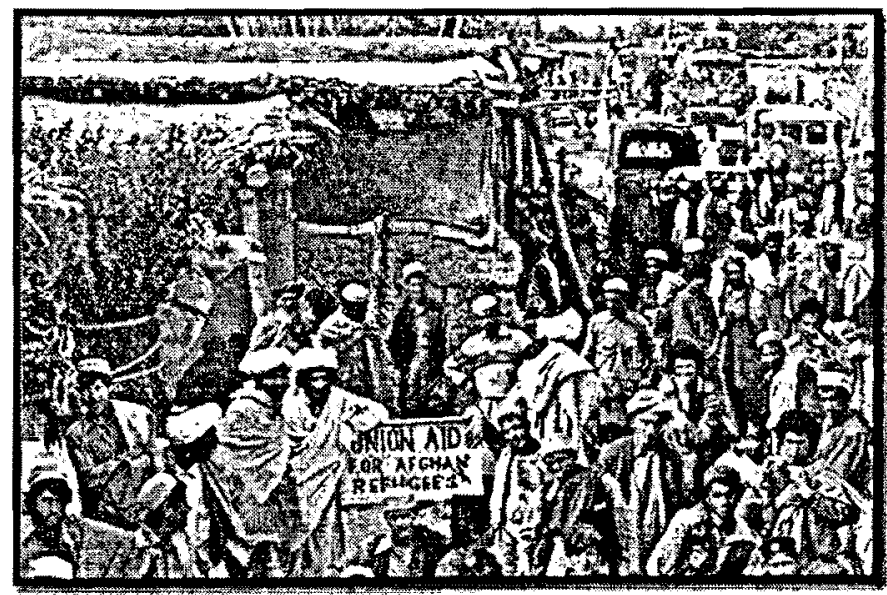

IMG (B)3: UNHCR/14139/1984/H.Gloaguen 'filled' and incapable of providing space

for the infinite masses of Third World refugees.

The transition from visual representations of small groups of refugees, which constituted the majority of European Cold War images, to depictions of enormous hordes of Third

World refugees, serves to legitimate that there were inherent differences in the nature of these two flows. However, the strategic portrayal of Third World refugees as such a large mass serves 
a greater purpose than merely providing a threatening scale to existing refugee crises. These images serve an ideological function, stripping any notion of individuality from the refugee, placing them amongst an interchangeable crowd, and removed of any personal characteristics. This was a great departure from the iconic images of the heroic European refugee, which utilized the individual identity of refugees to rally support for their plight.

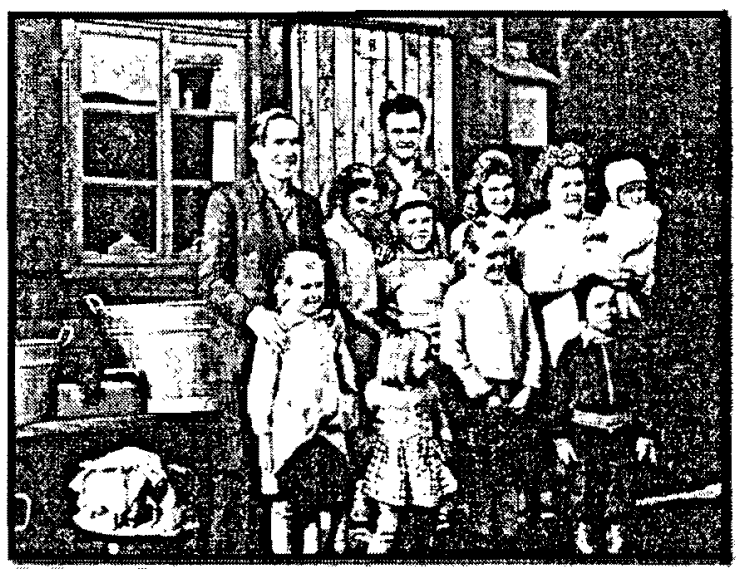

IMG (A)2: UNHCR

\section{Constructing Character}

As previously mentioned, Cold War European refugees procured a very central position within the ideological battle between the East and West. The representations of refugees were predominantly male-specific, constructing the refugee as both a glorified heroic political exile, and also a common man, with similar attributes and values to those residing in the West.

Photographs thus constructed the identity of the individual male refugee by showing him in proximity to his family, as depicted in IMG (A)2, and in association to his traits, as reflected in

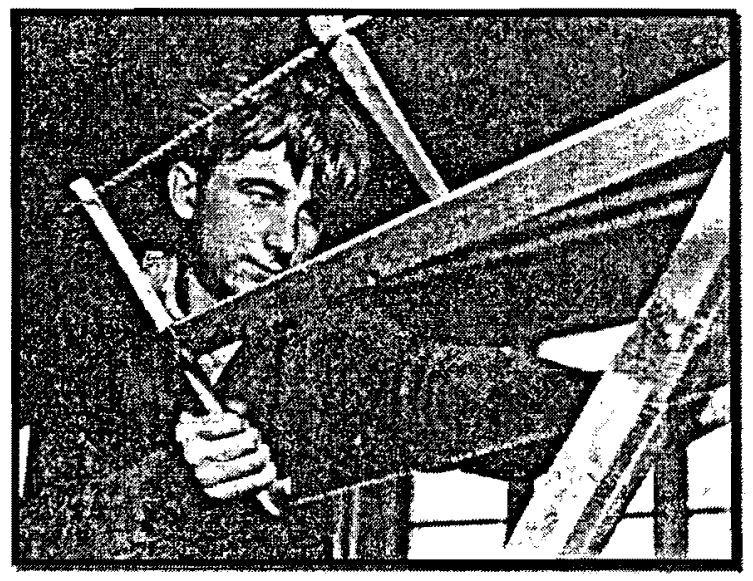

IMG (A)3: UNHCR
IMG (A)3. These images thus served to reinstate the constructed vision of a 'normal' refugee as a white anti-communist, family-man (Johnson, 2003). It was against this 'normal' refugee binary that all other refugees were compared and qualified. By depicting Third World refugees in 
massive gatherings, rather than within a similar illustrative discourse as European refugees, Third World asylum seekers were constructed as existing outside of the established refugee 'norm'. These refugees were presented as the binary opposite to the European 'other-insider' refugee. Aside from the numerical statistics, which indicate a favoring toward portraying larger groupings of Third World refugees, the construction of identity both in the presentation of family and profession, reinforced the differences between these 'new' refugees.

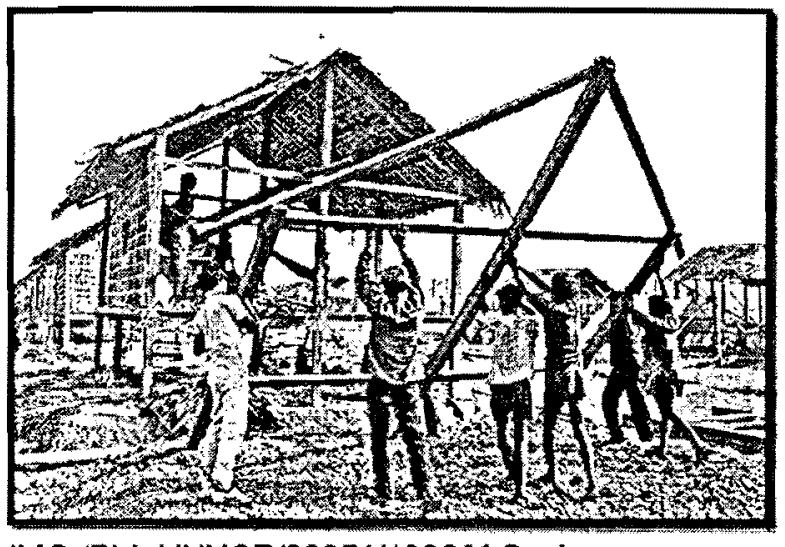

IMG (B)4: UNHCR/22051/1992/K.Gooi
The 'Production' theme used in numerous images provided an example of how difference was demonstrated even through depictions of similar subject matters. 'Production' denotes activities commonly undertaken for monetary gain or exchange, such as trading, farming, or constructing buildings. Although this frame

appeared in both collections, it was not employed frequently, representing only $8 \%$ in Series A and $4 \%$ in Series B. When this frame was utilized in Series A however, it afforded a face and identity to the European refugee, permitting viewers to develop an intimate connection to the individuals depicted. For example, IMG (A)3, provides a strong example for how the 'Production' frame not only illustrates the capacity of refugees to contribute to society and work independently, but also provides a clear depiction of the individual's face, enabling the viewer to not only identify with his craft, but also the individual within the image. In contrast, IMG (B)4 also showcases refugees at work, however the viewer is distanced from the refugees in this scene, and is thus forced to connect only to the labor and not the individuals at work. This distancing is obtained through the camera's location, and also the position of the figures in the 
frame. Unlike IMG (A)3, which provides a medium shot with a full view of the individual's face, the majority of refugees in IMG (B)4 have their back to the camera or are out the camera's focus, preventing the viewer from being able to discern the faces of the figures.

The European Cold War refugee was thus afforded an individual identity, while the portrayal of Third World refugees was limited to depictions of an indistinguishable mass. By juxtaposing the initial European refugee with the new 'hordes' from Third World, it becomes evident that there has been a strict departure from how the refugee was once constructed. Chimni notes that, "by producing the image of a 'normal' refugee - white, male, anti-communist - a clear message was sent to the population with regard to the 'new asylum seeker': that asylum seekers were here for no good reason, that they abused hospitality, and that their numbers were too large" (Chimni, 1998, 357). These images thus reinforce the 'Myth of Difference' by eliminating individual identity, and supporting the notion that while European refugees satisfied the individualist criteria of political persecution as defined by the Convention, refugees from the Third World do not. The suspicion aroused from the legitimation of these 'other' refugees, validates further facets of the myth, which proposes that Third World asylum claims are spurious and more likely thinly veiled movements of economic opportunists. The UNHCR's decision to illustratively represent Third World refugees as a faceless mob, as opposed to portraying them as individuals, assists the hegemonic interests of the West by legitimating the need for the creation of restrictive reforms, while also distancing Western society from identifying with refugees from the Third World.

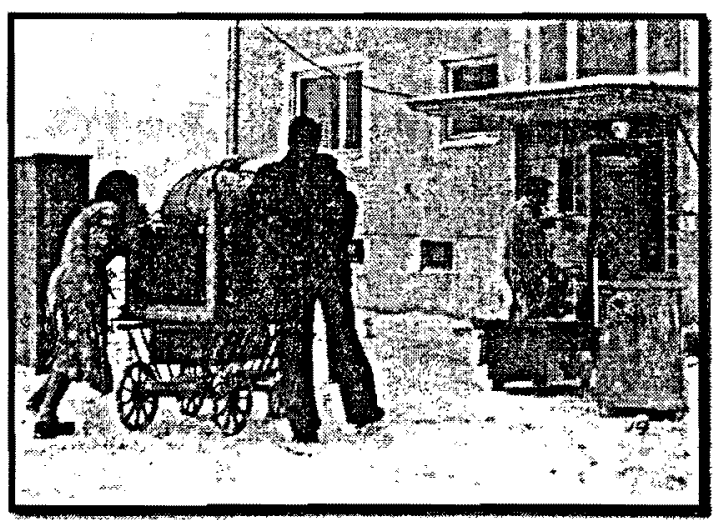

IMG (A)4: UNHCR 1958 


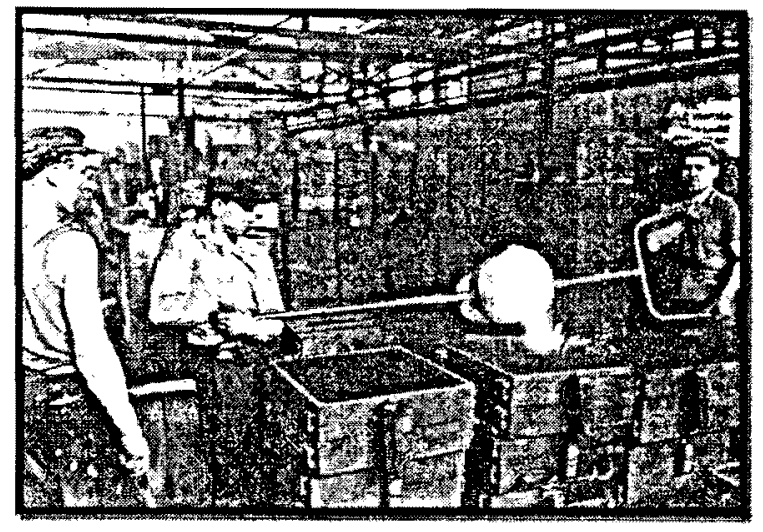

IMG (A)5: UNHCR 1958
One of the most significant differences

revealed in the whole image review was the employment of the theme of 'Passivity', which was not evident in any of the photographs from Series A, but was represented in $15 \%$ of Series B images, as indicated in Figure 2.1. The portrayal of 'Passivity' was also coupled with varying

depictions of agency from the two collections. $55 \%$ of images within Series A illustrated refugees displaying a high degree of agency, with only $45 \%$ of subjects displaying medium degrees of agency. For example, IMG (A)4 depicts (and its accompanying caption describes) a family moving themselves into their new home. This image, along with photographs like IMG (A)5, illustrates the ability for European refugees to support both themselves and the greater society.

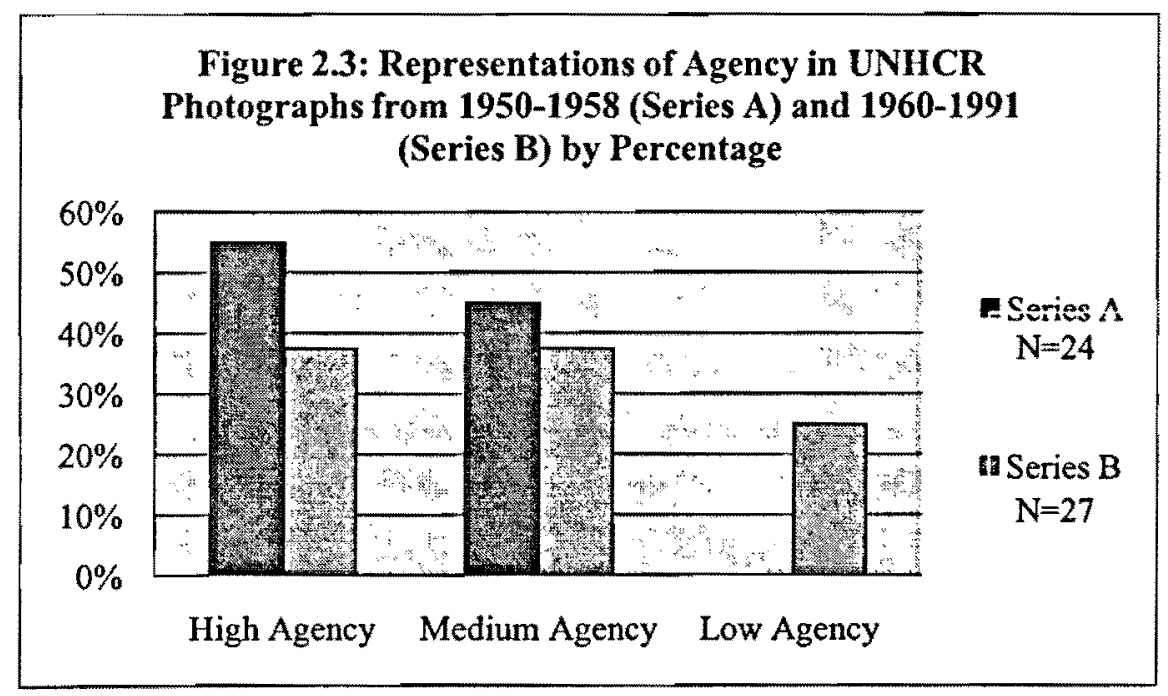


In contrast to the majority of European images, which depicted individuals working of their own accord, high agency levels were only depicted in $37.5 \%$ of activity frames in Series B.

While a startling $25 \%$ of the images in this collection presented refugees as having little or no agency. The utilization of the 'Passivity' frame, along with the corresponding decline in portrayals of high agency levels, presented the notion of helplessness, reducing Third World refugees to vulnerable victims.

The portrayals of passivity further accentuated and legitimated the differences of the new flows of refugees. Unlike the heroic European refugee who was exiled because of political

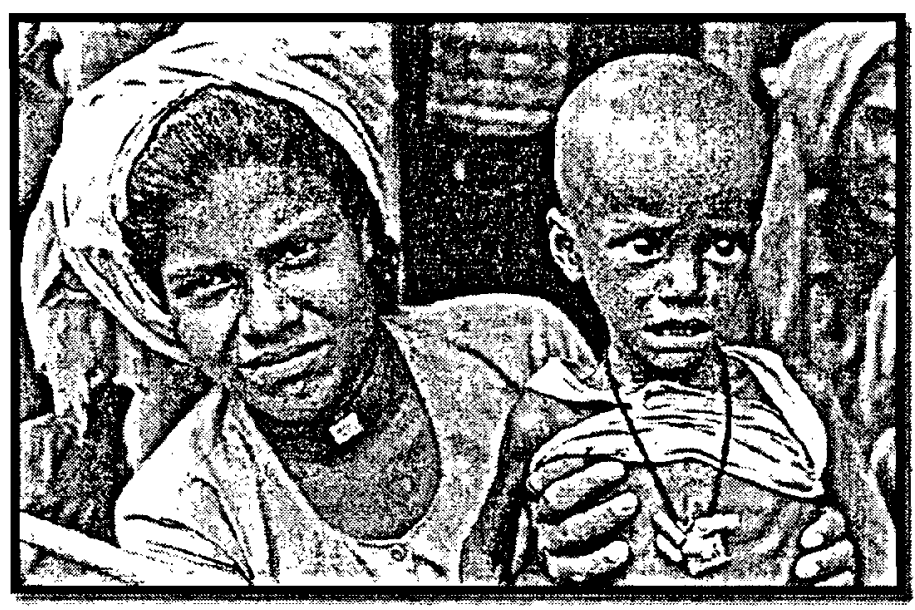

IMG (B)5: UNHCR/22073/1992/H.J.Davis persecution, and thus remained a gallant model of political agency; refugees from the Third World were described as fleeing because of more generalized violence. The political agency once inherent in the refugee figure was thus dislodged and reserved for 'normal' refugees. As

Johnson suggests:

As a victim of political persecution, as imagined for the European figure, a refugee is fundamentally political; as a victim of violence, however, the refugee is objectified and loses this political agency. Further, individual victims have the capacity to act. Agency is constructed in the Western imagination as an individual capacity; the "masses" of refugees constructed as characteristic of those from the Third World cannot express or access agency within this discourse. The difference between European refugees and Third World refugees was (and is) constructed specifically on this basis (Johnson, 2003,16).

IMG (B)5 and IMG (B)6 are examples of how 'Passivity' and agency are presented in Series 


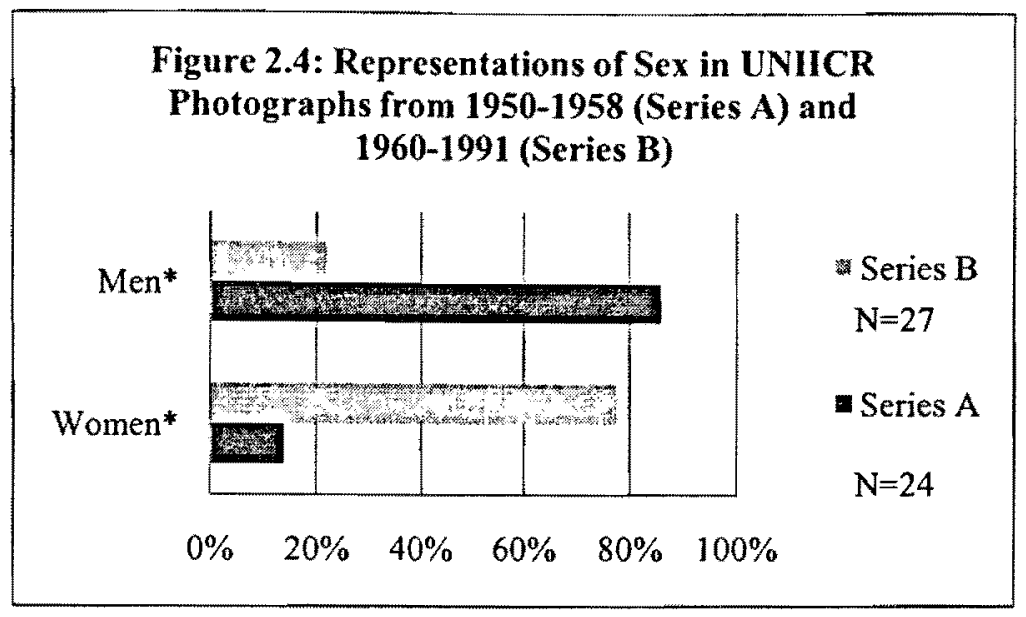

* Percentages include images where both genders were present

B. Both of these images reveal scenes that depict little activity, and suggest the refugees' inability to maintain their own welfare. The caption accompanying IMG (B)5 states: “...UNHCR provides assistance and monitors their wellbeing", while IMG (B)6's description reads, "drought and war resulted in a massive influx of Ethiopians into Sudan during the 1980s and tens of thousands of persons died before a relief effort became effective". These two captions allude to the inability of refugees to maintain their own welfare, reconstructing the refugee figure to once

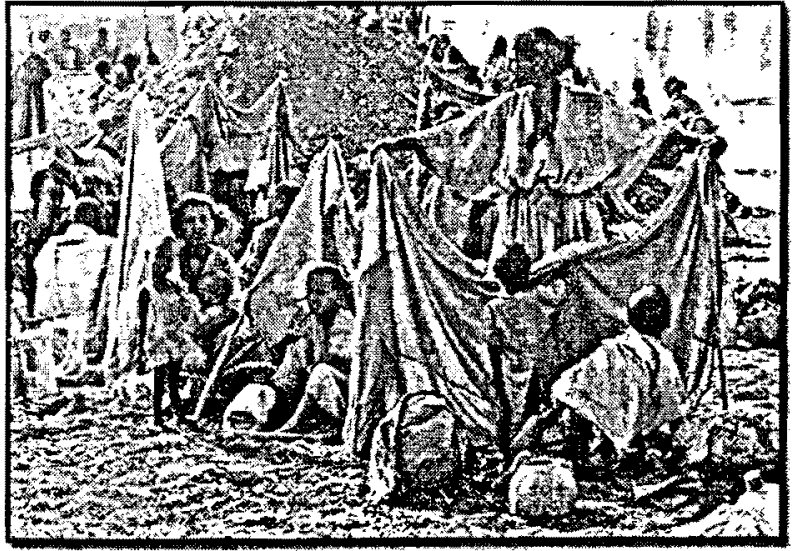

IMG (B)6:UNHCR/15065/1985/M.Vanappelghem again denote a burden, depicting their vulnerability and dependence on the generosity and support of others. Both of these images also reflect the increased frequency with which women and children appeared in the images of Series B. Unlike Series A, where males were the most dominant sex depicted in $86 \%$ of photographs, females formed the majority of subjects within Series B, represented in $78 \%$ of the images. Similarly, children appeared in over half of the photographs in Series B, compared to Series A, where they appear in less than a quarter of images. 


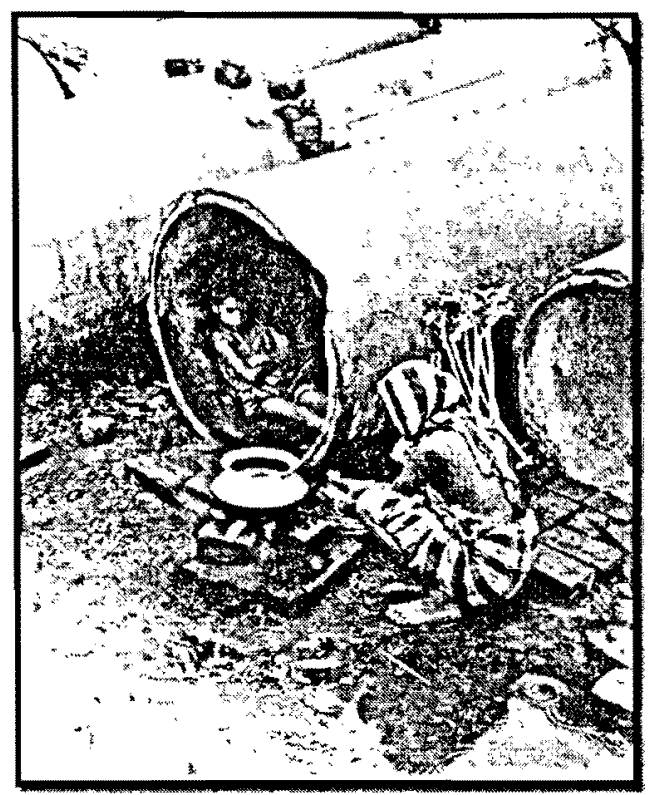

IMG (B)7: UNHCRWHO/2096/1971/D. Henrioud

These findings clearly correlate to the claims

made by refugee scholars Liisa Malkki and Erin

Baines. In 1996, Malkki stated that the prominence of women and children as embodiments of refugeeness "has to do with not just the fact that most refugees are women and children, but with the institutional, international expectation of a certain kind of helplessness as a refugee characteristic" (Malkki, 1996, 388). This statement is echoed by Baines, who suggested that although women first became visible within refugee crises through their sheer size, the overwhelming feminization of refugee representations provides a strategic role in reinforcing the victimization of Third World refugees. Baines qualified this idea in her 2004 text, "Vulnerable Bodies" by stating that traditional gender assumptions, which infer inherent female vulnerabilities and innocence, are utilized while forming refugee policy to mobilize the depoliticization of the refugee. Female refugees have been framed as not only 'the exotic', but also 'homogeneously vulnerable and dependant' (Baines, 2004). This construction infers a sense of 'female' helplessness, implying the need for the first world to rescue and protect them. Baines further references Cynthia Enloe's conflated wordplay, womenandchildren, to identify how the regularity of the phrase 'refugee women and children' gives cause for an amalgamation of these two terms into a singular form. As explained by Nahla Valji, this conflation provides several useful purposes:

It identifies man as the norm, against which all others may be grouped into a single leftover and dependent category. Second, it reiterates the notion that women are family members rather than independent actors - that any reference to them must also refer to 
their domestic role. Last it allows for the paternalistic role of savior to be played out, in that "states exist... to protect women and children (As cited in Baines, 2004, 37).

The strategic portrayals of women and children in Third World depictions are therefore used to depoliticized the refugee, by inferring that refugees are comprised of mainly domestic actors who retain little to no political agency. The frequency of refugee 'womenandchildren' subjects in Series $\mathrm{B}$ is reflective of the dominance of vulnerability discourse highlighted by Enloe. Images such as IMG (B)7, focus on emphasizing the helplessness of these subjects rather than establishing the context or identity of the individuals in the frame. It is through this emphasis on the vulnerability of universal women, and universal children, that the universal Third World refugee is depoliticized and assumes an ahistoric position of helplessness.

Underscoring the universal vulnerability of refugee women, the local context of their situation is removed, and conceptually, refugee women are relocated to the global frame... This framing of "women as vulnerable'... reinforced the passivity and voicelessness of refugee women, in addition to silencing the contestations over the root causes of displacement (Baines, 2004, 38).

The visualization of women and children has thus served a highly ideological function, not only inferring a state of victimization but also depoliticizing the refugee figure and its accompanying crisis. This depoliticization reiterates the 'Myth of Difference', by reinforcing the changing nature of refugees from heroes to burdens, and thus legitimating the need for policy modifications in the post-Cold War refugee regime.

Overall, the review of images in both Series A and B supports the claims that between the early 1950 s to late 1990 s, refugees from the Cold War were depicted by the UNHCR as vastly different from those of the Third World. By examining the framework employed to differentiate these shifting representations of refugee identity, the ideological motivations supporting these depictions is more evident. Representations of the normalized European refugee, afforded the 
West a hegemonic tool for illustrating Western ideology and reinstating their interests during the Cold War. While the Conventional definitions legalized the humanitarian support of European refugees, it was through their visual construction that 'normal' refugees were able to validate the superiority of the West and its hegemonic values.

With the arrival of Third World asylum seekers, however, the refugee figure was partitioned from this 'normal' image, constructing it as victimized and therefore depoliticized. The UNHCR's visual choices to frame these new flows in terms of magnitude resulted in the ascription of a universalized Third World refugee identity. By removing both the political context of their plight, along with ignoring their human agency, Third World refugees were marred by a vulnerability discourse which appealed to the patriarchal ideas dominant in Western values. The reconstruction of the Third World refugee identity thus serves a similar ideological function as Cold War European refugees. The victimization of the 'new' refugee figure also reinforces the superiority of the West, this time by presenting Western states as the benevolent philanthropists that compassionately assist these vulnerable refugee victims; not through opening their borders to resettlement, but rather through the allocation of aid.

\section{***}

This image review has provided empirical evidence that the UNHCR's past visual discourse reinforces the West's ideological positioning of the refugee figure. Although the UNHCR may have attempted to expand the Conventional definitions of refugees, while also challenging reformation changes, such as the adoption of the 'non-entre regime'; the agency's illustrative publications remained congruent with Western ideology. When observing both the Statute limitations, presented in Chapter One, with the illustrative discourse trends identified in 
this chapter, it is suggested that the UNHCR's depictions are a response to its precarious funding relations. It is directly because of this compromising position that the Agency has been forced to justify its existence to both its donors and the international community. Consequently, the UNHCR's publications reiterated Western ideological frames in an attempt to reconcile its mandate and core principles with its current policies which concede with the will of influential states. As Chimni highlighted, "it is this need to justify its current policies and practices which explains the new focus on research and analysis. It also explains why UNHCR is an uncritical consumer of concepts and theories which support a particular (Western) vision of the global refugee order" (Chimni, 1998, 368). Despite the best of intentions from the UNHCR, the illustrative publications from the 1950s-1990s have unwittingly subscribed to Western ideological frames in order to lobby for Western aid. Unfortunately, by employing a vulnerability discourse to Third World refugee illustrations, an internalist perspective proliferates, which negates the impact that external states and macro-economic reforms have played in exacerbating the political and social collapses which foster refugee situations. The visual presentation of a non-threatening, easily digestible refugee discourse has thus contributed to increasing protracted refugee situations, and further turmoil in Third World countries. Although the UNHCR is utilizing these frames in order to elicit support from donors, the implication of these images has enabled the commodification of the refugee. 


\section{Chapter Three: Commodifying Speechless Bodies}

In 1996, with the appointment of an Assistant High Commissioner and the establishment of the Center for Documentation and Research (CDR), the UNHCR adopted a new directive within the realm of knowledge production and dissemination, by engaging in research and policy analysis in collaboration with primarily Western academic and research institutions (Chimni, 1998). The UNHCR solidified its self-appointed position as the principal knowledge producer for refugee affairs with the dissemination of its in-house publications and a content-rich website. As noted in Chapter Two, this newly developed post was a means through which the UNHCR was able to reconcile its current programming with its original mandate. The UNHCR thus mobilized this position to direct how the affairs of refugees were perceived globally. However, because the Agency was continually forced to legitimate its existence, while constantly pleading for funding from state donors, the UNHCR inevitably reinforced Western ideological narratives, which constructed the Third World refugee as a universal and helpless victim.

As explored explicitly in Chapter Two, Third World refugees were caught within a shifting epoch of identity politics, through which asylum seekers from the Third World were depicted in contrast to the heroic European refugees of the Cold War. These refugees were thus constructed through illustrative frames as being one large homogeneous and helpless mass, entirely dependent upon international assistance. Although the proliferation of vulnerability discourse was well documented by refugee scholars in the mid-to-late 1990s, there has been debate as to whether or not this frame has been sustained in modern publications.

As reviewed in Chapter Two, Clark-Kazak 1999 study analyzed the proliferation of vulnerability discourse in contemporary texts, by examining the proportion of children depicted 
in UNHCR publications, as compared to their demographic presence in refugee populations. This study conducted an age-specific longitudinal analysis of the UNHCR's annual appeals and reports published from 1999 to 2008, interrogating both textual and visual representations of children. Clack-Kazak found that although contemporary visual discourse does not overrepresent children in refugee imagery, there is still a consistent employment of the vulnerability discourse that spans across different generations, and reinforces gender differences.

By examining some of the major findings from Clark-Kazak's research, it becomes evident that vulnerability is still being framed in a manner consistent with the UNHCR's past pictorial trends. One way vulnerability was reinforced in the UNHCR's reports was through assigning particular 'areas of concern' for refugees of varying age ranges. Clark-Kazak's findings uncovered that images depicting infants were predominantly focused on issues of health, "particularly in relation to their perceived vulnerability to mortality and morbidity" (Clark-Kazak, 2009, 16). The helplessness of children's welfare was further accentuated by increased gender representations. In particular, references to children and young adults were dominated by specific references to females (Clark-Kazak, 2009). "In the Global Report 2007, for example, there are six references to boys compared with seventy-six references to girls - a gender differential of more than ten-fold" (Clark-Kazak, 2009, 14). Similarly, young women were often depicted alongside adult women, and were singled out as needing special services and listed within the vulnerable person's category.

The depiction of elders, who were among the least represented demographic in all images, was a particularly interesting finding. Clark-Kazak highlighted that although the UNHCR did allude to the respect garnered by this group; elders were disproportionately portrayed within 'passivity' and 'portrait' images, which equated to over $50 \%$ of all images 
which featured elders as a principle character. Clark-Kazak contextualizes this statistical data by highlighting that,

While elders are sometimes engaged in active roles in images of mobility or documentation, they are more likely portrayed as recipients of general assistance or social services such as health or education. These images, coupled with dominant textual references to 'vulnerability' of elders, reinforce discourses surround their need for care and assistance (Clark-Kazak, 2009, 16).

Any experience or wisdom of elder populations is therefore dismissed and replaced with the UNHCR's articulation of this demographics' particular helplessness.

The empirical findings put forward by Clark-Kazak confirm that the combined representation of women, children, young people, and elders - all of whom are categorized as 'vulnerable persons' - have sustained the ideological discourse of victimization initiated during the post-Cold World era. Her findings suggest that although adults have become the most prominent group depicted in these UNHCR publications, representing $59 \%$ of the subjects in the studied texts (Clark-Kazak, 2009), the presentation of vulnerability is still an explicit narrative underlying the refugee figure. As highlighted by Clark-Kazak, "discourses surrounding the vulnerability of particular groups have been remarkably tenacious despite some changes in language, such as a shift from 'needs' to 'rights', and 'vulnerables' to 'age, gender and diversity mainstreaming' (AGD) "(Clark-Kazak, 2009, 17). Thus in spite of policy changes made by the UNHCR and the adoption of AGD, the presentation of vulnerability has continued to occupy a vital facet of the represented Third World refugee's character.

The implications of the proliferation of this vulnerability discourse were briefly explored by Clark-Kazak, when she proposed four significant outcomes of this framing. First, she notes that essentialist categories inferred by this discourse are not reflective of the dynamic reality through which vulnerabilities are constituted within different contexts, and thus cannot be 
conceptually prescribed to any group. Second, the increasing inclusion of differing groups within the 'vulnerable persons' category has created cognitive dissonance, since a significant majority of the refugee population is represented as requiring specialized interventions. Third, the singling out of these groups counters the goals of mainstreaming, by contributing to the 'othering' process that reinforces the concept of dominant norms. Fourth, refugees have become dehumanized through the discursive and practical reference of refugee populations as simple 'priorities', listed alongside other inanimate 'priority' issues. (Clark-Kazak, 2009).

Although the last argument highlights the dehumanizing implication of the vulnerability discourse, these outcomes fail to accurately account for the severity of this oppressive framing. As noted in Chapter Two, the proliferation of vulnerability as a dominant narrative negates the individual identity of refugees, which depoliticizes the refugee and promotes the idea of a universal Third World refugee victim. These universal victims are therefore devoid of historical and political contexts, and are instead employed to represent a 'primordial humanity', as described by Malkki. Reflecting on illustrative portrayals of mass displacement, Malkki stated:

An utter human uniformity is hammered into the viewer's retina. This is a spectacle of 'raw,' 'bare' humanity. It in no way helps one to realize that each of the persons in the photographs has a name, opinions, relatives, and histories, or that each has reasons for being where he is now: inside the frame of this photograph (Malkki, 1996, 388).

Third World refugees are not identified through their individual humanity, but rather as a mass whose constituents are condensed into a single identity, the universal victim. Apart from presenting a 'special kind of powerlessness', which Malkki elaborates as the tendency to not appear as a 'dangerous alien' (Malkki, 1995), the refugee victim is reduced to a compatible subject for state-centric discourse (Rajaram, 2002). This subjectivity is constructed through the endorsement of the refugees' lack of political agency, which is reinforced by the depoliticization 
of these ahistorical subjects. Political agency denotes an individual's capacity to act, and impact both the life of him or herself as well as the lives of others. However, this capacity is located within the auspices of citizenship (Johnson, 2003). Citizenship, as defined by Johnson, is a "political identity that embodies all modern claims to liberty, equality, rights, autonomy, selfdetermination, individualism, and human agency" (Johnson, 2003, 15). Since refugees have left their countries of origin and exist within a condition of statelessness, they are effectively noncitizens, and are thus not entitled to the aforementioned attributes. The position of statelessness becomes a threatening concept to the international system, which is founded on state-centric ideologies. In order to minimize the potential risk inherent within the position of statelessness, the refugee is constructed as being devoid of meaningful political identity.

In the 1998 publication "Refugees, Humanitarian Emergencies, and the Politicization of Life", Peter Nyers reinforces this argument by asserting that political agency is emptied from Third World refugee subjectivity. In this text, he notes that refugees have been negatively defined as "registering a twofold lack with respect to the privileged resolutions to questions of political identity (citizenship) and community (nation-state)" (Nyers, 1998, 18). Unlike the citizen, who is grounded securely in the sovereign space of the state, the refugee is effectively dislocated from this territorial rooting, and is thus "an unwilling exile of the community of citizens" (Nyers, 1998, 18). As such, the Third World refugee is constructed to infer a lack of political subjectivity, which is afforded by restricting refugees to the realm of their bodies, ultimately silencing them. "By constructing the refugee as a voiceless victim, the agency of the citizen is preserved and the perceived political threat (and, subsequently, the economic threat) of the refugee is diminished" (Johnson, 2003, 15). 
The risk attributed to Third World refugees was not inherent within European Cold War refugees because stateless populations were immediately ushered into new citizenships of Western states. These refugees were therefore heralded for their agency, and afforded a political voice. However, within the non-entrée regime refugees are no longer welcomed with open borders, but are instead frequently warehoused for decades within protracted refugee camps . The options for rectifying this lack of citizenship through resettlement and integration into another country have therefore narrowed. The Third World refugee occupies a perpetual condition of statelessness, until they voluntarily repatriate back to their country of origin (Nyers, 1998). Until the refugee assumes a positive presence as a citizen, their potential to act politically threatens the ideological foundations of sovereignty and nation-states. Third World refugees are muted and denied political agency, reducing them to a 'bare humanity'.

The silenced Third World refugee is the ultimate consequence of the proliferation of victimization and vulnerability discourse within UNHCR publications. Malkki's 1996 text "Speechless Emissaries: Refugees, Humanitarianism, and Dehistoricization”, echoes Nyers argument, noting that Third World refugees have become silenced victims, whose photographed bodies are regarded as adequate accounts of the refugee experience. "The refugee is commonly constituted as a figure who is thought to 'speak' to us in a particular way: wordlessly. Just the refugee's physical presence is 'telling' of his or her immediate history of violence" (Malkki, 1996, 390). The Third World refugee does not need to use his or her voice or story to construct an understanding of their plight; rather their body and refugee title have prescribed their identity to be akin with the universal refugee narrative. Rajaram eloquently summarizes the cyclical relation of refugees and political identity stating that: 
the connection of political identity and discourse to the territorial state means that those without citizenship or bereft of it are speechless (or taken to be speechless), requiring an agency or expert to speak for them. The 'speechlessness' of refugees reinforces the statecentric political imagination; refugees become a site where certain forms of knowledge are reproduced and justified (Rajaram, 2002, 251).

In Chapter Two, the ideological connotations which are reproduced on the site of refugee bodies were expounded. The remainder of this chapter moves beyond acknowledging the presence of these political frames and focuses on critically examining the implications of the UNHCR's reinforcement and dissemination of the silenced refugee icon. This critique contends that the UNHCR's role in proliferating this iconic imagery has not only effectively rendered the refugee voiceless, but has ultimately commodified Third World refugees, utilizing their ideological positioning to lobby for state-donor funding. This critique thus re-examines how the UNHCR attempts to overcome its structural limitations have effectively oppressed refugees, and left the organization even further away from obtaining its mandate to source durable solutions. In order to assess this practice, the UNHCR's role within the humanitarian framework must first be explored. This assessment utilizes the theoretical framework espoused by seminal Brazilian scholar Paulo Freire in "Pedagogy of the Oppressed", to investigate the effects of humanitarianism.

Since the initial publication of "Pedagogy of the Oppressed" in 1970, the text has become prophetic, selling over 750,000 copies worldwide. Although a conventional reading might only allude to an educational model for addressing class struggles, the Freirian pedagogy promotes a critical understanding of the interplay between power and knowledge, and the means through which these dynamic forces construct societies and their inhabitants. Freire's pedagogy is thus a theory of human nature, rooted both in his lived experiences and within what Stanley Aronowitz articulates as a fully developed 'philosophical anthropology' (Freire, 2000). Despite the dated 
nature of this text, Freirian pedagogy provides provocative insights into contemporary humanitarianism still relevant today.

\section{False Generosity and Humanitarianism}

Humanist (not humanitarian) generosity, presents itself as a pedagogy of humankind. Pedagogy which begins with the egoistic interests of the oppressors (an egoism cloaked in the false generosity of paternalism) and makes of the oppressed the objects of its humanitarianism, itself maintains and embodies oppression. It is an instrument of dehumanization (Freire, 1970, 54).

It is not the intent of this thesis to (in any way) infer that the UNHCR maliciously dehumanizes refugees as a way of ensuring its own existence and legitimization. Rather, it proposes that the system through which the UNHCR was created, and currently operates, embeds an oppressive order into its structure. The UNHCR has ultimately become an instrument used by the West to ensure the maintenance of the status quo, and thus Western dominance. The operations of the UNHCR have forcibly conceded to the will of West, which directs the agenda of the Agency through the careful allocation of earmarked funds. As highlighted in Chapter One, only $3 \%$ of UNHCR's current funding comes from the regular UN budget. The remainder is allocated by voluntary contributions, of which ten state donors account for $80 \%$ of the funding (Milner, 2008). Of the funding from these ten donors, only $20 \%$ remains unrestricted, while the remainder of the funds are earmarked by donor countries, as congressional provisions direct the expenditure of funds to approved specified projects (Loescher, 2008). The UNHCR thus finds itself within a precarious position, negotiating the needs of refugees against the political priorities of its dominant donors. In an attempt to abridge this predicament, the UNHCR resourcefully began operating as the dominant knowledge producer of refugee discourse, utilizing media publications to shape public perception, and to lobby for financial assistance from the international community. 
In order to effectively appeal to the sentiments of the Western public, the UNHCR reiterated dominant ideologies, which utilized vulnerability discourse and presented a 'raw' humanity, and rendered the refugee voiceless. Italian philosopher Giorgio Agamben, highlights how this arrangement reinforces state-centric ideologies instead of focusing on the real oppressive forces which devalue the lives of refugees.

Agamben $(1998,133)$ suggests that when humanitarian organizations portray refugees in the figure of bare human life they may, despite themselves, maintain a secret solidarity with the very powers they ought to fight." In the end, prevailing 'solution' to the refugee's plight focus on returning refugee statist identities so as to restore the conditions under which they may once again enjoy a properly 'human' life as citizens (Nyers, 1998, 20).

The UNHCR's complacency to evoke these ideological frames and to focus on state-centric solutions, make it an active collaborator in the dehumanization of refugees. Frierian pedagogy states "an act is oppressive only when it prevents people from being more fully human" (Friere, 1970, 57). The illustrative discourse published by the UNHCR can thus be defined as an act of oppression that serves to reinforce an oppressive humanitarian order.

In Chimni's 2000 publication, "Globalization, Humanitarianism and the Erosion of Refugee Protection", he proposed that humanitarianism is "the ideology of hegemonic states in the era of globalization marked by the end of the Cold War and a growing North-South divide... Humanitarianism mobilizes a range of meaning and practices to establish and sustain global relations of domination" (Chimni, 2000, 244). In adopting Chimni's definition, it is clear that the UNHCR's operations are entrenched within this humanitarian discourse. As noted in Chapter One, the UNHCR is mandated to maintain a non-political and humanitarian character. Although the effectuality of this clause might be highly debated, it cannot be denied that the UNHCR is located, and operates within, this oppressive humanitarian order. 
The underlying motivations inherent within this humanitarian system seek to obscure the fact that the West's commitment to humanitarianism is coupled with a range of practices that directly violate the human rights of others (Chimni, 2000). Although the UNHCR is often not actively involved in the practices which exacerbate refugee flows, they are a means through which the West is able to both conceal its involvement, and ensure its own interests; all through the allocation of aid and assistance. As Chimni notes:

The ideology of humanitarianism has used the vocabulary of human rights to legitimize the language of security in refugee discourse, blur legal categories and institutional roles, turn repatriation into the only solution, and promote a neo-liberal agenda in post-conflict societies leading to the systematic erosion of the principles of protection and the rights of refugees (Chimni, 2000, 251).

It is under the guise of humanitarianism that the West has utilized its 'generosity' to implement a highly monitored and controlled system, which ensures that the recipients of this assistance are complacent within the current relations of power.

As Freire highlighted in 1970, "pedagogy which begins with the egoistic interests of the oppressors (an egoism cloaked in the false generosity of paternalism) makes of the oppressed the objects of its humanitarianism, itself maintains and embodies oppression. It is an instrument of dehumanization" (Freire, 1970, 54). Freire further contended that the majority of attempts made by oppressors to improve the lives of the oppressed are almost always manifested in forms of 'false generosity' (Friere, 1970). Within this pedagogical frame, the UNHCR's assistance in providing the West's 'false generosity' to refugee populations relegates the Agency to the role of oppressor. The application of Freirian pedagogy to the refugee regime would thus infer that the financial aid, afforded to the UNHCR by donor states is not a humanist-benevolent gesture, but rather an attempt to "turn the prevailing political situation to their own advantage, and seek to dominate them" (Freire, 1970, 140). 
Since the start of the refugee regime, 'false generosity' has procured an imperative role in legitimizing its humanitarian nature. Foreign aid adopted an important ideological function from its onset, as noted by Loescher, who stated that "in the face of an escalating Cold War struggle, Western governments came to perceive assistance to refugees as a central part of their foreign policy towards newly independent states, thus using foreign aid as one of the principle tools in the East-West struggle for influence" (Loescher, 2001, 38). In the contemporary regime, foreign aid is still used as the principle tool for the materialization of a neo-liberal agenda (Chimni, 2000). The assistance provided by both the donor states' financial contributions and the UNHCR, performs a manipulative function, acting as an anaesthetic; distracting refugees from acknowledging the true causes of their plight.

Chimni highlighted that unification is a key mode through which humanitarianism actualizes itself, noting the unity of 'humankind' as the particular form which is articulated through the modern language of rights (Chimni, 2000). The UNHCR's illustrative discourse, which is reliant on the images of 'raw humanity', is consistent with this notion. Furthermore, the inherent motivations underlying this ideological imagery is also consistent with Chimni's contention that the real unifying factor of global material reality is transnational capital (Chimni, 2000). The UNHCR's iconic depictions of Third World refugees thus enable Western states to exchange financial aid for an easily digestible discourse congruent with Western ideology under the guise of humanitarianism. Western states are therefore effectively buying the silence of both the UNHCR, whose mandate contradicts these restrictive reforms, as well as the silence of refugees, who are effectively turned into the objects of Western politics.

The UNHCR's willful acceptance of these financial arrangements is motivated largely by the temporal and financial limitations embedded within the UNHCR's Statute. However, 
regardless of the binding impetus for which the UNCHR has been forced into these funding relations, the Office is still responsible for its actions. Väyrynen echoes this sentiment, stating that "the governments that are narrowly pursuing their own interests or ideas by extensively earmarking funds deserve to be criticized, but UNHCR itself is not entirely blameless either" (Väyrynen, 2008, 160). Thus this exchange has reinstated an oppressive order, which has dehumanized refugee reducing them to a mere commodity to be 'traded' on the global market.

\section{Commodifying Refugees}

Frierian pedagogy clearly dictates that "to impede communication is to reduce man to the status of 'things"' (Friere, 1970, 128). Refugees having been silenced through the UNHCR's illustrative discourse, have been reduced to the status of 'things'. Reification, or 'thingification', is described as the process through which subjects are turned into objects (Lukács, 1971). This process has become a prominent facet of the current hyper-capitalist state, which has unified the globe in a race to maximize profits, not human development (Chimni, 2000). Georg Lukács identifies the essence of the commodity-structure stating that "its basis is that a relation between people takes on the character of a thing and thus acquires a 'phantom objectivity', an autonomy that seems so strictly rational and all-embracing as to conceal every trace of its fundamental nature: the relation between people" (Lukács, 1971, 83). Although Lukács definition originated to describe the abstraction of human labour within materials of production, reification can also be applied to the production of refugee imagery. The 'phantom objectivity' that abstracts the social relations of labour is active within the commodification of the refugee, abstracting the iconic Third World refugee from its material reality and political economic structures which have exacerbated and maintained refugee situations. 
Political economist Vincent Mosco defined commodification as the "process of transforming use values into exchange values" (Mosco,1996 141). Use value is defined as value derived from the fulfillment of a specific human want or need, while exchange value is ascertained from the worth a product warrants during exchange (Mosco, 1996, 141). Through a capitalist system, the process of commodifying an object is thus defined as the process through which economic value is assigned to something which had previously not been considered in economic terms (Sturken, 2001). In his seminal text "Society of the Spectacle", Guy Debord advances the discourse of commodification by claiming that life is a stage through which the commodity has colonized social life. "Commodification is not only visible, we no longer see anything else; the world we see is the world of the commodity" (Debord, 1994, 46). Debord elaborates on this sentiment to highlight that human life has been transformed into a spectacle, which is no longer lived, but observed from a distance and mediated through images. He further contends that the satisfaction once acquired from using commodities has since been ascertained through "recognition of their value as commodities" (Debord, 1994, 42). "By mobilizing all human use values and monopolizing its fulfillment, exchange value ultimately succeeded in controlling use. Usefulness has come to be seen purely in terms of exchange value" (Debord, $1994,46)$. It is thus from this understanding that the term commodification has been applied to the refugee. Although Third World refugees, and their subsequent images, retain no intrinsic use value for the Western world, their exchange value is bound within their ideological positioning.

The projected image of the voiceless refugee victim serves to establish a binary between the impoverished victim (the refugee) and the benevolent donor (Western states). The exchange value of refugees is thus not bound strictly to their identity, but rather is housed within how the identity of Western states is constructed in relation to them. The UNHCR's utilization of 
vulnerability discourse has silenced refugees, thus transforming them into ahistorical and depoliticized 'things'. The 'refugee-thing' appeals to the ideological interests of Western states because it enables these countries to negate the role they have played in exasperating refugee situations, and instead assume the position of compassionate and benevolent provider.

This arrangement thus involves three players: the refugee, the state-donor, and the UNHCR. Each of these actors has a specific role, which houses its own inherent implications. The role of the UNHCR in this arrangement is that of the facilitator, which directly implicates them as the commodifier of refugees. The UNHCR is responsible for producing and disseminating representations of refugees that appease the agendas of state-donors, and entice them to contribute and be acknowledged for their immense 'generosity'. By presenting refugees as depoliticized vulnerable victims, the UNHCR is marketing an internalist view of refugee crises, enabling state-donors to exchange financial contributions for the maintenance of an ideological framework that reinforces their hegemonic interests.

In 1998, Chimni criticized Hathaway's 1991 recommendation of a system for formulating the duties associated with refugee protection; whereby states could account for their responsibilities through either resources or absorption capacity (Hathaway, 1991, 127). Through this system, states would be able to fulfill their moral and international responsibilities by either resettling refugees into their country, or instead by providing resources. Chimni's response to this suggestion was one of alarm, stating that:

Apart from the fact that by endorsing the refugee-resource transaction Hathaway turns the refugee into a commodity which can be 'traded' on the world market, the proposed scheme allows hegemonic states to turn to their advantage structural inequalities to constructed and sustained by them (Chimni, 1998, 362). 
Although Hathaway's suggestion has never been formally implemented, the UNHCR has been unofficially managing a similar 'resource-absorption capacity' transaction. The Agency markets the 'refugee-thing' as a means to sustain an internalist perspective of the crises, enabling states to 'buy' their exemption from fulfilling their greater international responsibilities to resettle refugees and amend the external causes which exacerbate refugee flows. The financial contributions from donor-governments are therefore essentially purchasing an internalist ideology, which includes the refugee's depoliticization, the UNHCR's compliance, and the overall sustainment of a non-entrée refugee regime.

The UNHCR as facilitator of this transaction has three responsibilities. The Agency is first responsible for producing a marketable refugee-commodity, which is achieved through the utilization of vulnerability discourse. The UNHCR is also in charge of managing the financial exchange, as well as the welfare of refugees. Consequently, as noted earlier in Chimni's criticism, the endorsement of these exchange systems enables hegemonic states to use their structural advantages to sustain inequalities. The UNHCR's direct involvement in this exchange therefore prevents the Agency from obtaining its initial directive to source durable solutions. By silencing refugees and representing them as 'objects' for consumption, the UNHCR actively participates in, and thus reinforces, the very systems that it needs to confront.

The state-donor's role in this exchange is that of a consumer. The consumer achieves a greater sense of self through the relationship between itself and the things it possesses. The identity of state-donors is therefore constructed and maintained in relation to the 'refugee-thing'. According to Frierian pedagogy, state-donors are located as oppressors whose understanding of self is fostered through those they oppress. As Friere states, 
Apart from direct, concrete, material possession of the world and of people, the oppressor consciousness could not understand itself - could not even exist. Fromm said of this consciousness that, without such possession, 'it would lose contact with the world' - the oppressor consciousness tends to transform everything surrounding it into an object of its domination. The earth, property, production, the creations of people, people themselves, time - everything is reduced to the status of objects at its disposal (As cited in Friere, $1970,58)$.

The 'refugee-thing' is thus an object at the disposal of state-donors. By participating in the UNHCR's exchange, state-donors utilize the 'refugee-thing' as a way of mediating their image within the international community, projecting notions of 'generosity', 'benevolence', and 'caring'. State-donors are thus the ultimate benefactors of this exchange. Their participation in this transaction reasserts neo-liberal agendas, and thus reinstates the hegemonic interests of these states.

Ironically, as the state-donor invests more into this arrangement, the refugee becomes further oppressed. The refugee's role within this exchange has been the site of exploration throughout the duration of this Chapter. In sum, it can be concluded that within this transaction, the refugee's role is characterized by a lack of participation, as the UNHCR assumes the voice for the refugee and represents them as a 'thing' for consumption. This Chapter has explored the prevalence of the vulnerability frame within contemporary UNHCR images, and examined how these frames have encouraged the silencing of the refugee voice. The commodified refugee is thus a product of a larger humanitarian order which has sustained global relations of domination.

While the implications associated with this dehumanized role have been mentioned at various points during this critique, Chapter Four begins by examining more explicitly the impact that commodification has had on a particular group of refugees. After assessing the implications of commodification, the Chapter will evaluate the effectiveness of alternative communicative practices in recasting ideological depictions of refugees through the visual-articulation and 
celebration of traditionally silenced narratives. This evaluation is directed through a participatory photography project, which attempts to provide refugees a means of challenging commodification. Chapter Four will therefore analyze the usefulness of participatory approaches which propose to resituate the voice and humanity within the Third World refugee figure by highlighting the ability for refugees to construct diverse depictions of refugee life, and thus emphasize the inherent agency of the refugee. The main focus of this assessment is towards the development of a participatory ICT-inclusive pedagogy that serves to amplify the voice of marginalized populations through the provision of ICT access and the platform to advocate on their own behalf. 


\section{Chapter Four: Overcoming the Implications and Imaging a Way Forward}

For Friere, communication is the essence of human beings. 'The UNHCR's ability to commodify refugees was only possible once their voices were silenced, and they were reduced to the level of a 'thing'. The representation of a muted refugee victim enabled the UNHCR to reconstruct refugees in a matter which assisted its own interests. Although the UNHCR's main directive is to protect refugees and source durable solutions for these populations - the UNHCR's illustrative discourse instead reified global power relations which have participated in exacerbating situations responsible for forced migration ${ }^{\text {xiii. }}$. Thus, in spite of the Agency's best intentions, their contributions to the production of refugee knowledge have ultimately silenced refugees, distancing them from becoming active agents of their own emancipation.

As noted during the introduction to this thesis, many of the refugees I encountered in the Kakuma Camp stood in stark opposition to the passive refugee victim depicted in so many of the UNHCR's photographs. However, the constant projection of the commodified image has had an impact on the self-identity of refugees. Post-colonial scholars have acknowledged the role that representations play in prescribing traits of behaviour, which are internalized by the represented. Although it is not the focus here to investigate this matter in depth, it is relevant to briefly qualify the implications that refugee commodification have had on developing the refugee-self.

Despite scholars' aversion to directly making the link between commodity and refugee, research has been dedicated to expounding the diverse implications which have resulted from the commodified refugee image. One of the most significant implications of this imagery has been how refugees negotiate confrontations with images of their commodified selves. The iconic Third World Refugee image has not only impacted the external conception of the refugee, but it has also directed both the on-the-ground treatment of refugees, and the refugee's self-identity. 
The statements made by these refugees reflect the internalization of the constructed refugee identity. These sentiments evoke state-centric ideologies, dismissing the capacity for refugees to become active social agents in spite of their statelessness. The 'rich refugees' are thus not celebrated for their entrepreneurial accomplishments, but rather disregarded and chastised by both their stateless community and humanitarian workers. As Freire highlights:

Almost always, during the initial stage of the struggle, the oppressed, instead of striving for liberation, tend themselves to become oppressors, or 'sub-oppressors.' The very structure of their thought has been conditioned by the contradictions of the concrete, existential situation by which they were shaped (Freire, 1970, 45).

By applying Freire's insight to the previous accounts, it is evident that refugees are not only oppressed, but also utilize their oppressive experience to regulate the actions of others. Refugees are thus compelled by, what Frantz Fanon terms interpellation; identifying themselves within the imagined qualifications of 'refugeeness' (Fanon, 1968). Through this introspection, refugees begin to conduct themselves in a manner consistent with this iconic image. Key scholars including Appadurai, Bhabha, Fanon, Foucault, Hall, Said and countless others, have all explored the disciplinary practices which construct the subjugated 'other' into being (Appadurai, 1993; Bhabha, 1994; Foucault, 1979; Hall, 1997; Said, 1978). For Freire, the 'other' is primarily affected by the duality of the oppressed, through which "they are contradictory, divided beings, shaped by and existing in a concrete situation of oppression and violence" (Freire, 1970, 55). For the refugee, this dualism stems from his or her past experiences and past markers of his or her identity and political agency. Although these markers might not have procured recognition globally, any acknowledgment they may have acquired on a regional, national or international level is ultimately disregarded with their new position of statelessness. 
The degree to which the refugee adapts to this commodified image is something that requires further investigation. However, Malkki's observations provide evidence that representations of refugees do, at least to a degree, impact how refugees identify themselves within the refugee regime. Whether this identification is simply 'performed' or is in fact 'internalized' is another area which would require future research. However, what these findings do suggest is that representations have a greater impact beyond simply affording the international community a biased conception of refugee identity.

Clearly the contradiction still remains between the individuals I observed in the camp and the iconic image of Third World refugees published by the UNHCR. Much like the "rich refugees' in Tanzania, not all refugees have adhered to these iconic prescribed traits, and even when they do, interacting with these individuals reveals their unique history, voice, and agency. However, one needs to be open and willing to see it. The second portion of this chapter is thus dedicated to finding an alternative illustrative solution which depicts these elements of refugee life, while also reconstructing and decommodifying the iconic refugee image. Based on Freirian pedagogy, this alternative is housed within a participatory approach for refugee illustrations. By enabling refugees to use ICTs to capture their own images of refugee experience, they are able to shift conventional illustrative discourse. They are also able to identify and reject the ideological frameworks that have instituted the voiceless and commodified refugee, by demonstrating their lived experiences and collective agency.

Freire's emphasis on participatory methods is based on his understanding of internalization and the means through which oppressive structures are naturalized into the oppressed's consciousness. Freire thus acknowledges and discredits forms of false generosity, by 
highlighting the need for participatory approaches to unveil the conditions of the oppressive state.

Only in a dialectical understanding... of how awareness and the world is given, is it possible to comprehend the phenomenon of the introjections of the oppressor by the oppressed, the latter's 'adherence' to the former, the difficulty that the oppressed have in localizing the oppressor outside themselves (Freire, 1992, 90).

It is based on this approach that Freire maintains that liberation from an oppressive state cannot be granted from those who control it (the oppressors); rather it must stem from the reflections and actions of the oppressed. Oppressors who wish to aid in the battle to liberate the oppressed must not assume a position of hierarchical power, but must fight it together. "The oppressor is solidarity with the oppressed only when he stops regarding the oppressed as an abstract category and sees them as persons who have been unjustly dealt with, deprived of their voice" (Freire, 1970, 49). Therefore, in order to restore the refugee's humanity, the international community, and the UNHCR in particular, need to stop dictating and restricting the agency of refugees, and instead need to recognize and celebrate their unique experiences, voices and agency. It will only be once refugees are active in the conversations and construction of the refugee regime that durable solutions can be unveiled.

In 2001, Chimni echoed the need for participation, stating that the international refugee regime had reached a new state of crisis. His recommendation was to reform the regime through the implementation of a dialogic model which proposed a dialogue between the UNHCR, states, NGOs, academics, and most importantly, refugees. "In conducting the dialogue these acts must of course ensure that they do not always speak on behalf of, but in conversation with, refugees. The need to listen to refugee voices, and allow them to participate in decisions which directly affect their lives, is of supreme significance in giving content to the concept of refugee protection" (Chimni, 2001, 152). Chimni's proposal ultimately acknowledges both the 
importance and the capacity of participatory communicative practices to enable refugees to contribute to their own development.

Although it was only in the early years of the century that refugee scholars began to recognize the importance of including refugees within these dialogues, participatory communication discourse emerged in the early 1970 s, after years of disconnected top-down communication approaches that failed to yield substantive social change. During the 1970 s, the United Nations Food and Agriculture Organization (FAO) and The World Bank (WB) were the first to acknowledge the substantial benefits of incorporating people as active subjects through

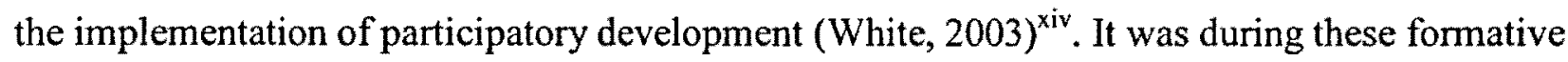
years that it quickly became apparent that an instrumental asset to participatory development is participatory communication.

Participatory communication is defined by participatory video theorist Shirley White, as "a dynamic, interactional, and transformative process of dialogue between people, groups and institutions that enables people, both individually and collectively, to realize their full potential and be engaged in their own welfare" (White, 2003, 15). The essential differentiating factor between other forms of communication and participatory communication is that participatory approaches work with people, whereas other forms work for people. It is within this notion that participation is viewed as an end in itself. Participatory proponent Gumucio-Dagron outlined in his 2001 text "Making Waves - Stories of Participatory Communication for Social Change", that the participatory communication method has eight diverse characteristics that oppose traditional non-participatory strategies. These include: 1 . An emphasis on horizontal-lateral communication between all participants, instead of vertical top-down methods. 2. A focus on viewing communication as a process of dialogue as compared to a campaign to mobilize short-term 
initiatives. 3. An emphasis on long-term and sustainable change instead of quick-fix solutions. 4. A spotlight on materializing collective empowerment compared to individual behaviour changes.

5. A stress on ensuring participation and community involvement, instead of working for or on behalf of the community. 6 . A directed scope with a specific content, language and culture, as oppose to massive and broad-based objective. 7. A focus on people's needs instead of donor's musts; ensuring community ownership instead of community access. 8. Lastly, an emphasis on consciousness raising compared to persuasive tactics aim to suffice short-term objectives (Dagron, 2001, 109).

Within these established characteristics, two interrelated but diverse approaches to participatory communication have evolved; the Freirian approach and the alternative communication approach (Servaes, 1999). The alternative approach focuses on the appropriateness of media; specifically the incorporation of people into the design of messages and production of media. This area often concentrates on community radio, television, guerilla theatre, participatory video, Internet, and telecenters. In contrast, the Freirian approach, centers on Freire's dialogic pedagogy; emphasizing an interpersonal group dialogue facilitated through a community setting. While both of these approaches offer significant potential for incorporating the oppressed into their own liberation, the particular problem of refugee commodification is best addressed by employing a Freirian approach through which the oppressed are able to "unveil the world of oppression and through the praxis commit themselves through its transformation" (Freire, 1970,54). This method does not simply propose to incorporate refugees into the established regime, but rather engages refugees in dialectical thought enabling them to first become aware of the conditions of their oppression, and then attempt to identify potential solutions. Frierian pedagogy thus maintains that through interaction and introspection, oppressed 
people, such as refugees, can become conscious of the oppressive structures restricting them, and then confront them.

Based on Freire's theory, it can therefore be assumed that by employing a participatory methodology, refugees are able to become active in not only articulating the parameters of 'refugeeness', but also within the system which affords them protection. The facilitation of participatory methodology can therefore be viewed as an imperative step towards sourcing durable solutions for two reasons. First, it has the potential to offset the ideological connotations of Third World refugees, by presenting alternative illustrative discourses. Second, it proposes to unveil the oppressive system through which refugees are constructed and commodified, shifting the focus to examine the systematic and external causes of forced migration movements. While the realization of these outcomes yield significant benefits for refugees, it is important to examine the pragmatics of Freirian theory. In order to qualify the practicality of Freire's pedagogy, this study thus employs a pilot photography project entitled Kapturing Kakuma, as a means of engaging Freire's theoretical concepts and their ability to offset refugee commodification.

\section{Participatory Photography Study}

Kapturing Kakuma assumed the form of a participatory photography project, and was implemented during the summer of 2008 in the Kakuma Refugee camp. Inspired by this Freirian approach, this project distributed digital cameras (under the guidance of the present author) to five students, who had already been selected for the World University Service of Canada's (WUSC) Student Refugee Program (SRP). The deployment of this project occurred during a period prior to the students' relocation to Canadian Universities, and proceeding a year of 
extensive English training. This timing was ideal, because it enabled the students to articulate their experiences of using the cameras, independent of translators.

This study was geographically situated within the Kakuma Refugee Camp. The Kakuma camp is located in northwestern region of Kenya, in the Turkana district of the Rift Valley Province; approximately one-hundred and twenty kilometers north of Lodwar District Headquarters, and ninety-five kilometers south of the Kenyan border town, Lokichogio. Initially, Lokichogio was a temporary settling ground for refugees fleeing across the Sudanese border. However, due to a constant influx of asylum claimants, the Kakuma camp was established by the Kenyan government and the UNHCR in 1992. During June of that year, the first settlements of Sudanese refugees were relocated to Kakuma. The camp has since expanded to host a variety of refugees from Eastern African countries, including Somalia, Ethiopia, Burundi, the Democratic Republic of Congo, Eritrea, Uganda, and Rwanda. In 2007, the UNHCR stated that the Kakuma Refugee Camp hosted approximately fifty-thousand refugees; nearly $21 \%$ of the total refugee population in Kenya at that time (UNHCR, 2008).

From the camp's inception through until January 2008, there was a constant increase in the number of refugees inhabiting Kakuma. In 1994, the camp's size inflated as Ethiopians fleeing the toppled Mengistu Regime arrived, settling linearly along the camp's highway. The new arrivals were instrumental in developing businesses, and thus created a strong relationship with their camp predecessors. During the time that this study took place, the camp was host to two dominant populations; Sudanese and Somali. These two populations represent the spectrum of stages of the refugee process. 
Somali refugees have claimed asylum in Kenya since the fall of the Siad Barre regime in 1991. The U.S. Committee for Refugees and Immigrants (USCRI) estimates that nearly sixtysix-thousand Somali refugees arrived in Kenya in 2008, despite the border being officially closed as of January, 2007 (USCRI, 2009). The Dadaab Refugee Camp, located at the border to Somalia, is currently hosting over two-hundred thousand refugees; over twice the camp's intended capacity. Since early 2008, the UNHCR and IOM transferred two-thousand Somali refugees to the Kakuma Camp. Recent consultations have proposed relocating up to fiftythousand more Somali refugees in the upcoming year (USCRI, 2009). The presence of a Somali population at the Kakuma Camp provided this study with a representation of new arrivals, and their initial settlement into camp life.

In contrast to the Somali situation, more than two-thousand Southern Sudanese refugees repatriated from the Kakuma camp in 2008. Although repatriation is continuing to take place, over twenty-nine thousand Sudanese refugees still remain in Kenya (USCRI, 2009). This population therefore represents the full duration of life in protracted refugee camps, and repatriating refugee populations. Together, these two populations provide diverse subjects and stages for the framing of refugee life.

To capture an intimate rendering of life in Kakuma, voluntary participants were equipped with cameras for an allocated time period of twenty-four hours. Recruitment for this study occurred during one of WUSC's informational pre-departure sessions, where SRP students were informed about the study and invited to participate, resulting in the five volunteer participants. Four of the five refugees participating in this study were Southern Sudanese males, aged 22-24, who resided in different sections of the camp. The fifth participant was a 26 year-old Ethiopian male. Each volunteer was allocated his own digital camera for the twenty-four hour time period, 
and was asked to take a minimum of ten pictures. The participants were instructed that they had full discretion as to the subject matter of their photographs, and that they were able to reserve some of their photographs for personal publication. After an initial tutorial demonstrating the camera's functions, WUSC representatives accompanied the participants for the first hour in the field, to verify that participants were following the assigned procedures for acquiring verbal consent. After the twenty-four hour allotment window had concluded, participants were asked to present their favourite images and participate in a round-table discussion and a written reflection on their experiences using the camera.

A total of the 1079 images were taken by the participants. Each participant was then asked to select a sampling of less than thirty images for the study. These images were produced on a contact sheet and participants were once again asked to verify that consent had been acquired from all of the subjects within the photographs. The participants were also provided an opportunity to name their images and highlight particular photographs they wanted to ensure were included in the final publication. From the sample collections, thirty-four images were compiled into a photographic exhibition, which was presented at WUSC's annual conference as well as at various lecture presentations and university events [IMG (X)1, IMG (X)2, IMG (X)3].

The purpose of this participatory exercise was twofold. The primary purpose was to disrupt the image of a depoliticized mass of voiceless refugees, through the facilitation of selfarticulation and the promotion of the individual. This project also sought to analyze the differing visual narratives depicted within these alternative communication models. Overall this study found that the images produced by participants had distinctly different framing trends than the UNHCR's images of Third World refugees. 

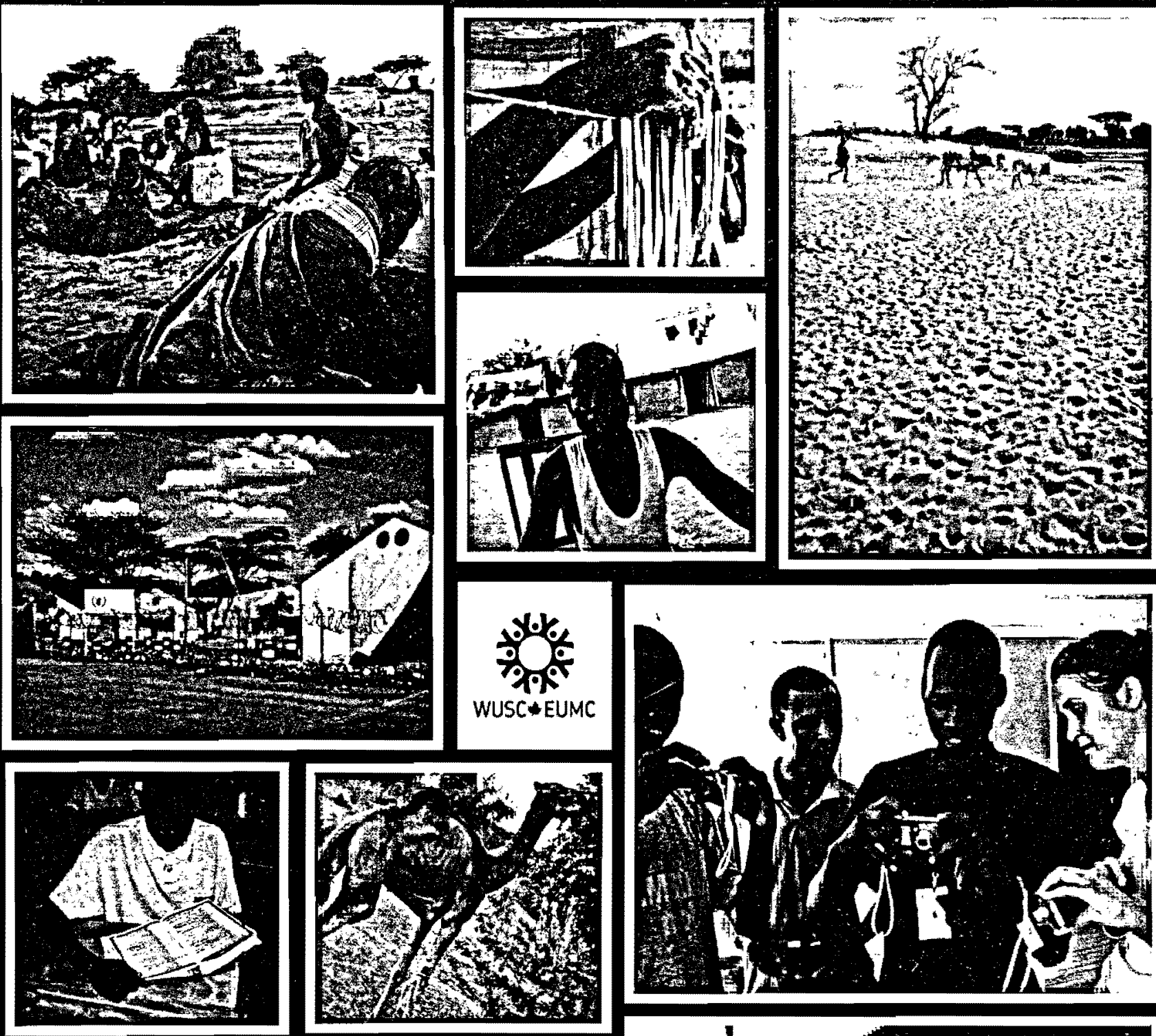

WUSC $\star E U M C$
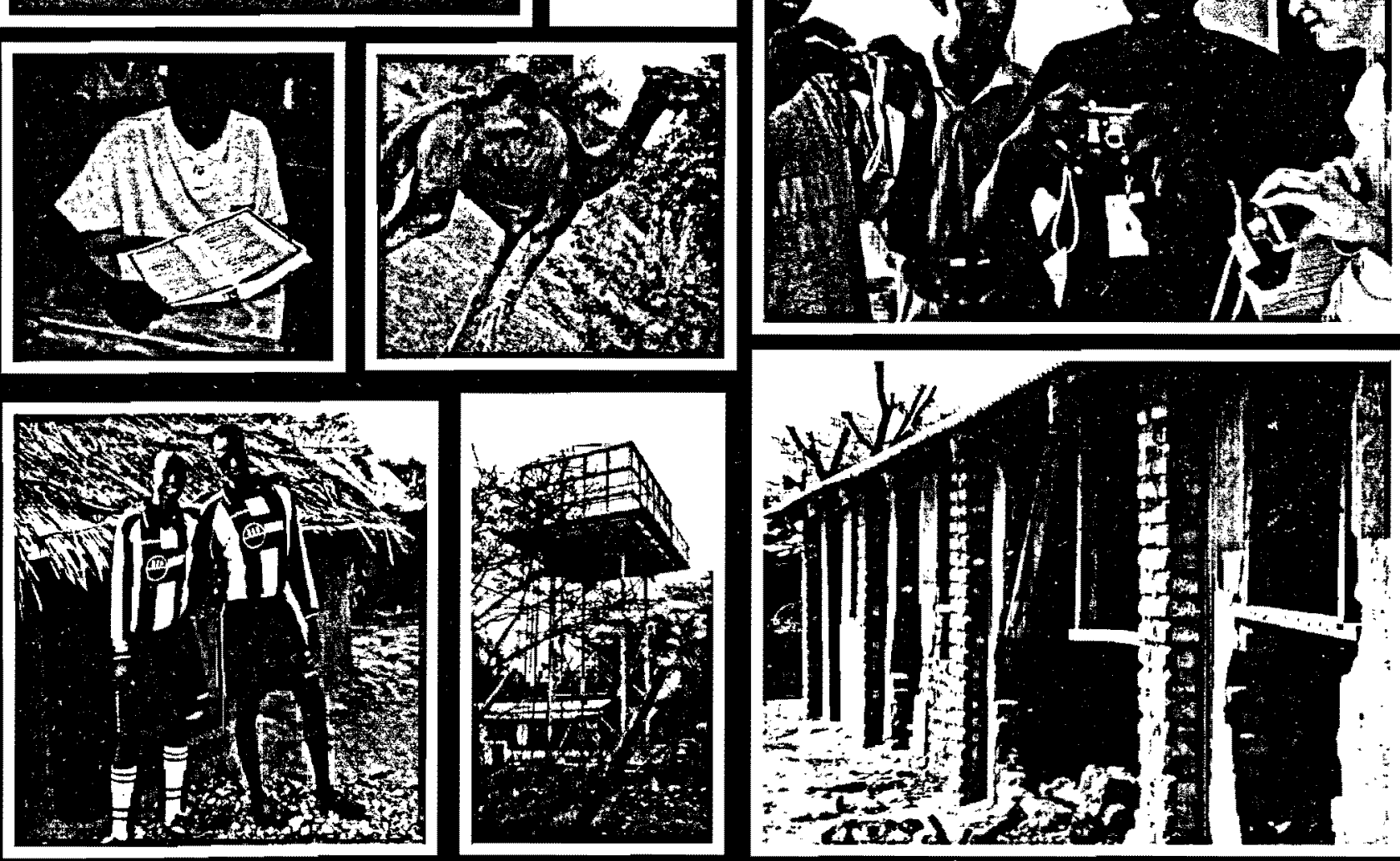

IMG (X)1: Kapturing Kakuma/2009 

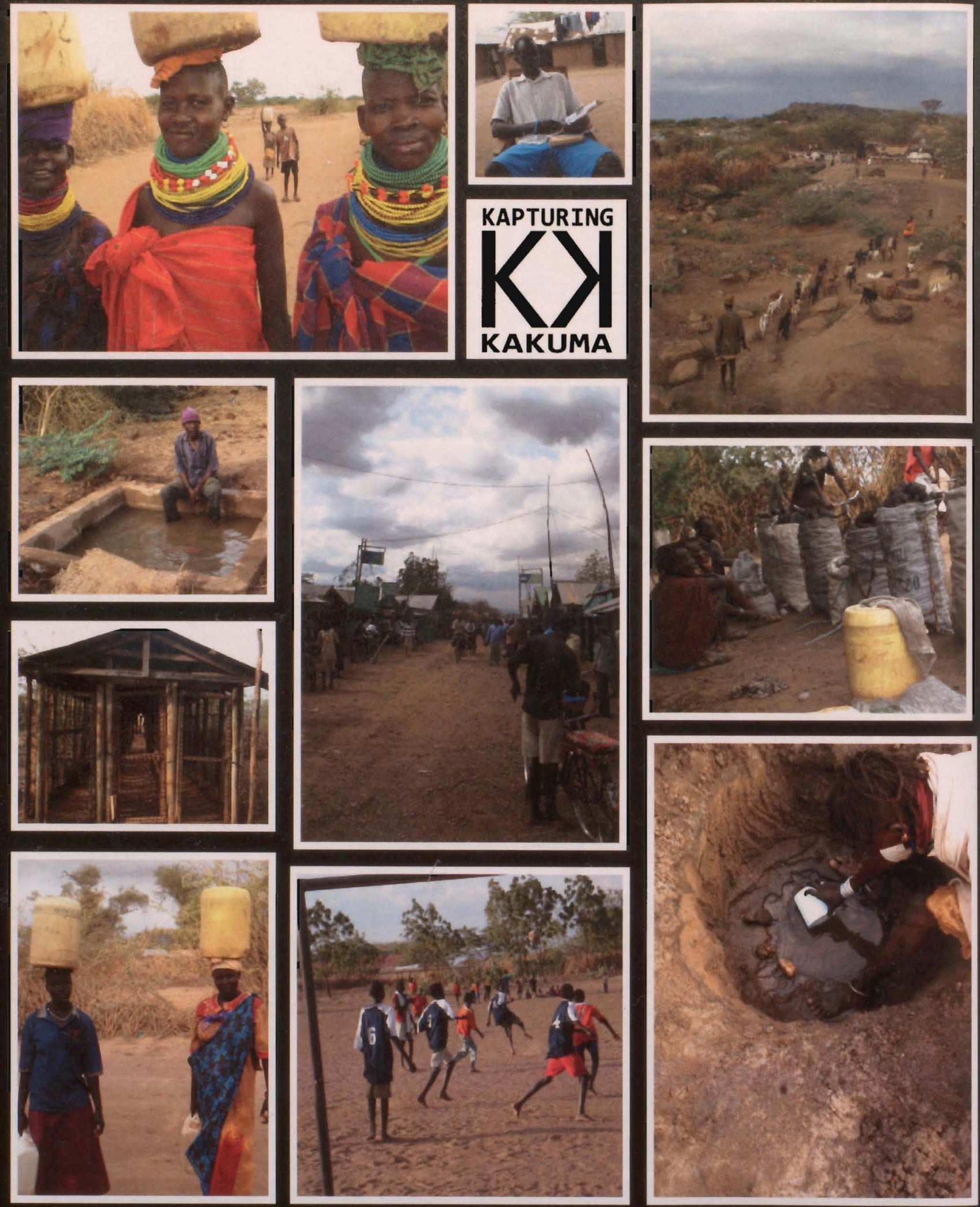

IMG (X)2: Kapturing Kakuma/2009 

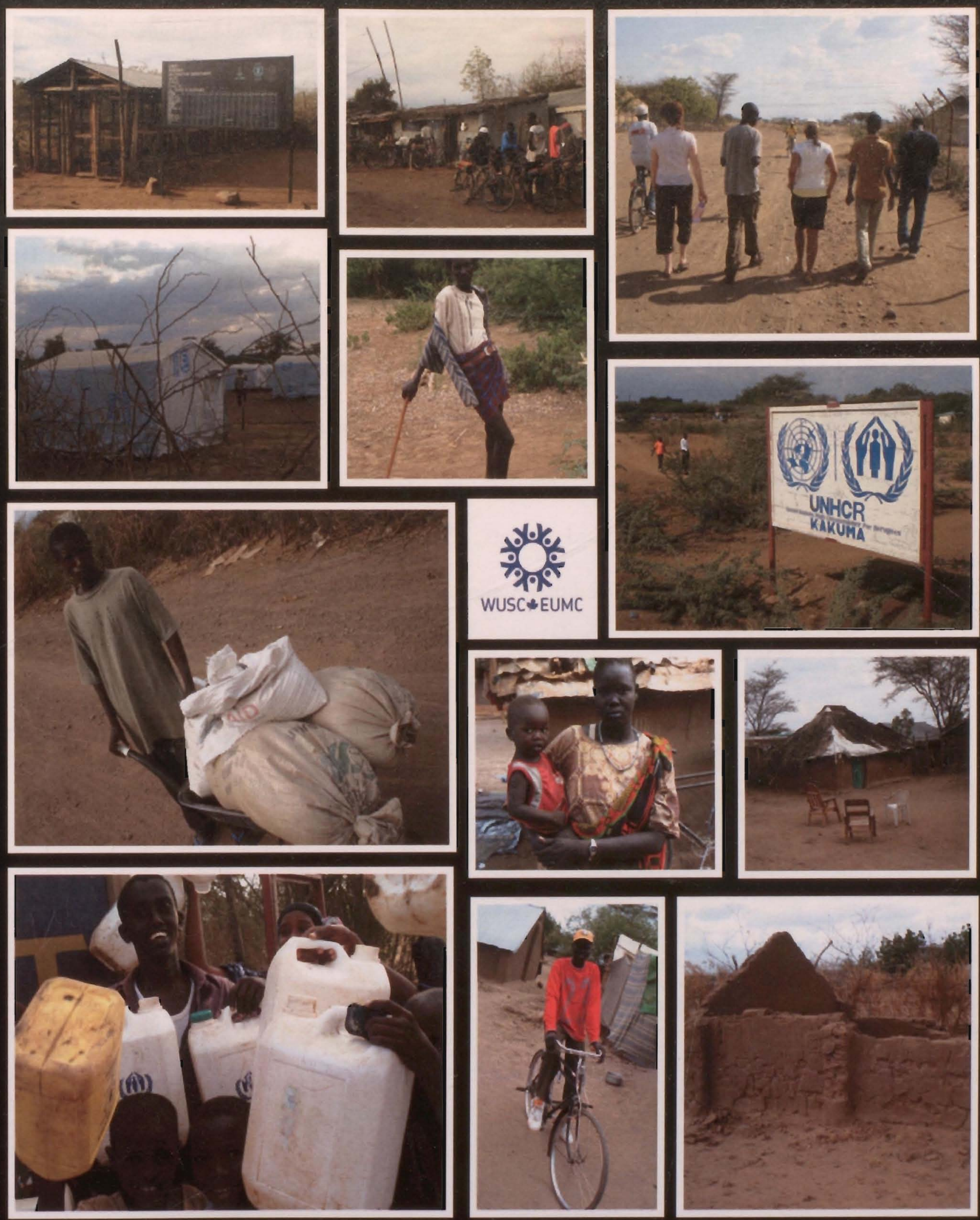

IMG (X)2: Kapturing Kakuma/2009 


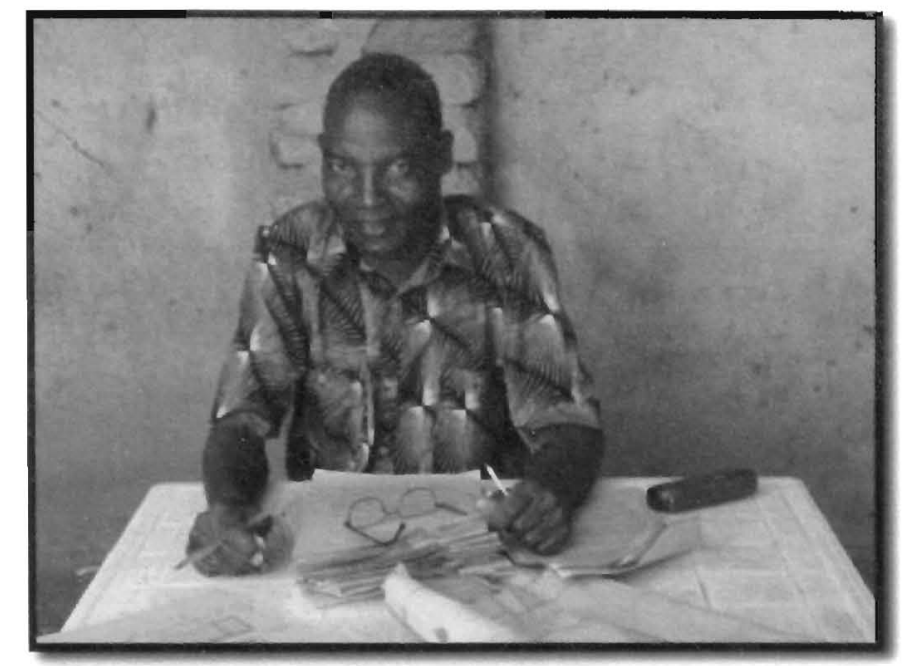

IMG (C)1: Kapturing Kakuma/P4/2008
In contrast to the UNHCR's

Third World images, which featured mobility as the dominant frame, 'portrait' images were the most prevalent within the participatory collection. which represented $31 \%$ of all the photographs, as indicated in

Figure 4.1. These images often featured one individual positioned in relation to their corresponding environments. For example, some images featured a football player standing in isolation on a football pitch, a shop keeper posing in front of his store, or a refugee shepherd featured proudly in front of his herd of goats. These images not only served to further humanize these refugees, but also highlighted their unique characters by associating them with identifiable objects, permitting the viewers to attribute a deeper understanding to the human being featured

\begin{tabular}{|r|r|r|r|l|l|}
\hline \multicolumn{5}{|c|}{ Figure 4.1: : Kapturing Kakuma Series: Images } \\
by Theme and Sex \\
Aerial \\
Reproduc..
\end{tabular}


within the portrait. IMG $(C) 1$ is one example of how the 'portrait' frames are used to infer a greater identity of the photographed subject. Instead of simply capturing a portrait of this man sitting passively at an empty desk, he is featured surrounded by piles of papers, which suggest that he is a

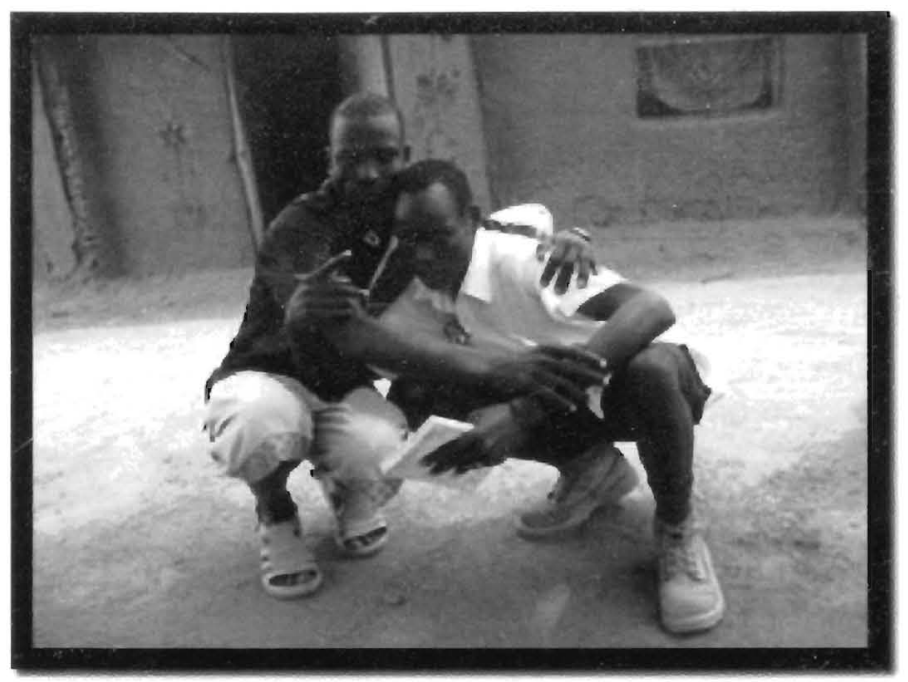

IMG (C)2: Kapturing Kakuma/P2/2008 teacher at work. This image not orily qualifies this man's profession, but also further humanizes this individual implying a high degree of agency, inferred from both his contributions to his community and his inherent knowledge.

Along with the frequency of the 'portrait' frame, the images captured from this participatory study focused on a lesser number of subjects than depicted within the UNHCR's Third World imagery. Of the ninety-eight images which were coded, fifty of these photographs

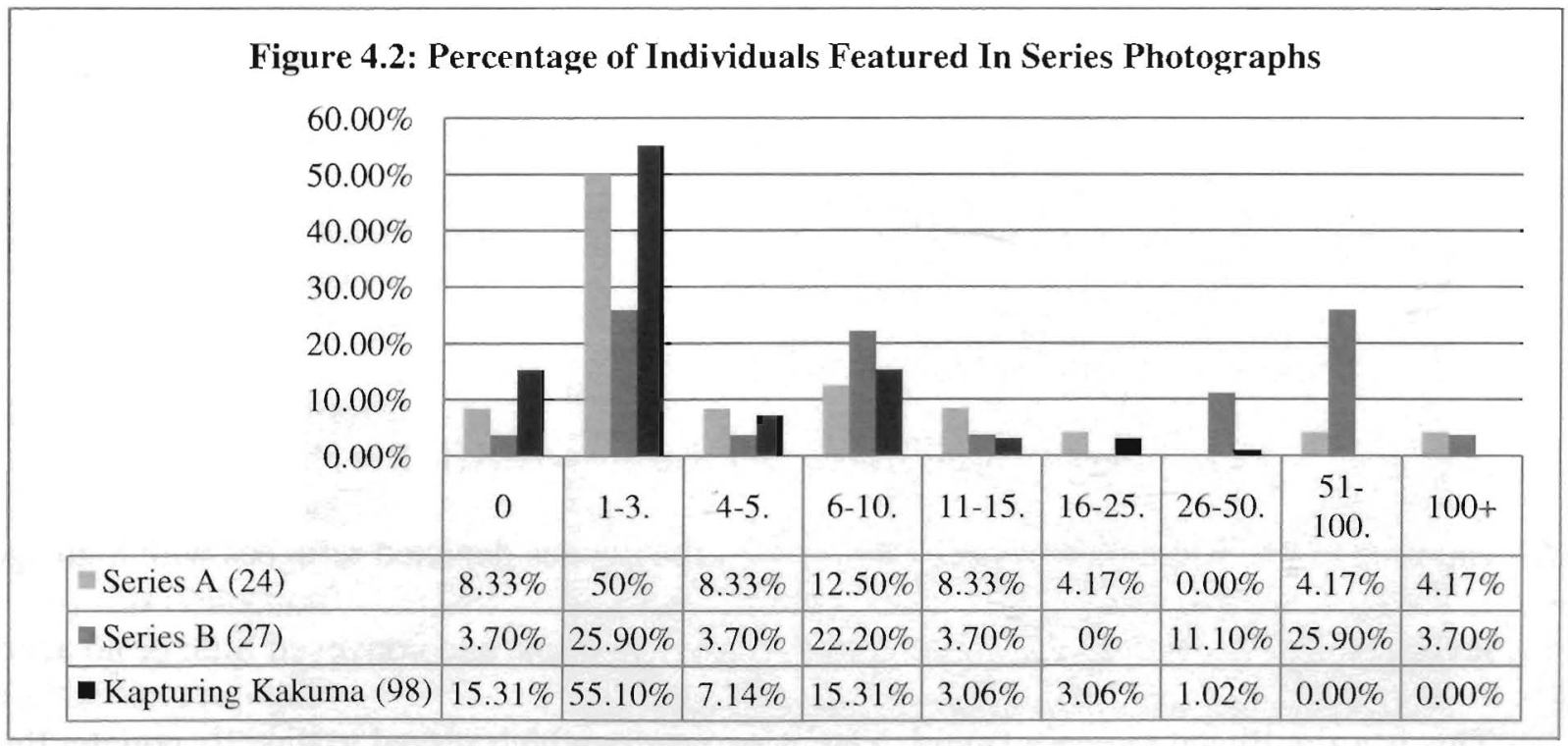


contained less than three subjects per frame. This represents $55 \%$ of images which featured refugees. The correlation between the frequency of the 'portrait' frame and the limited subjects enables viewers to individualize the refugees depicted. Instead of viewing a mass of homogeneous refugees constituting a 'bare humanity', 'portrait' frames permit the focus to be centered on individual people. Although these featured subjects were not the participants of this study, agency is attributed to these subjects in two ways. First, as previously mentioned, many of the subjects of these images were featured in relation to their respective careers, and thus infer agency from their contributions as a community. Second, for the refugee youth which were depicted in the majority of the 'portrait' shots, agency was reflected in their willingness to pose for the camera. IMG (C)2 and IMG (C)3 are examples of how refugee-subjects assumed an active role in constructing their identity by adjusting their posture and positively smiling for the camera's view. These subjects were thus not passively being captured by the participatory photographer; rather they willfully submitted themselves to the camera's gaze.

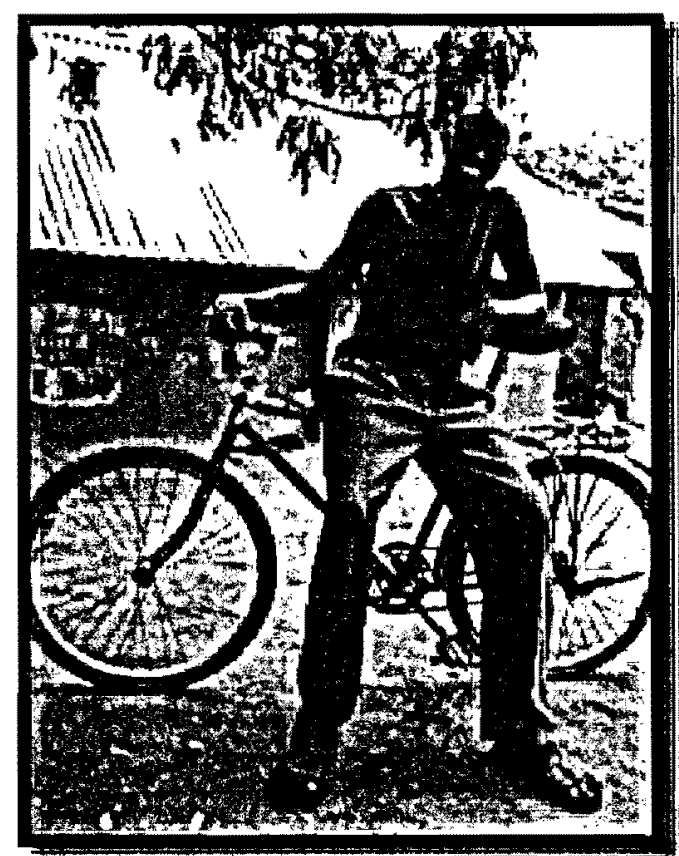

IMG (C)3: Kapturing Kakuma/P3/2008

The depictions of agency conveyed in the photographs was the most striking difference between the UNHCR's photographs and those captured by the Kakuma study. Overall $63 \%$ of the images depicted refugees with high agency levels, while only four images utilized the 'passivity' frame and conveyed little or no agency. This is a significant increase from UNHCR's imagery which served to directly counter the 
vulnerability frame. Overall, the majority of participatory pictures featured refugees engaged in some form of 'reproductive' $(21 \%)$ or 'productive' (13\%) labour. These frames illustrated the capacity of refugees to contribute to both their communities and to their general welfare. The dominance of these frames yet again contradicts vulnerability discourse, especially considering the frequency with which 'vulnerable populations' appear within these frames.

Within images of 'reproduction' and 'production', women were represented in $86 \%$ and $31 \%$ of the photographs, respectively. Similarly, children were featured in $19 \%$ and $15 \%$ of these respective frames, and elderly subjects were photographed the least out of all of the 'vulnerable populations'. However, in contrast to the UNHCR images, the single image which contained an elderly man [IMG (C)4] did prescribe a medium level of agency, illustrating the man's ability to care for a small infant. These findings therefore conclude that the presentation of "vulnerable populations' were not constructed in the same light as the UNHCR's depictions. Instead of focusing on the helplessness of this group, these participatory images illustrated the ability of these individuals to utilize their labour capacities to produce and care for both themselves and others.

Overall, the findings of this small sample expose the capacity for alternative illustrative refugee discourse. This is not to suggest that the depictive narratives espoused by this collection constitute the 'real refugee

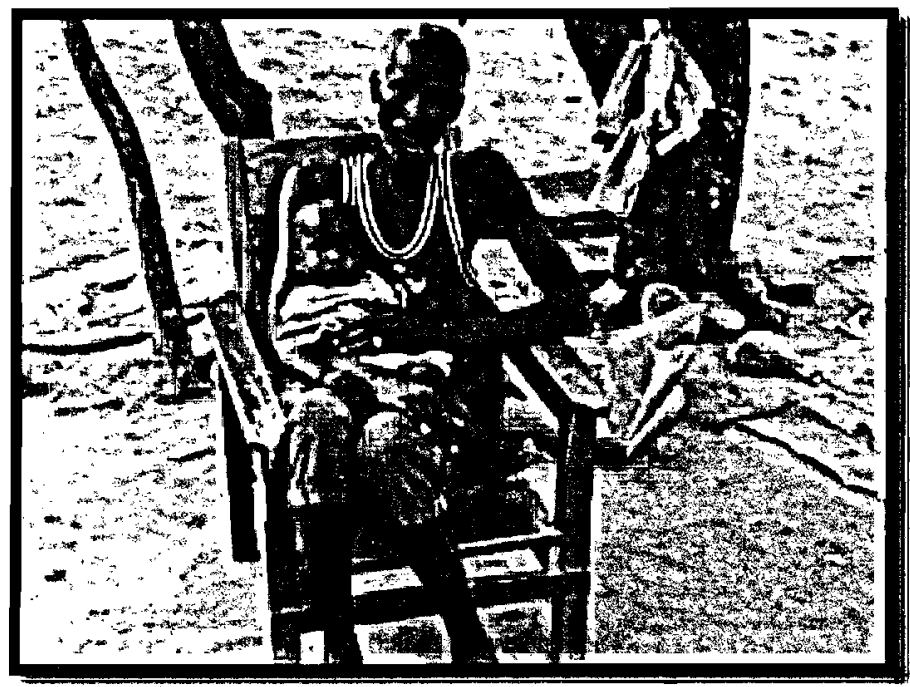

IMG (C)4: Kapturlng Kakuma/P2/2008 
experience', but rather this experiment suggests the degree to which the UNHCR's images do not represent a full or accurate rendering of refugee life. The existence of alternate narratives further serves to indicate that the UNHCR has in fact constructed and maintained a specific framing of the refugee figure.

The juxtaposition of these two illustrative discourses presents an interesting terrain for investigating the structures governing the proliferation of the iconic refugee. Freire highlighted in 'Pedagogy of the Oppressed' that along with dialogue, visualization was an important way of engaging vulnerable populations in exercises of self-representation, and also stimulating introspection (Freire, 1970). By allowing refugees to photograph the camp, their lived experiences are not only respected but also are expressed within 'their vernacular'; affording a recognizable ground for refugees to engage with issues in a manner coherent to them.

By employing participatory photography within this study, the participants and researcher were able to overturn the restrictive dichotomies of 'teacher-learner', by facilitating mutual learning opportunities through which collective ambitions were able to materialize. Freire (1970) acknowledged the repressive dialectical relationship which is constituted through a traditional teacher-student (or as Freire presents it - oppressor-oppressed) relationship. This relationship asserts the teacher as the 'subject' and identifies the learner as the 'object' being acted on. "The oppressor denies the legitimacy of the oppressed voice by assuming that learning, development, and progress are only achievable via the intervention of the oppressor" (Srinivasan, 2006). However, within a participatory system, learning is viewed as a mutually transformative process. True participation is seen as not involving relationship between teacher-learner, or subjectobject, but rather being found in an inclusive subject-subject environment. According to Freirian pedagogy, viewing learners as empty receptacles ready to be filled with knowledge oppresses the 
learner's lived agency, and negates the importance of their experiences. The Freirian approach therefore advocates that learning should be viewed as an involving problem negotiated through a dialectic exchange.

By enabling refugees to construct their own depictions of refugee life, the study validated and celebrated their perspective and engaged participants in meaningful dialogue. While one may assume that the participatory project was directed by the research facilitator, making them 'participatory' but still influenced by the researcher's objects, this was not the case. The facilitator of this project, as with all participatory projects, had an imperative role to ensure a safe and inviting atmosphere for reflection. It was not their position to lead the selection of images or to direct the resulting conversations. Rather, the researcher implemented a 'Problem-Posing' methodology. This approach to educational projects was presented by Friere and "enables teachers and students to become Subjects of the educational process by overcoming authoritarianism and an alienating intellectualism; it also enables people to overcome their false perception of reality" (Freire, 1970, 86). The Problem-Posing method presents both facilitator and participant in a communicative exchange, recognizing the knowledge inherent in both actors. "Through dialogue, the teacher-of-the-students and the students-of-the-teacher cease to exist and a new term emerges: teacher-student with students-teachers" (Freire, 1970, 80). Together as a group, all actors contribute to the conscious unveiling of reality, becoming jointly responsible for the process.

The Problem-Posing methodology was used during the round-table discussion of this study, during which each participant reflected upon their time with the camera. It was throughout these discussions that participants commented on the importance of photography, and how their 
images helped to shape what they perceived as part of the refugee identity. One volunteer commented that:

Photography is a powerful means of communication, [it] can tell a certain story for its audience. Sometimes, there are some photographs which we can never forget. Apart from - this, photography is an important tool for learning because it can help people to visualize their thoughts (Participant Three, 2008).

Although each respondent had a different experience, and captured different dimensions of camp life, each one of them identified important characteristics of refugee life and together they were able to point out salient issues which were repeated in various images captured by all photographers. One of these dominant subject matters was education, which appeared in every participant's photoset. One participant highlighted that he specifically sought out areas of the camp which needed increased attention from the UNHCR, but were often neglected. In particular, this respondent photographed several different schools located throughout the camp, highlighting the inadequacies of the camp's school system,

The photos for some of the schools pose signals of an atmosphere not conducive for learning. In addition to this harsh environment, the learning facilities (schools) are also under-equipped with learning materials and other stuff usable in academic settings yet these are the very schools where most of the WUSC sponsored students and many more students walked through. In spite of the unfriendly surroundings, many of them passed their high school exams (Participant Two, 2008).

This participant's reflections nor only point out the insufficient education structures within the camp, but also the capacity for refugees to overcome this 'harsh environment', and acquire the necessary scores needed to attain University scholarships within Canada. Another participant echoed the importance of education stating that,

The photographs being taken in the Kakuma Refugee Camp tell us that even if many young people have separated with their parents [it] is not the end of the world. . . Most of these young people are very serious with their academic work. They have considered education to be their parents that can make their future life better (Participant One, 2008). 
These powerful words speak not only to the courageous resilience of refugees but also demonstrate their inherent agency; highlighting the ability of refugees to transcend their oppressive conditions and actively emancipate both themselves and others through economic and educational achievements. The capacity of refugees was another theme repeatedly discussed during the round table. Participant Two articulately summarized the group's sentiments, stating, "I want Canadian[s] to see the environment the refugees live [in]. I also would like them to understand that although refugees undergo hard situations; they are still determined to work as hard as anybody who is in his/her country" (Participant Two, 2008). This reflection stemmed from the participant's awareness of the passive refugee perception, and demonstrated his determination to dismiss this connation of refugee identity.

Through the round-table exchanges, the refugee participants began to collaboratively uncover many salient issues which restricted refugee life. Although the time for conversing was limited, the energy and ideas put forward by this group demonstrated the agency, knowledge, and determination of the refugee participants. The refugees who participated in this study were harsh contradictions to the iconic renderings of Third World refugees. They each had a voice, a story, and the drive to change the limiting circumstances.

Although this pilot study was limited in the diversity of its participants, as well as restricted by the allotted time for dialogic exchange, the findings gather support for the first objective of participatory methodology, thus confirming that refugee-photographs can offset the illustrative trends of the UNHCR. While it cannot be suggested that these photographs are representative of all potential participatory frames, these images do demonstrate the availability of alternative narratives. This data therefore challenges the proliferation of the vulnerability frame, by highlighting both the prevalence of other narratives, as well as showcasing the capacity 
of refugees to affect change and author insights into salient social issues often ignored or limited within UNHCR publications. While further in-depth research is needed to confirm the extent to which participatory images contradict the frames produced by the UNHCR, this text concludes by proposing that the mere inclusion of these refugees as active producers within refugee publications dislocates the ideological conception of the passive refugee. By employing refugees as photographers, they are no longer simply an object for consumption, but rather the producers of refugee discourse. The refugee, as producer, is not a silenced dehumanized figure, but one who stands in opposition to the commodified image of the agentless victim.

This research therefore suggests that by incorporating refugees as producers of the UNHCR's regular photographic publications, the Agency will be able to offset the current commodification process by actively promoting the capacity of refugees to function as active agents of change. However, it is imperative to highlight that in order for this recommendation to hold merit, refugees must procure an active role in not only the photographing of refugee life, but also within the entire publication process. Therefore refugees must be involved in the both the selection of photographic subject matter, as well as the selection of final images for publication.

Refugee participation must also not be facilitated as an experimental or 'special' project, but rather become part of the UNHCR's regular operations. To simply endorse participation under these headings suggests that refugee involvement is something that only assumes a 'temporary' position. This framing not only devalues the contributions made by refugees, but also negates the capacity for refugees to occupy a permanent role as actors within the refugee regime. 
It should also be noted that while this research does theorize the potential for participatory approaches to offset the commodification of the refugee within the UNHCR's illustrative publications, this thesis is not naïve to the many obstacles that impede the successful implementation of participatory programs. To execute a large-scale program, the UNHCR would have to address various ethical and pragmatic considerations. Some of these issues include, but are not limited to: 1 . Democratically selecting a representative population of refugees, located in a variety of camps, to be trained and employed as photojournalists. 2. Ensuring that this selected group receives adequate technical and ethical training. 3. Providing reliable access to equipment to take high-resolution photographs, as well as edit these images. 4. Implementing an efficient, democratic, and participatory system in which refugees could be involved in the selection of images, to challenge the illustrative agenda put forward by the UNHCR headquarters. While these considerations only account for four of the issues the Agency would have to address, they suggest a significant commitment and program reform for the UNHCR.

It would be easy for the Agency to dismiss the implementation of a participatory program, regarding it as simply too expensive and outside the Agency's mandate. However, if the UNHCR wants to obtain its original directive of sourcing durable solutions, it cannot afford to disregard its role in the commodification of refugees, nor can it ignore the ability for participatory programs to offset this process. This thesis therefore provides a theoretical proposal for the UNHCR, highlighting how the implementation of participatory programs has the potential to subtly dislodge the oppressive ideologies supporting the internalist perspective of refugee crises.

Although Kapturing Kakuma provides an example of a well-executed participatory project, the implementation of a large-scale program, like the one suggested for the UNHCR, 
created a precarious arrangement through which the Agency concedes to the will of these influential states in order to maintain positive donor-relations.

The UNHCR's concession to these prominent donor-states is manifest in two forms. First, the UNHCR wilfully assumes its mandated position of acting non-politically, and refrains from publicly challenging the increasingly restrictive immigration policies adopted by Western states. Secondly, the UNHCR has also failed to publicize or address the impact that donorcountries have made on exacerbating the internal situations that result in forced migration flows. Instead, the UNHCR has tried to distance itself from the political will of its contributing states by adopting financial reforms that will reduce the degree to which donors are able to earmark the direction of their contribution. Unfortunately, the most recent reforms had significant weaknesses, and were ultimately unsuccessful in curbing earmarking trends. Therefore, although the UNHCR is aware of, and attempting to reform, the limitations of its budget, to this day it has been unable to free itself from the political agendas put forward by governmental earmarking.

Although the UNHCR has attempted to address the restrictive nature of donor-states' earmarking procedures, the Agency has more importantly also developed a role of fundraiser/advertiser, through which it constantly lobbies for continued funding from these statedonors. Since the contributions from states are never guaranteed each year, the UNHCR is forced to annually appeal to the interests of these states, in order to obtain their financial support. It is through this role as a fundraiser that the UNHCR has utilized its position as the foremost knowledge producer of refugee discourse to present an attractive narrative through which Western states are able to perceive the utility of the refugee as an ideological figure. This is not to say that the UNHCR has been maliciously constructing the refugee to the ideological specifications of the West, but that the formation of the refugee figure was a product of the 
UNHCR's evolving interests that gradually constituted the refugee to its present oppressive pictorial state.

When the refugee figure was first depicted it was viewed as a politically significant figure, and as such the UNHCR was quick to support these illustrative frames; as they not only ensured increased funding for the Agency, but they also contributed to the development of unrestrictive immigration policies from countries of asylum. However, when the Western world began to take more notice of Third World refugees, the UNHCR was left with a large predicament. The Statute restrictions of the UNHCR restricted its initial role from the Third World, and thus the Agency was forced to once again appeal to its sponsoring countries for their support to venture into new geographical and political territories. As argued in this thesis, although the initial support from Western states was bound to hegemonic interests working to diminish the reach of Communist values, the Third World eventually retained no ideological value for the West. At that time the UNHCR's operations were primarily focused on the Third World, and thus the Agency was under increasing pressure to uncover new ways of eliciting interest and support from the international community.

As Chapter Two highlighted, the figure of the refugee acquired a new value through the development of a vulnerability discourse. The UNHCR's post-1960s' illustrative approach reduced Third World refugees to the role of helpless victims in need of Western saving. This called upon paternalistic ideologies, which once again reinstated the superiority of Western states which were contributing to 'resolving' these 'localized' conflicts through the allocation of aid. Unfortunately, as discussed in Chapter Three, this paternalistic framing had greater implications than merely ascertaining increased financial contributions from prominent donor-countries. The UNHCR's active role in disseminating the image of these victims has served to depoliticize and 
silence refugee populations. The dismissal of both the refugees' voices and stories negates their political agency, and effectively dehumanizes them; reducing them to a commodifiable object.

The UNHCR therefore assumes an active role as the commodifier, through which it exchanges ideological narratives of refugee discourse for monetary contributions from statedonors. Although this text does not contend that the UNHCR has any malicious intentions to dehumanize refugees, the promotion of its current illustrative discourse commodifies the very individuals the agency attempts to protect. While there are numerous implications of this arrangement outlined within Chapter Three, the most apparent is the reinforcement of this cyclical structure through which refugee commodification reinstates the hegemonic interests of the West. By reinforcing these interests, and ultimately the status quo, the view supporting internalist causes for refugee flows is sustained. As previously mentioned, this view negates the role that both Western states and the international refugee regime have had in sustaining the conditions which lead to forced migration movements.

It is because of this cyclical arrangement that this research highlights the imperative need for the dissemination of alternative refugee discourses that counter these ideological constructions, to foster a more holistic and external view of refugee crises. As examined in Chapter Four, participatory communication methods, such as participatory photography, offer one means through which refugees are able to assume a vocal role in constructing public perception of refugee life, by helping them to become public. Based on the findings from the examined participatory study, it can be inferred that incorporating refugee photographers into the UNHCR publication strategy would assist in not only decommodifying the refugee, but also in subtly dislodging the Western ideological interests which have monopolized and managed the refugee regime. Unlike traditional development power relations, which regard refugees as 
recipients of aid, participatory approaches locate power within people, recognizing refugees as not only active participants but as leaders of their own emancipation.

Participatory approaches therefore afford the UNHCR the opportunity to foster a unique and intimate relationship with refugees. By incorporating refugees into the production of illustrative discourse, refugees are able to deconstruct the framework that has limited the UNHCR`s capacity to set their own mandate. The inclusion of participatory photographers would not create a dramatic revolt within the refugee regime, but would provide a subtle and consistent shift in the ideological framing of the refugee identity. This would enable the UNHCR to continue receiving funding from its state-donors, while gradually reconfiguring the refugee regime around the revised hegemonic position of refugee-producer. Over time, the proliferation of the reconstructed refugee figure would disrupt humanitarian and state-centric ideologies, affording refugees and the UNHCR a platform to seek adequate solutions to refugee crises that directly address the external influences of states and global institutions.

During reflections of his seminal text 'Pedagogy of the Oppressed', Freire stated that:

A more critical understanding of the situation of oppression does not yet liberate the oppressed. But the revelation is a step in the right direction. Now the person who has this new understanding can engage in a political struggle for the transformation of the concrete conditions in which the oppression prevails (Freire, 1992, 23).

It would be naïve to assume that the images produced by participatory projects could resolve the inherent flaws within the contemporary refugee regime, and within the UNHCR's mandate. However, as Freirian pedagogy has highlighted, through inclusion of participants in dialogic reflections, 'the oppressed' become conscious of their oppressive environment and feel an increasing challenge and obligation to transform it (Freire 81). The UNHCR's inclusion of refugee voices within both their illustrative publications, and also within their overall 
programming, would therefore encourage refugees to become invested leaders of their own protection, rather than passive recipients.

As Chimni highlighted, the contemporary refugee regime has reached a new state of crisis. It is imperative that at this breaking point, new approaches are pursued. In Chimni's latest publication he called for a dialectical approach for refugee protection. While I affirm the need for participation amongst all stakeholders, especially refugees, I argue that it is not enough for refugees to merely participate from the sidelines. Rather, refugees must construct of both their image, and their protection. Although participatory communication only provides subtle changes to the dominant narratives and Western perception of refugee life, it is an imperative that the UNHCR must take if it wants to reform the current oppressive refugee regime. Only once refugees have assumed a permanent and empowered place within the knowledge-production of refugee discourse, can the genuine dialogue proposed in Chimni's new dialogic regime exist. 


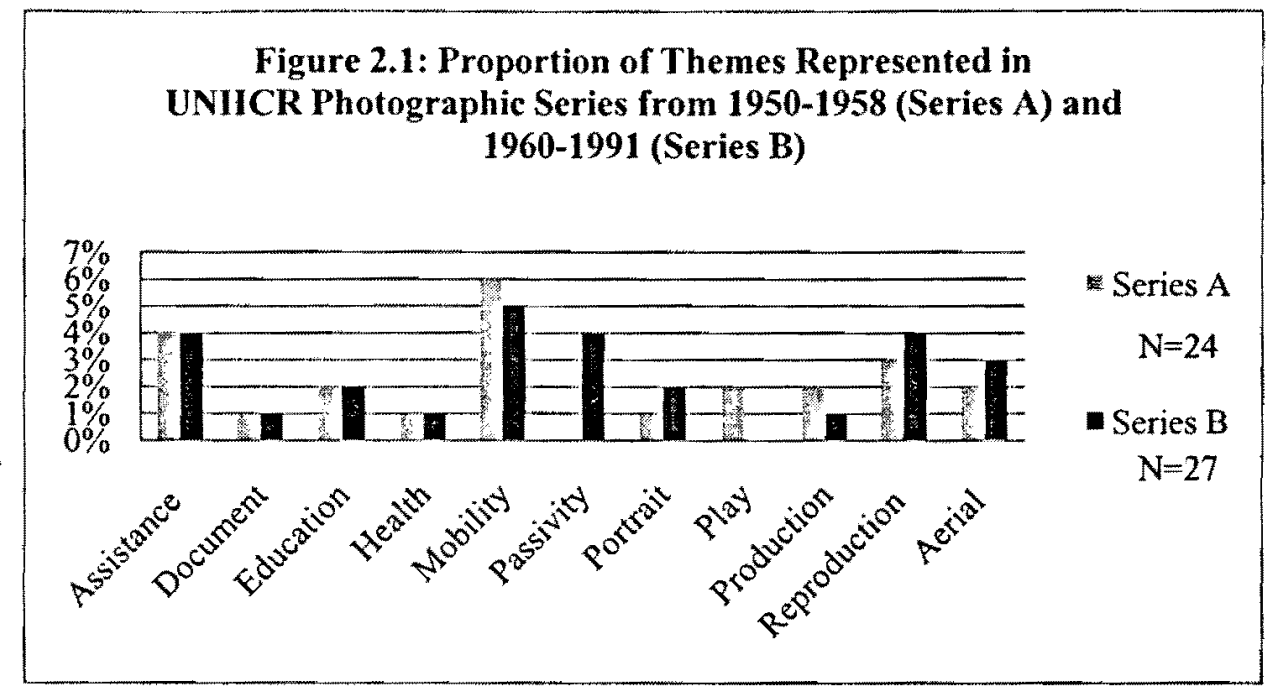

Figure 2.2: Number of Individuals Featured In UNIICR Photographic Series from 1950-1958 (Series A) and 1960-1991 (Series B) by Percentage

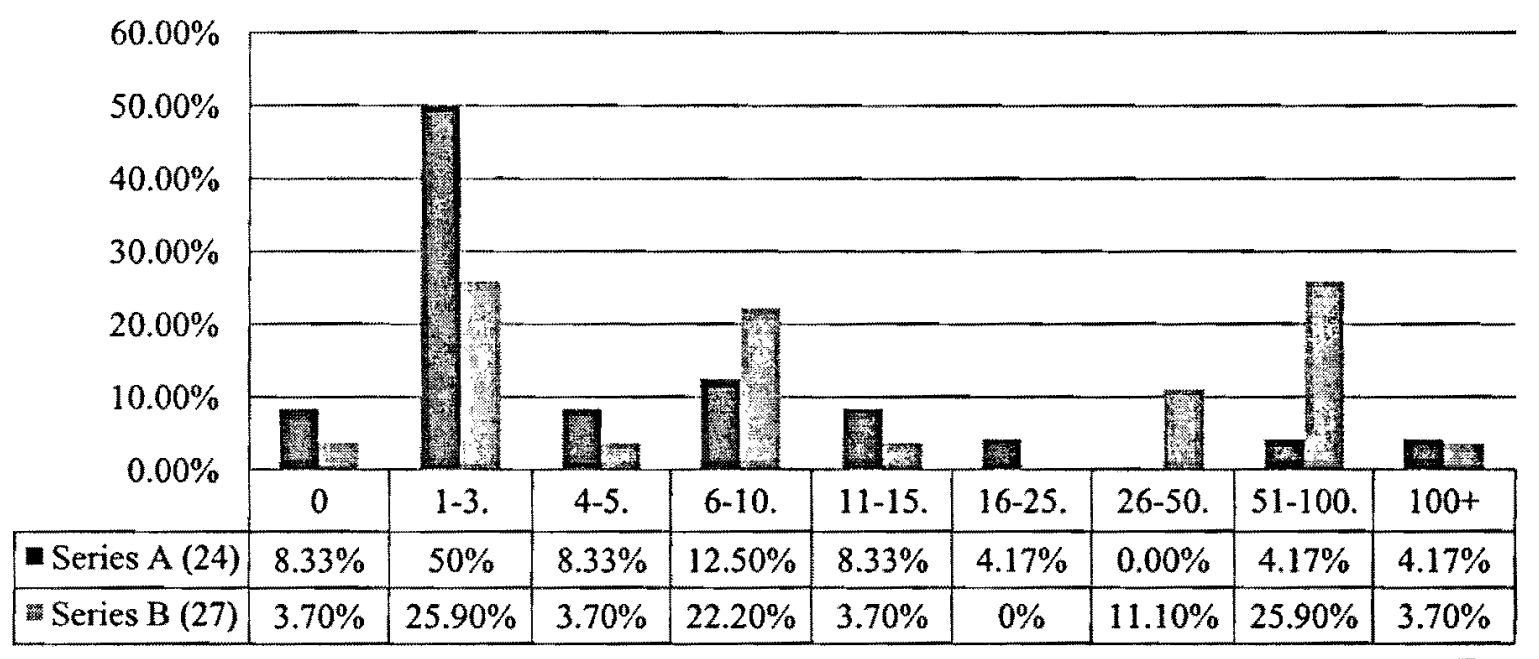

Figure 2.3: Representations of Agency in UNHCR

Photographs from 1950-1958 (Series A) and 1960-1991

(Series B) by Percentage

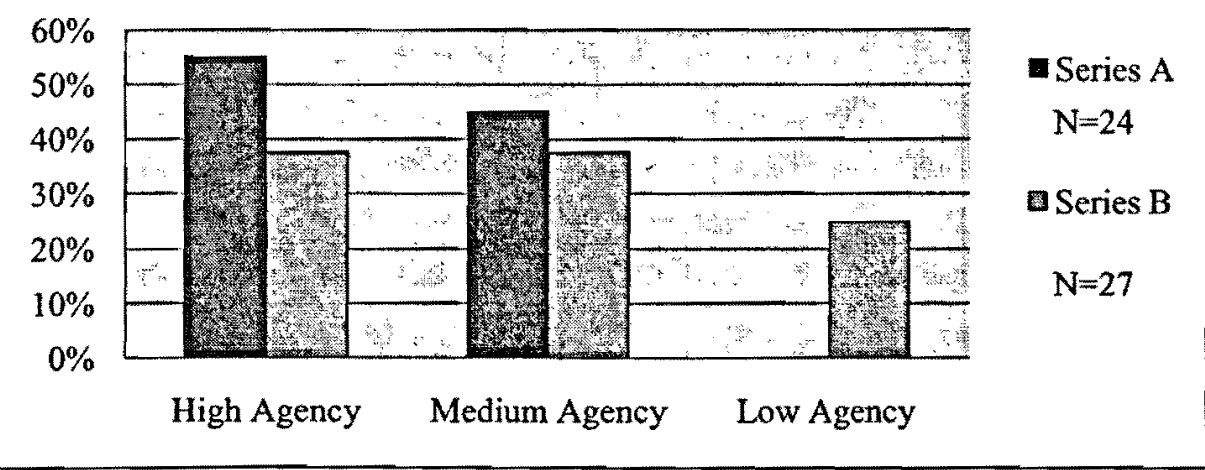




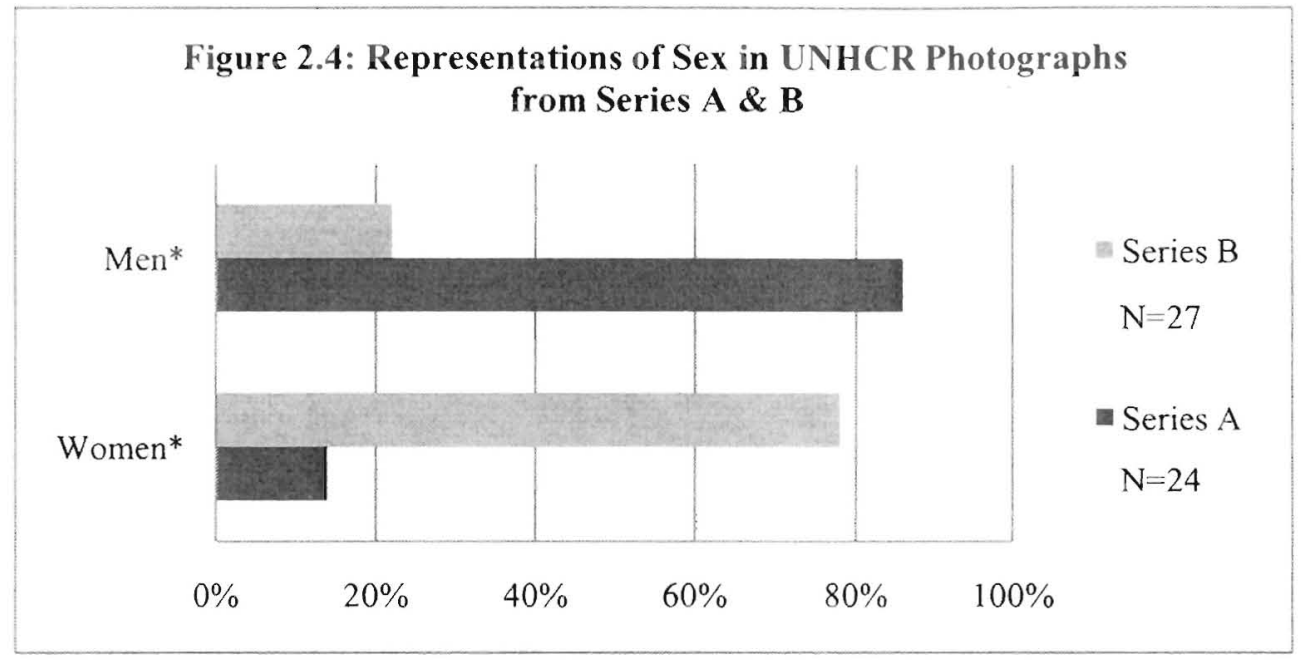

*Percentages include images where both genders were present

Figure 2.5A: Series A: Percentage of Themes and Sexes Represented in UNHCR Photograpns from 1950-1958

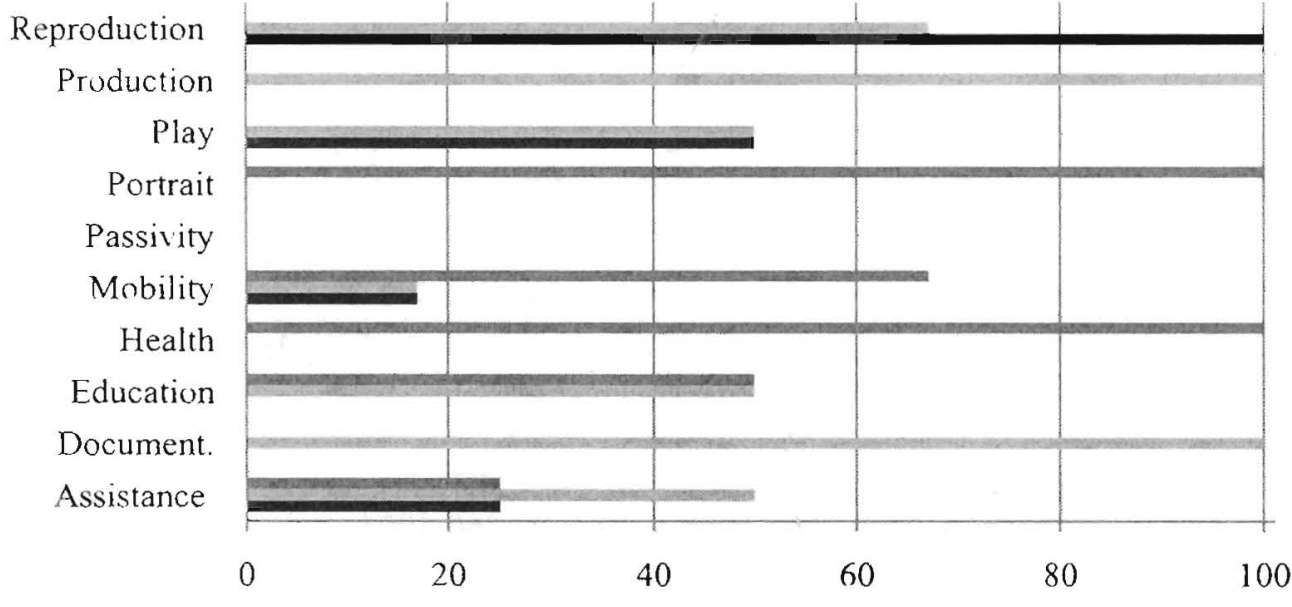

Percentage of Theme

Both Male $=$ Female 
Figure 2.5B: Series B: Percentage of Themes and Sexes Represented in UNHCR Photographs from 1960s-1991

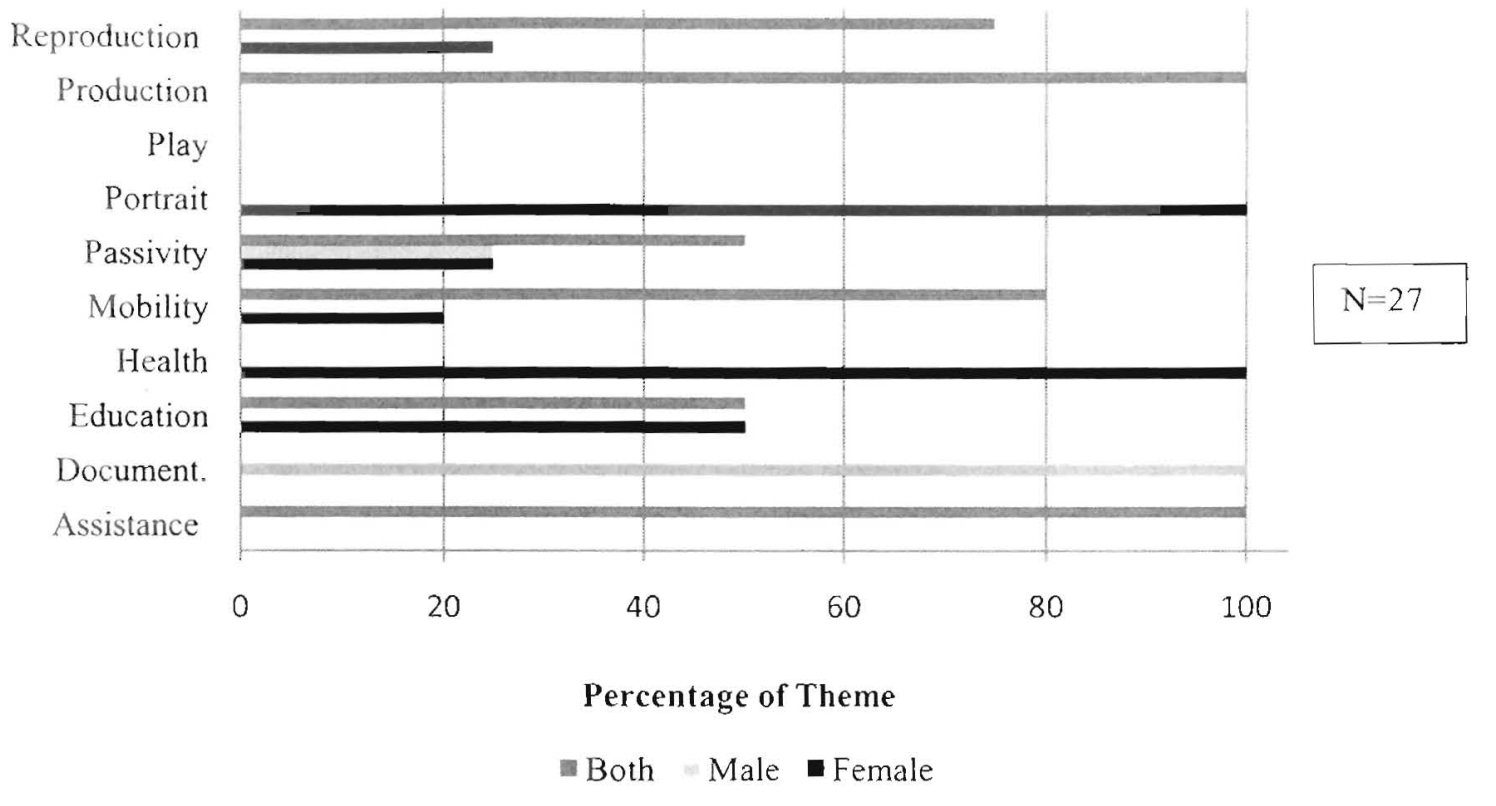

\section{Figure 2.6A: Portion of Agency Represented in Series A Themes}

All Themes

Reproduction

Production

Play

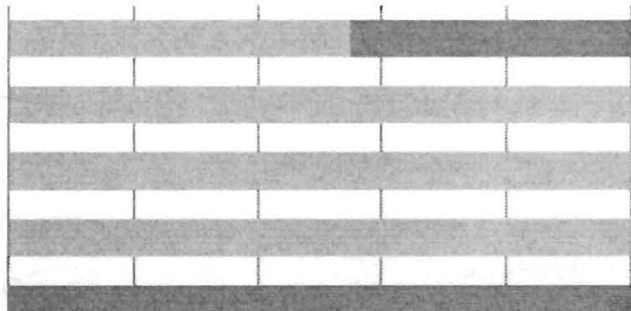

Portrait

Passivity

Mobility

Health

Education

Document.

Assistance

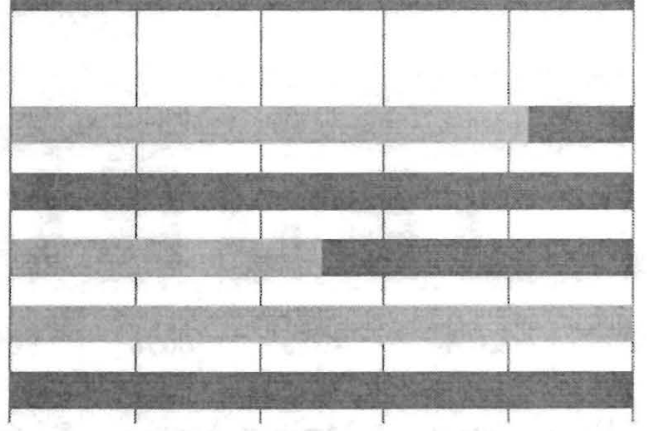

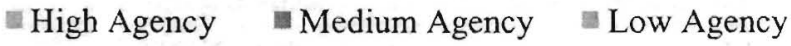



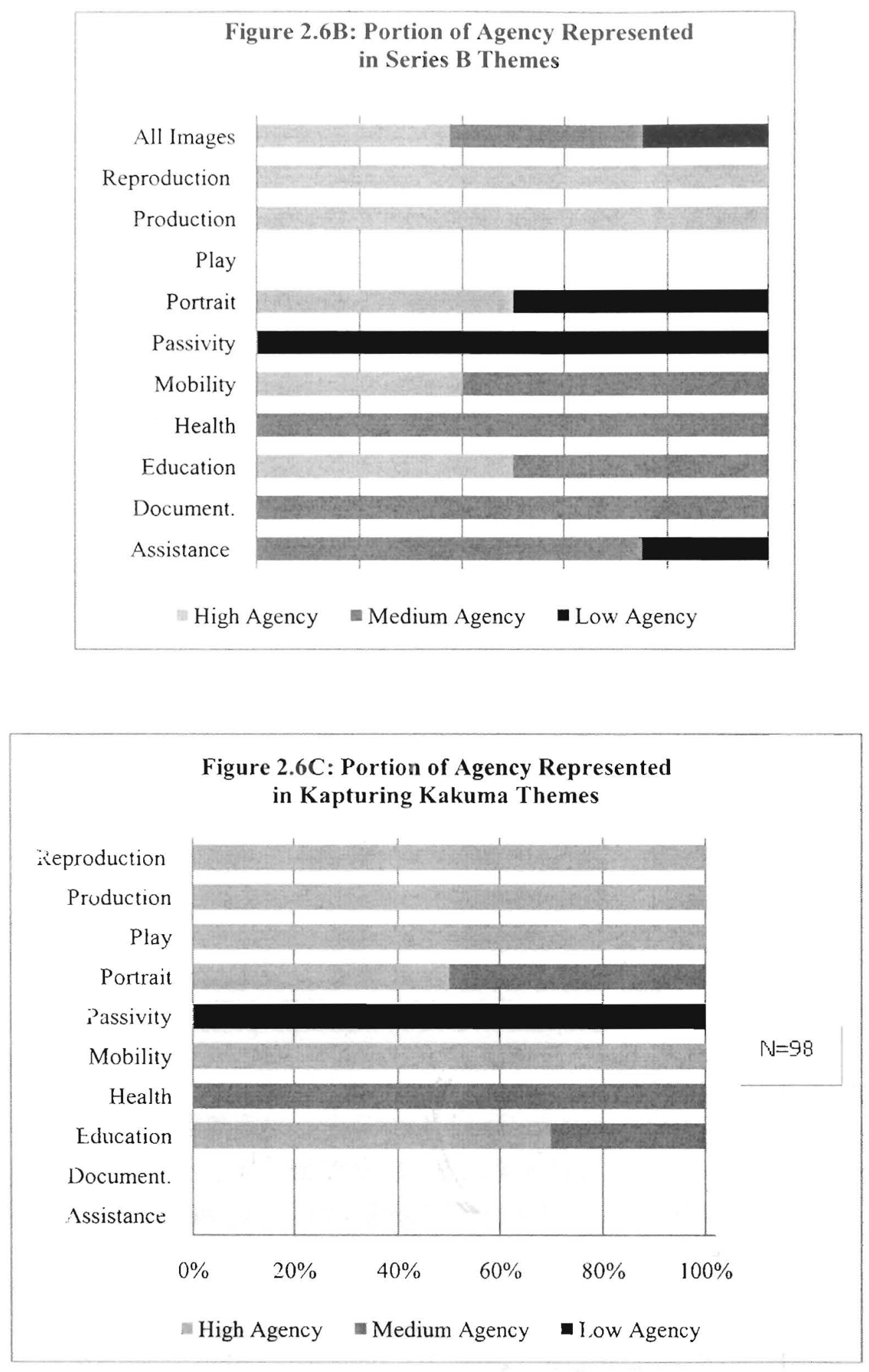
Figure 4.1: Kapturing Kakuma Series: Images by Theme and Sex

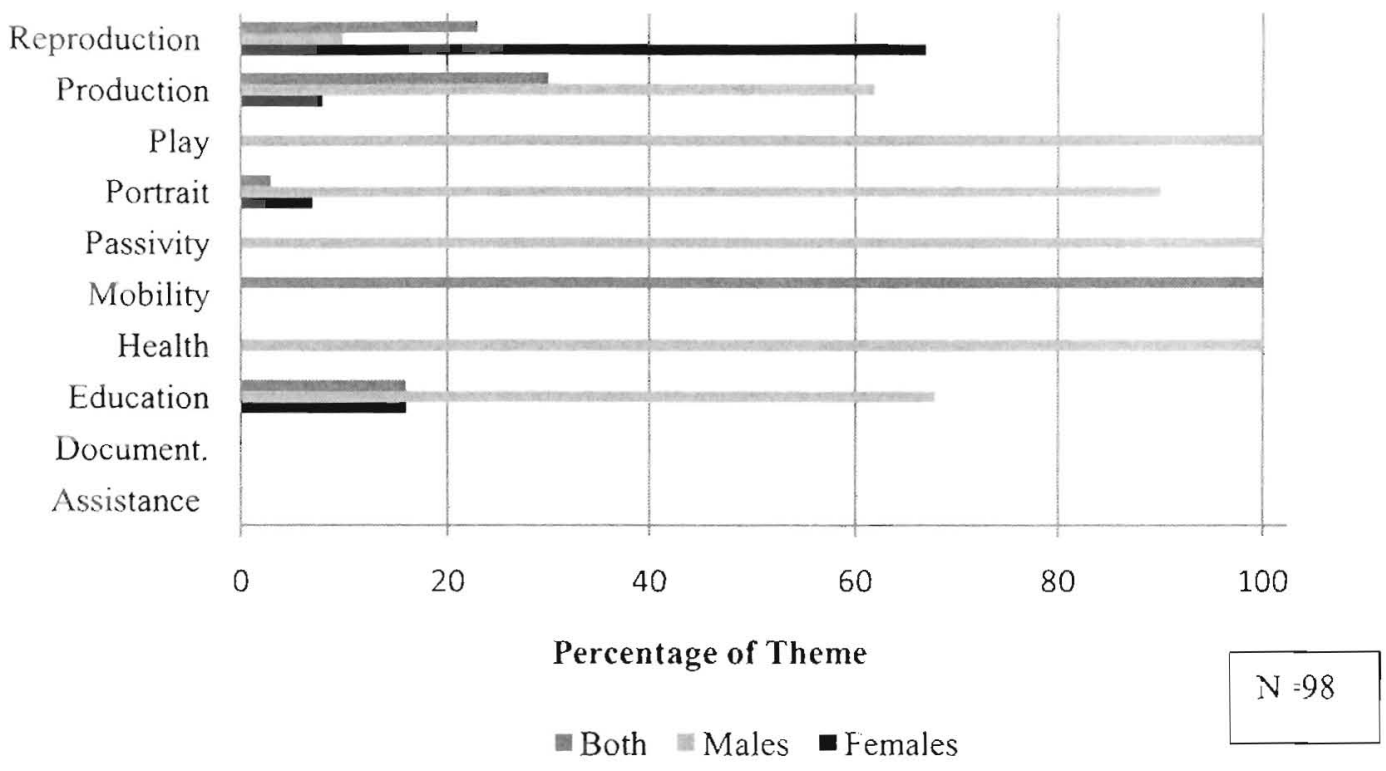

Figure 4.2: Percentage of Individuals Featured In Series Photographs

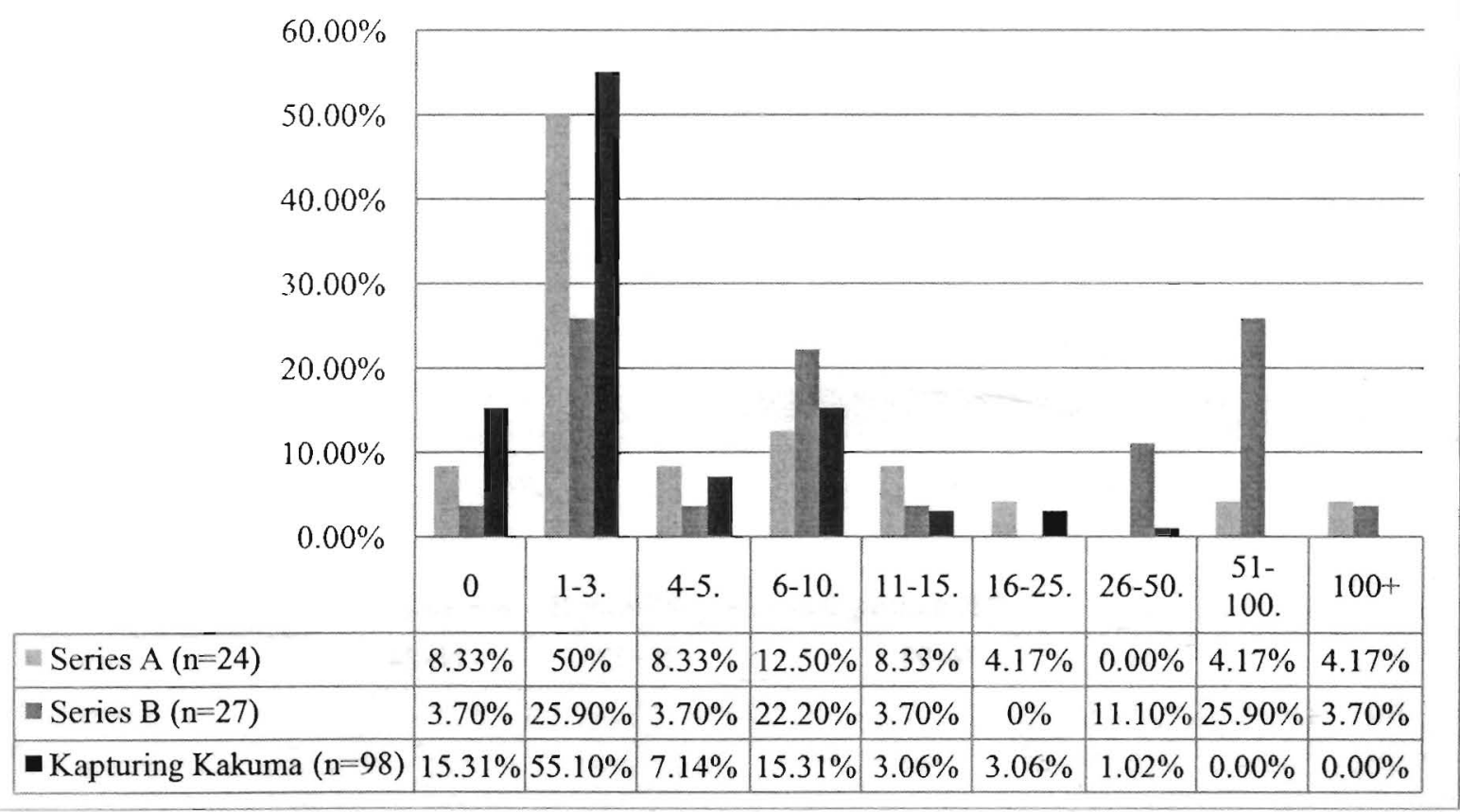


Figure 4.3: All Series Percentages of Gender Representations

Kapturing Kakuma

$\mathrm{N}=98$

Series B

$\mathrm{N}=27$

Series A

$\mathrm{N}=24$

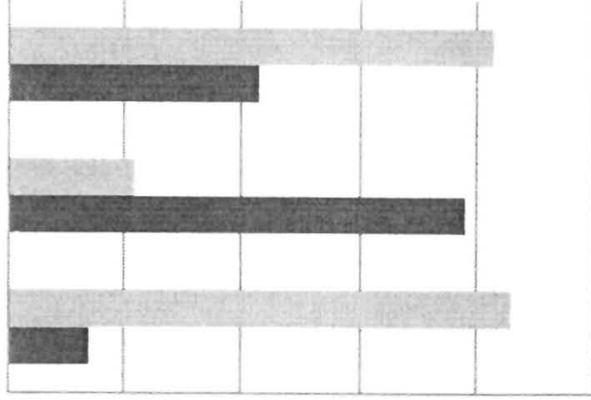

Men*

Women*

$0 \% \quad 20 \% \quad 40 \% \quad 60 \% \quad 80 \% \quad 100 \%$

Figure 4.4: Proportion of Themes Represented in Each

Photographic Series

Reproduction

Production

Play
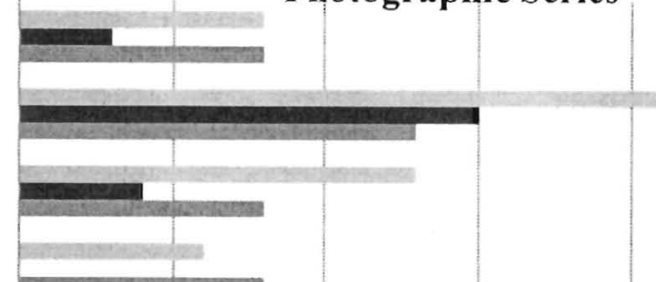

Portrait

Passivity

Mobility

Health

Education

Document.

Assistance
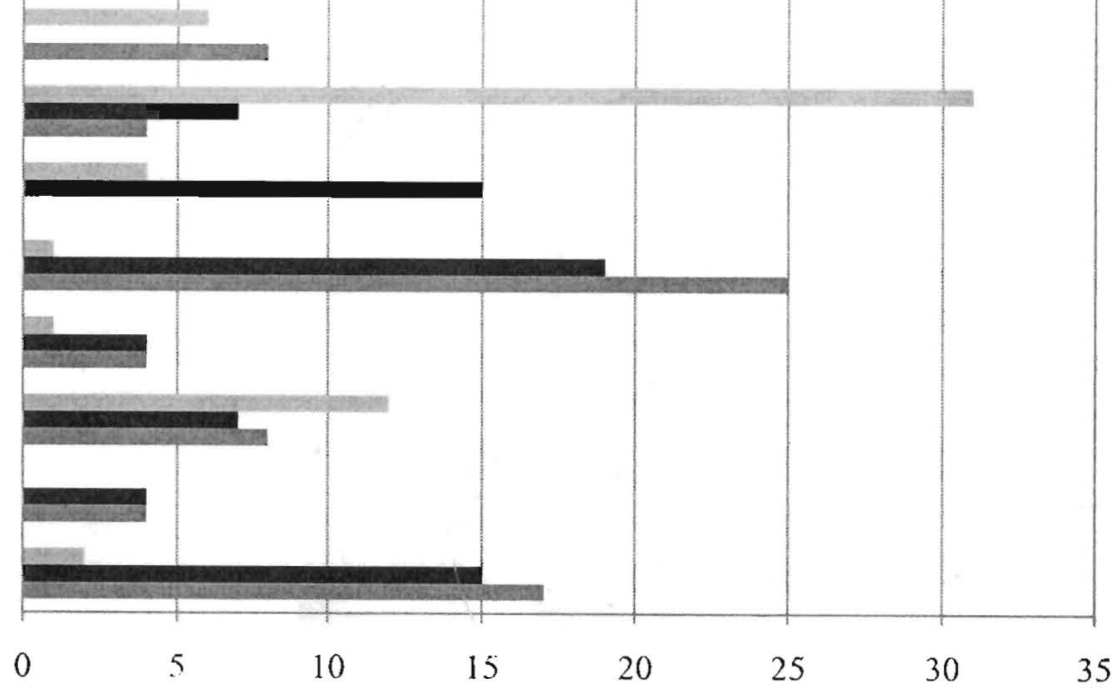

= Kapturing Kakuma

- Series B - Series A

$\mathrm{N}=98$

N 27

$\mathrm{N}=24$ 


\section{TABLES:}

Table 2.1 A:

Series A: Percentage of Sex \& Age Represented in UNHCR Photographic Themes from 1950-1958

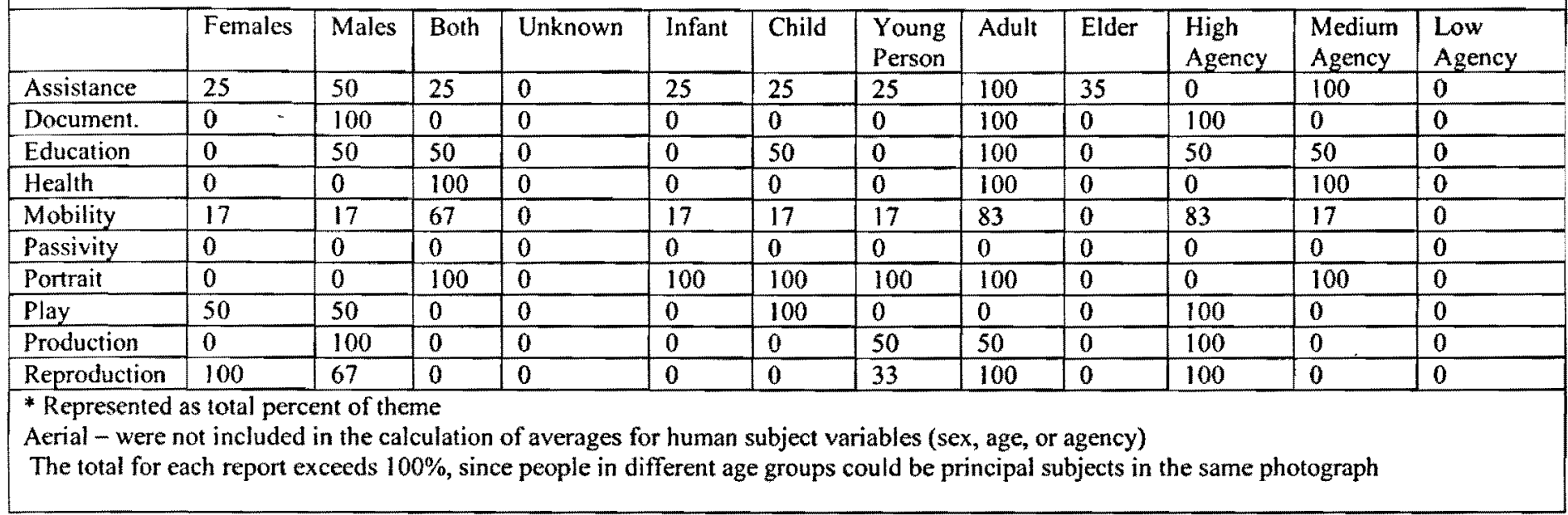

Table 2.1B:

Series B: Percentage of Sex \& Age Represented in Photographic Themes from 1960-1991

\begin{tabular}{|c|c|c|c|c|c|c|c|c|c|c|c|c|}
\hline & Females & Males & Both & Unknown & Infant & Child & $\begin{array}{l}\text { Young } \\
\text { Person }\end{array}$ & Adult & Elder & $\begin{array}{l}\text { High } \\
\text { Agency }\end{array}$ & $\begin{array}{l}\text { Medium } \\
\text { Agency }\end{array}$ & $\begin{array}{l}\text { Low } \\
\text { Agency }\end{array}$ \\
\hline Assistance & 0 & 0 & 100 & 0 & 50 & 25 & 50 & 100 & 0 & 0 & 75 & 25 \\
\hline Document. & 0 & 100 & 0 & 0 & 0 & 0 & 0 & 100 & 0 & 0 & 100 & 0 \\
\hline Education & 50 & 0 & 50 & 0 & 0 & 50 & 50 & 100 & 0 & 50 & 50 & 0 \\
\hline Health & 100 & 0 & 0 & 0 & 0 & 0 & 0 & 100 & 0 & 0 & 100 & 0 \\
\hline Mobility & 20 & 0 & 80 & 0 & 0 & 100 & 40 & 60 & 0 & 40 & 60 & 0 \\
\hline Passivity & 25 & 25 & 50 & 0 & 0 & 50 & 25 & 75 & 0 & 0 & 0 & 100 \\
\hline Portrait & 100 & 0 & 0 & 0 & 0 & 50 & 0 & 50 & 14 & 50 & 50 & 0 \\
\hline Play & 0 & 0 & 0 & 0 & 0 & 0 & 0 & 0 & 0 & 0 & 0 & 0 \\
\hline Production & 0 & 0 & 100 & 0 & 0 & 0 & 100 & 100 & 0 & 100 & 0 & 0 \\
\hline Reproduction & 25 & 0 & 75 & 0 & 0 & 75 & 25 & 100 & 0 & 100 & 0 & 0 \\
\hline
\end{tabular}




\begin{tabular}{l} 
Table 2.IC: \\
Kapturing Kakuma: Percentage of Sex \& Age Represented in Photographic Themes \\
\hline \\
\hline
\end{tabular}

\begin{tabular}{|c|c|c|c|}
\hline \multicolumn{4}{|c|}{$\begin{array}{l}\text { Table 2.2: } \\
\text { Total Percent of Themes Represented in Each Series }\end{array}$} \\
\hline & Series A & Series B & Kapturing Kakuma \\
\hline Assistance & 17 & 15 & 2 \\
\hline Document. & 4 & 4 & 0 \\
\hline Education & 8 & 7 & 12 \\
\hline Health & 4 & 4 & 1 \\
\hline Mobility & 25 & 19 & 1 \\
\hline Passivity & 0 & 15 & 4 \\
\hline Portrait & 4 & 7 & 31 \\
\hline Play & 8 & 0 & 6 \\
\hline Production & 8 & 4 & 13 \\
\hline Reproduction & 13 & 15 & 21 \\
\hline Aerial & 8 & 3 & 8 \\
\hline
\end{tabular}




\section{Notes}

${ }^{\text {i }}$ Forced migration studies encompass discourse which includes all populations which are compelled to leave their original place of origin (be that their country or location within a state). This category includes asylum seekers, internally displaced persons (IDPs) and refugees.

The definition of an asylum seeker is defined as individuals seeking protection from a state which they did not originated from. Asylum, is "a legal concept by which a government extends protection to a person escaping from political persecution in another country. Under contemporary international law, individual do not have a right of asylum, but only a right to seek it" (Gorman, 2000,51). If a state decides to confer asylum, the government agrees to not extradite or involuntarily repatriate the asylee to their country of origin.

An IDP is defined as "persons in a refugee-like situation who have not crossed the borders of their country" (As cited in Loescher et al., 2008, 105). These individuals do not remain outside their stateliness and therefore are unable to qualify as a refugee based on the 1951 Conventional parameters.

The standard definition of a refugee is that found within the 1951 Convention. Asylum seekers who satisfy the parameters outlined in this Convention along with the reform conditions articulated in 1967 Protocol, the OAU Convention, and the 1985 Cartagena Declaration are eligible to be granted refugee status by the UNHCR and/or the country of their asylum. It is important to note that refugee definition varies from regions and countries, depending on which legal instruments the state has ratified (Gorman, 2000, 177).

iithroughout this paper I have strategically chosen to employ the term Third World, following the lead of Vijay Prashad, author of The Darker Nations. Prashad utilizes the term Third World to represent a project, not a place, which assembled 'the darker nations' towards a unified agenda which demanded equitable distribution of the world's wealth, a dignified labor wage, and acknowledgement of their technological, cultural and scientific contributions. The Third World is not employed as a derogatory term, but rather is used to reference empowered nations which were at one time fiercely united in their attempts to overcome the obstacles of colonialism.

iii The employment of the term ideology is used within this text to reference 'meaning in the service of power' (Thompson, 1990,8); indicating practices which effectively legitimate the power and authority of a specified group.

iv 'Kapturing Kakuma' was the title collectively given to the series of participatory photographs which were selected for publication and exhibition across Canada.

'It is important to note that all UNHCR documents and policies refer to refugees as male-specific. While this thesis does acknowledge the gender issues imbedded within the UNHCR's rhetoric and policies, this research does not employ a gender analysis. Although chapters two and three, do call upon previous feminist refugee scholars, such as Bains (2004), Hyndman (2000), and Johnson (2006) in order to assess the dominance of certain gender representations; this thesis does not assume a feminist critique but rather focuses on drawing on a political economy framework to assess the commodification of refugee representation.

${ }^{v i}$ The draft Protocol was then reviewed by the Economic and Social Council before being passed to the General Assembly.

vii The 1992 Report of the United Nations High Commissioner for Refugees, highlights that several special financial appeals were made in 1991 to address new situations requiring an urgent response. "Among the most prominent were the massive exodus of over 1 million Iraqi nationals into neighbouring countries and their subsequent return to 
northern Iraq, the emergency in the Hom of Africa, the Comprehensive Plan of Action for Indo-Chinese Refugees (CPA), the repatriation of South African refugees and exiles, the preparatory phase of the voluntary repatriation to Cambodia and the humanitarian assistance programme in Yugoslavia" (UNHCR, 1992).

viii Clark-Kazak's 2009 study also included a textual analysis of the UNHCR's Annual and Global Reports. The textual analysis was removed from this study's methodology because the images appeared as part of a photostream, and not a texted-centered document. However, where applicable, the textual explanation that accompanied the photographs was recorded as a part of the denotative description.

${ }^{i x}$ The following definitions were used to discern physical age: "An infant is a human being in the early stages of development, who still relies on the care of another person for survival and cannot walk. A child refers to a human being who can walk, but has not yet reached puberty. A young person is someone who is past puberty, but is still physically developing. An adult refers to someone who has reached physical maturity. An elder is a person in the later stages of life, marked by physical signs of age, such as grey hair and wrinkles" (Clark-Kazak, 2009, 4).

${ }^{x}$ Principle subject are subjects engaged in the primary activity or are located in the central frame, while secondary subjects are individuals located in the background, or are not engaged in the primary activity (Clark-Kazak, 2009, 4).

${ }^{x i}$ This approach prevented images with a large number of subjects to be over-represented in the results, and thus attributed equal weight to each photograph.

xii The series 'UNHCR -Pictorial History' contained a total of thirty images, however three of the images were removed from this collect for this study, because they depicted Cold War refugees and were repeated in the 'Hungarian Crisis - 50th Anniversary'

xiii An example of these exacerbated situations can be found in the genocide which occurred in Rwanda. Chossudovsky highlighted that in spite of media portrayal that suggested that the Rwanda genocide was a case of ethnic conflict, the true impetus can be found within the "deterioration of the economic environment which immediately followed the collage of the international coffee market and the sweeping macro-economic reforms by the Bretton Woods institutions [which] exacerbated simmering ethnic tensions and accelerated the process of political collapse" (As cited in Chimni, 1996, 361).

${ }^{x i v}$ It is important to note that the origins of Participatory Communication originated with Canadian scholar Don Snowden, who partnered with filmmaker Colin Low and the National Film Board of Canada's Challenge for Change program to experiment with using film as a means of enabling participatory community development in the Fogo Island, Newfoundland. The approach and techniques development by Snowden were the catalyst behind for participatory communication and have been known around the world as the Fogo Process. 


\section{References}

Agamben, Giorgio. (1996). Beyond Human Rights. Radical Through in Italy: A Potential Politics. Ed. Paolo Virno and Michael Hardt. Minneapolis: University of Minnesota Press.

Annan, K. (2000). United Nations Secretary-General Addresses Executive Committee of UNHCR. UN Press Release. October 2.

Appadurai, A. (1993). The Heart of Whiteness. Callaloo. (16)4, 796-807.

Arnst, Randall. (1996). Participation Approaches to the Research Process. Participatory Communication for Social Change. Ed. Servaes, J., T. L. Jacobson \& S.A. White. New Delhi: Sage Publications.

Baines, Erin. (2004). Vulnerable bodies. Aldershot: Ashgate Publishing Company.

Betts, Alexander. (2008). North-South Cooperation in the Global Refugee Regime: The Role of Linkages. Global Governance. (14)2.

Bhabha, Homi K. (1994). The Location of Culture. New York: Routledge.

Biber, Katherine. (2006). The Spectre of Crime: Photograph, Law and Ethics. Social Semiotics. (16)1, 133-149.

Bleiker, Roland. (2001). The Aesthetic Turn in International Political Theory. Millennium: Journal of International Studies. (30)3, 509-533.

Bourdieu, Pierre. (2005). The Social Definition of Photography. Visual Culture. Ed. Jessica Evans and Stuart Hall. Thousand Oaks, CA: Sage, 162-181.

Baroody, J. (1998). Media Access and the Military: The Case of the Gulf War. Lanham: University Press of America.

Clark-Kazak, Christina. (2009). Representing Refugees in the Life Cycle: A Social age Analysis of United Nations High Commissioner for Refugees Annual Reports and Appeals 19992008. Journal of Refugee Studies. Advanced release.

Chimni, B. S. (2000). Globalization, Humanitarianism and the Erosion of Refugee Protection. Journal of Refugee Studies. 13, 243-263.

-- (1998). The Geopolitics of Refugee Studies: A View from the South. Journal of Refugee Studies. 11, 350-74. 
-- (2001). Reforming the International Refugee Regime: A Dialogic Model. Journal of Refugee Studies. (2) 14, 151-68.

-- (2009). The Birth of a 'Discipline": From Refugee to Forced Migration Studies. Journal of Refugee Studies. Advanced online release.

Clark-Ibanez, Marisol. (2007). Inner-City Children in Sharper Focus: Sociology of Childhood and Photo Elicitation Interviews. Visual Research Methods: Images, Society, and Representation. Ed. Gregory Stanczak. Thousand Oaks, CA: Sage, 167-197.

Cohen, Daniel G. (2008). Between Relief and Politics: Refugee Humanitarianism in Occupied Germany 1945-1946. Journal of Contemporary History. (43)3, 437-449.

Davis, Sara E. (2008). Redundant or Essential? How Politics Shaped the Outcome of the 1967 Protocol. International Journal of Refugee Law. (19)4, 703-728.

Debord, G. (1994). The society of the spectacle (1st pbk. ed. ed.). New York: Zone Books. de Waal, A. (1995). Compassion Fatigue. New Statesman and Society. 15-17.

Dimitrova, Daniela V. \& Neznanski, Matt. (2006). Online Journalism and the War in Cyberspace: A Comparison Between U.S. and International Newspapers. Journal of Computer-Mediated Communications, International Communications Association. 12, 248-263.

Entman, Robert M. (1993). Framing: Toward Clarification of a Fractured Paradigm, Journal of Communication, 43(4), 51-58.

Escobar, Aturo. (1999). Discourse and Power in Development: Michel Foucault and the Relevance of his Work to the Third World. In Jacobson and Servaes (Ed.), Theoretical Approaches to Participatory Communication. New Jersey: Hampton Press. 309-335.

Fanon, F. (1968, 1967). Black skin, white masks. New York, N.Y.: Grove Press.

Freire, Paulo. (1970). Pedagogy of the Oppressed (30th anniversary ed. ed.). NY: Continuum. --- (1992). Pedagogy of Hope. NY: Continuum.

Foucault, Michel. $(1979,1977)$. Discipline and punish: The birth of the prison. New York: Vintage Books.

Goldstein, Barry. (2007). All Photos Lie: Images as Data. Visual Research Methods: Images, Society, and Representation. Ed. Gregory Stanczak. Thousand Oaks, CA: Sage. 61-83. 
Gorman, Robert F. (200). Historical Dictionary of Refugee and Disaster Relief Organizations. International Organization Series, Eds 2. 18. Maryland: Scarecrow Press.

Gumucio-Dagron, Alfonso. (2001). Making Waves - Stories of Participatory Communication for Social Change. New York: The Rockefeller Foundation.

Gunkel, David J. (2004). Second Thoughts: Towards a Critique of the Digital Divide. New Media \& Society Vol. 5(4), 499-522.

Haddad, Emma. (2008). The Refugee in International Society: Between Sovereigns. Cambridge University Press, Cambridge.

Hall, Stuart. (1997). The Spectacle of the Other. Representations. Britain: Open University Press. 225-265.

Hathaway, J.C. (1991). Reconceiving Refugee Law as Human Rights Protection. Journal of Refugee Studies. 4, 113-131.

Hyndman, Jennifer. (2000). Managing Displacement: Refugees and the Politics of Humanitarianism. Minneapolis: The University of Minnesota Press.

Ishemo, Shubi L. (2004). Culture \& Historical Knowledge in Africa: a Cabralian Approach. Review of African Political Economy. 99, 65-82.

Karim, Karim H. (2006). Globalization, Transnational Communication, and Diaspora. Mediascapes: New Patterns in Canadian Communication. Ed. Paul Attallah and Leslie Shade. Ottawa: Nelson. 284-301.

Kyoichi, Sugino. (1998) The "Non-Political and Humanitarian" Clause in UNHCR's Statute. Refugee Survey Quarterly. (17)1,33-59.

Jackson, Ivor C. (1999). The Refugee Concept in Group Situations. Cambridge: Kluwer Law International.

Johnson, Heather. (2006). "Constructing Victims: Visual Images, Victimization and Imagining the Female Refugee" Draft Presentation. McMaster University.

Loescher, Gil; Betts and Milner, (2008). UNHCR: The Politics and Practice of Refugee Protection into the Twenty-First Century, Routledge.

Loescher, Gil. (2001). The UNHCR and World Politics: State Interests vs. International Autonomy. International Migration Review. 35, 33-56.

Lukacs, Georg. (1971). History and class consciousness: Studies in Marxist dialectics. Cambridge, Mass.: MIT Press. 83-223. 
Macheche, John. (2008). "Kakuma Refugee Camp”. Kakuma, Kenya. Interview August 02, 2008.

Malkki, Lissa H. (1992). National Geographic: The Rooting of Peoples and the Territorialization of National Identity Among Scholars and Refugees. Cultural Anthropology. (7)1, 24-44.

--- (1995). Purity and Exile: Violence, Memory and National Cosmology Among Hutu Refugees in Tanzania. Chicago: University of Chicago Press.

--- (1996). Speechless Emissaries: Refugees, Humanitarianism, and Dehistoricization. Cultural Anthropology 11(3), 377-404.

Marx, Karl. (1867). Capital: A Critique of Political Economy. Friedrich Engels, ed., Samuel Moore and Edward Aveling, trans. New York: The Modern Library.

Mihic, Ljiljana, Gordon Hodson, Victoria M. Esses, and Scott Veenvliet. (2008).Justice, Morality, and the Dehumanization of Refugees. Social Justice Research 21, 4-25.

Milner, James. (2008). “UNHCR”. Center for Refugee Studies. York University, Toronto. 08 July 2008.

Mosco, Vincent. (1996). The Digital Sublime: Myth, Power, and Cyberspace. Cambridge, MA: MIT Press.

--- (1996). The Political Economy of Communication: Rethinking and renewal. Thousand Oaks, Calif.: Sage Publications.

-.- (2009). The Political Economy of Communication. Eds. 2. Thousand Oaks, Calif.: Sage Publications.

Mouffe, Chantal. (2000). The Democratic Paradox. New York: Verso Press.

National Telecommunications and Information Administration (NTIA). (1998). Falling Through the Net II: New Data on the Digital Divide..Washington, DC: US Department of Commerce. <http://www.ntia.doc.gov/ntiahome/net2/falling.html>

Nyers, Peter. (1998). Refugees, Humanitarian Emergencies, and the Politicization of Life. Refuge. (17)6, 16-21.

--- (1999). Emergency or Emerging Identities? Refugees and Transforming in World Order. Millennium: Journal of International Studies. 28(1), 1-26.

Ogata, Sadako. (1997). Humanitarian Action: Charity or Realpolitik?. Speech, Oslo, 21 October 1997. 
Rajaram, Prem Kumar. (2002). Humanitarianism and Representations of the Refugee. Journal of Refugee Studies. 15, 248-263.

Reese, Stephen D. (2007). The Framing Project: A Bridging Model for Media Research Revisited. Journal of Communication, 57(1), 148-154.

Reese, S. (2001). Framing public life: A bridging model for media research. In S. Reese, O. Gandy, \& A. Grant (Eds.), Framing Public Life. Mahwah, NJ: Erlbaum. 7-31.

-- (2003). Participatory video: Images that transform and empower. In White S. A. (Ed.), Thousand Oaks, Calif.: Sage Publications.

Prashad, V. (2007). The darker nations: A people's history of the third world. New York: New Press. Distributed by W.W. Norton.

Said, E. W. (1978, 1995). Orientalism. London: Penguin Books.

Sassi, Sinikka. (2005). Cultural Differentiation or Social Segregation? Four Approaches to the Digital Divide. New Media \& Society. 7(5), 684-700.

Selwyn, Neil. (2004). Reconsidering Political and Popular Understandings of the Digital Divide. New Media \& Society. 6(3), 341-362.

Servaes, J. (1999). Communication for Development: One World, Multiple Cultures. Cresskill, NJ: Hampton Press.

Servaes, J., T. L. Jacobson \& S.A. White. (1996). Participatory Communication for Social Change. New Delhi: Sage Publications.

Shapiro, A.L. (1999). The Control Revolution: How the Internet ls Putting Individuals in Charge and Changing the World We Know. New York: Century Foundation Books.

Shaw, J. (1997). In Robertson C. (Ed.), Participatory video: A practical approach to using video creatively in group development work. New York: Routledge.

Singhal, A \& K. Devi. (2003). Visual Voices in Participatory Communication. Communicator. $37,1-15$.

Soguk, Nevzat. (1999). States and Strangers: Refugees and Displacements of Statecraft. Minneapolis: University of Minnesota Press.

Sontag, S. $(1978,1977)$. On photography. London: Allen Lane, Penguin Books.

--- (2003). Regarding the pain of others (1st ed. ed.). New York: Farrar, Straus and Giroux.

Storey, John. (2001). Cultural Theory and Popular Culture. Harlow: Pearson Education Limited. 
Sturken, Marita, and Lisa Cartwright. (2001). Practices of Looking: An Introduction to Visual Culture. New York: Oxford.

Srinivasan, Ramesh. (2006). "Where Information Society and Community Voice Intersect." The Information Society 22, 355-65.

Suginom, Kyoichi. (1998). The "Non-Political and Humanitarian" Clause in UNHCR's Statute. Refugee Survey Quarterly. (17)1, 33-59.

Szprenyi, Anna. (2006). The Images Speak for Themselves? Reading Refugee Coffee Table Books. Visual Studies. (21)1, 24-41.

Thompson, J. B. (1990). Ideology and Modern Culture, Cambridge: Polity Press.

Thompson, Mark. (2004). Discourse, 'Development' \& the 'Digital Divide': ICT \& the World Bank. Review of African Political Economy. 99, 103-123.

Tuepker, Anais. (2002). On the Threshold of Africa: OAU and UN Definitions in South African Asylum Practice. Journal of Refugee Studies. (15)4, 409-433.

UNHCR. (1950). Official Mandate. United Nations. Geneva, Switzerland.

--- (1951). Convention Relating to the Status of Refugees. United Nations, Treaty Series, 189, 137.

--- (1985). The Cartagena Declaration of 1984. UNHCR. Geneva, Switzerland.

--. (1992). Report of the United Nations High Commissioner for Refugees. 28 August 1992, A/47/12, available at:

http://www.unhcr.org/refworld/docid/3ae68c860.html [accessed 25 November 2009]

-- (2004). Chapter 2: Organizational Strúcture and Responsibilities. UNHCR Manual. Geneva, Switzerland.

-- (2006). The state of the world's refugees 2006: Human displacement in the new millennium. In Office of the United Nations High Commissioner for Refugees. (Ed.). New York: Oxford University Press.

-- (2007). Earmarking Patterns in 2006. United Nations. Geneva, Switzerland.

-- (2008). Global Appeal 2009. United Nations. Geneva, Switzerland.

USCRI. (2009). Country Report Kenya. World Refugee Survey. 07 June 2009. $<$ http://www.refugees.org/countryreports.aspx?_VIEWSTATE=dDwtOTMxNDcwOTk 
7O2w8Q291bnRyeUREOkdvQnV0dG9uOz4\%2BUwqzZxIYLIOSfZCZue2XtA0UFEQ $\% 3 \mathrm{D} \& \mathrm{cid}=2332 \&$ subm $=\& \mathrm{ssm}=\&$ map $=\&$ searchtext $=\&$ CountryDD $\% 3$ ALocationList $=>$

Väyrynen, Raimo. (2001). Funding Dilemmas in Refugee Assistance: Political Interests and Institutional reforms in UNHCR. International Migration Review. 35(1), 143-167.

Wang, C. \& M. Burris. (1994). Empowerment through Photo Novella: Portraits of Participation. Health Education Quarterly, 21(2), 171-186.

Whitaker, Beth Elise. (2008). Funding the International Refugee Regime: Implications for Protection. Global Governance. 14, 241-258.

White, Shirley. (2003). Involving People in a Participatory Process. Participatory Video. London: Sage. 33-62.

Wilkins, Karin Gwinn. (2000). Redeveloping Communication for Social Change: Theory, Practice, and Power. New York: Rowman and LittleField.

Windle Trust Kenya. (2008). "Kakuma Camp." Kakuma, Kenya. Interview. 19 July 2008.

WUSC. (2008). "World University Service of Canada". About Us. WUSC. 10 Aug. 2008 $<$ http://www.wusc.ca/en/about/about_us>.

Ya'u, Y.Z. (2004). The New Imperialism \& Africa in the Global Electronic Village. Review of African Political Economy. 99, 11-29.

Zetter, Roger. (2007). More Labels, Fewer Refugees. Remaking the Refugee Label in an Era of Globalization. Journal of Refugee Studies. (20)2, 172-192. 